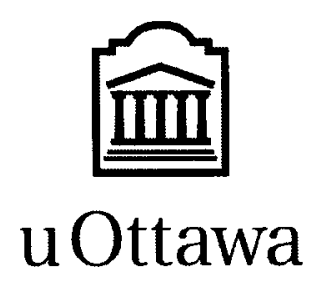

L'Unversite canadienne Canada's unversity 
FACULTÉ DES ÉTUDES SUPÉRIEURES ET POSTOCTORALES

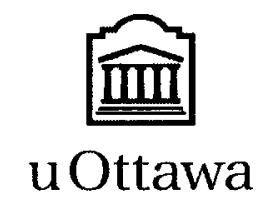

L'Unversté canadionne

Canada's unversity

\section{FACULTY OF GRADUATE AND POSDOCTORAL STUDIES}

Lauren Elizabeth Roberts

AUTEUTR DE LA THESE / AUTTHOA OF THESIS

M.Sc. (Human Kinetics) GRADE/DEGREE

School of Human Kinetics

FACULTE, ECOLE, DEPARTEMENT / FACULTY, SCHOOL, DEPARTMENT

Carbohydrates and Feeding: An Extension of the Glucostatic Theory of Appetite Regulation

TITRE DE LA THESE / TITLE OF THESIS

E. Doucet

DIRECTEUR (DIRECTRICE) DE LA THESE / THESIS SUPERVISOR

CO-DIRECTEUR (CO-DIRECTRICE) DE LA THESE / THESIS CO-SUPERVISOR

F. Haman

P. Imbeault 


\title{
CARBOHYDRATES AND FEEDING: AN EXTENSION OF THE GLUCOSTATIC THEORY OF APPETITE REGULATION
}

\author{
By \\ Lauren E. Roberts \\ B. KinH (Hons) Acadia University, 2007
}

Submitted to the Faculty of Graduate and Postdoctoral Studies

In partial fulfilment of the requirements for the degree of

Masters of Science in Human Kinetics

School of Human Kinetics

University of Ottawa

Lauren Roberts, Ottawa, Canada @ 2010 
Library and Archives

Canada

Published Heritage

Branch

395 Wellington Street

Ottawa ON K1A ON4

Canada
Bibliothèque et

Archives Canada

Direction du

Patrimoine de l'édition

395, rue Wellington

Ottawa ON K1A ON4

Canada
Your file Votre référence
ISBN: $978-0-494-74166-5$
Our file Notre référence
ISBN: $978-0-494-74166-5$

\section{NOTICE:}

The author has granted a nonexclusive license allowing Library and Archives Canada to reproduce, publish, archive, preserve, conserve, communicate to the public by telecommunication or on the Internet, loan, distribute and sell theses worldwide, for commercial or noncommercial purposes, in microform, paper, electronic and/or any other formats.

The author retains copyright ownership and moral rights in this thesis. Neither the thesis nor substantial extracts from it may be printed or otherwise reproduced without the author's permission.
AVIS:

L'auteur a accordé une licence non exclusive permettant à la Bibliothèque et Archives Canada de reproduire, publier, archiver, sauvegarder, conserver, transmettre au public par télécommunication ou par l'Internet, prêter, distribuer et vendre des thèses partout dans le monde, à des fins commerciales ou autres, sur support microforme, papier, électronique et/ou autres formats.

L'auteur conserve la propriété du droit d'auteur et des droits moraux qui protège cette thèse. $\mathrm{Ni}$ la thèse ni des extraits substantiels de celle-ci ne doivent être imprimés ou autrement reproduits sans son autorisation.
In compliance with the Canadian Privacy Act some supporting forms may have been removed from this thesis.

While these forms may be included in the document page count, their removal does not represent any loss of content from the thesis.
Conformément à la loi canadienne sur la protection de la vie privée, quelques formulaires secondaires ont été enlevés de cette thèse.

Bien que ces formulaires aient inclus dans la pagination, il n'y aura aucun contenu manquant.

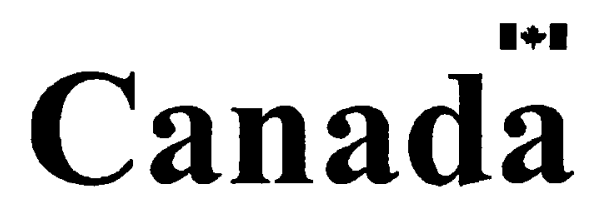




\section{AKNOWLEDGMENTS}

First of all I would like to give special thanks to my supervisor Dr. Eric Doucet. It has been a pleasure to work with him on this project and I am thankful for all the support and guidance he was able to provide me. I would also like to thank my advisors Dr. Pascal Imbeault and Dr. Francois Haman for their comments and suggestions throughout this process and their commitment to this committee despite a less than normal timeline.

I would also like to thank my colleagues at the Behavioural and Metabolic Research Unit (BMRU) especially at the Lee's campus for their support during my testing. I would also like to especially thank Ann Beninato and Michael Hopkins for their help in testing.

Saving the most important for last I would like to thank my parents for their unwavering love and support during my whole academic career and especially as I worked through this stage of my Master's degree. A big thank you as well goes to my sister and brother and their partners for being there for me as I worked through this project and always. Lastly, to my friends home and away and my main man Gatsby who keeps me sane day to day. 


\begin{abstract}
Mayer's Glucostatic Theory of appetite regulation has been a precursor for many studies in this field. No studies have applied this model to extreme fluctuations of blood glucose. The present study examined if Mayer's theory holds true with carbohydrate $(\mathrm{CHO})$ loading and reduction in healthy men. Six normal weight, healthy men $\left(23.8 \pm 1.3 \mathrm{~kg} / \mathrm{m}^{2}\right)$ participated in a randomized crossover trial. Three day eucaloric diet conditions $(75 \% \mathrm{CHO}, 45 \% \mathrm{CHO}$, and $10 \% \mathrm{CHO}$ ) preceded a 10 $\mathrm{h}$ testing day in the lab where blood glucose measured every $5 \min$ for $9 \mathrm{~h}$. with appetite ratings measured every $30 \mathrm{~min}$. Food was available upon request; hunger, intake and food preference were measured. No differences in daily energy intake (EI), blood glucose and appetite were noted between conditions. In all subjects during all phases, blood glucose levels decreased by $7.8 \pm 11.1 \%$ prior to meal requests. Meal requests were preceded by declines in blood glucose but changes in appetite, $\mathrm{El}$ and $\mathrm{CHO}$ preference were not seen.
\end{abstract}

Key words: Glucostatic Theory, appetite, blood glucose, hunger, feeding, carbohydrates 


\section{TABLE OF CONTENTS}

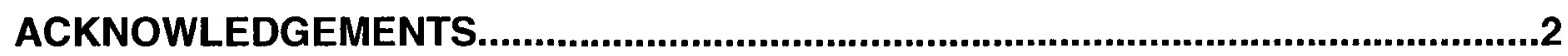

ABSTRACT

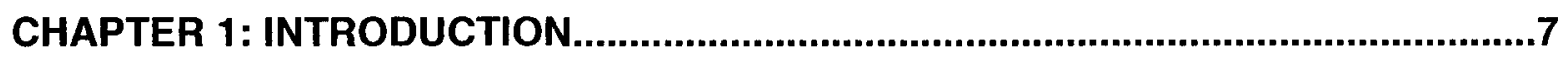

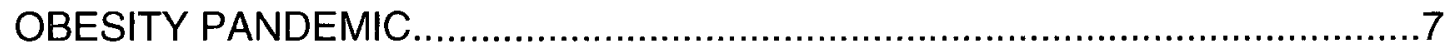

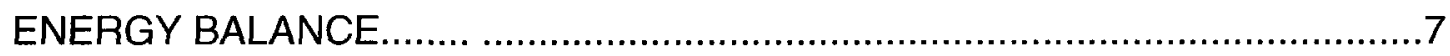

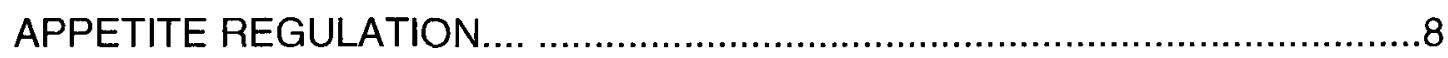

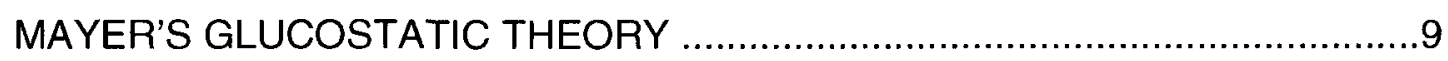

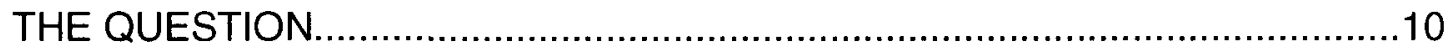

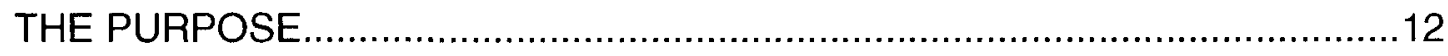

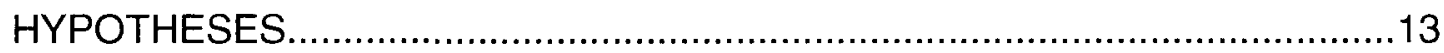

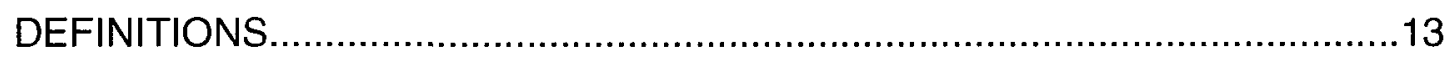

LIMITATIONS, DELIMITATIONS, AND ASSUMPTIONS................................14

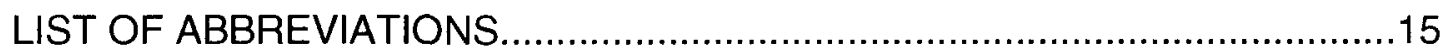

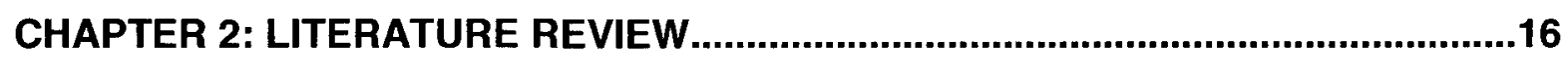

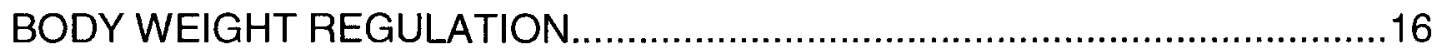

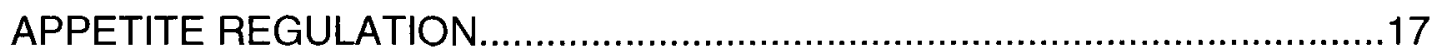

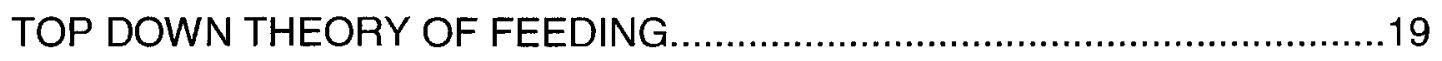

INFLUENCES ON CIRCULATING BLOOD GLUCOSE..................................21

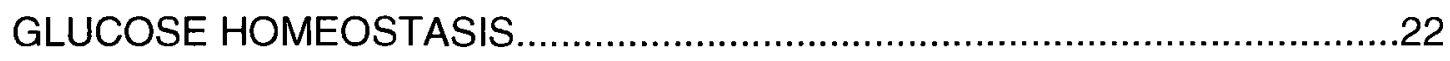

MUSCLE GLYCOGEN AND HEPATIC GLYCOGEN..................................24

CARBOHYDRATES AND FOOD INTAKE REGULATION..............................24

THE GLUCOSTATIC THEORY OF APPETITE........................................27

EXPERIMENTAL SUPPORT FOR MAYER'S THEORY ...................................29 
EXTENSION OF MAYER'S GLUCOSTATIC THEORY .32

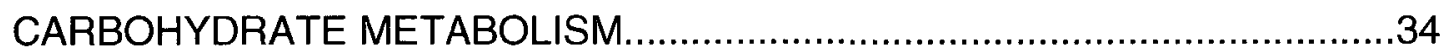

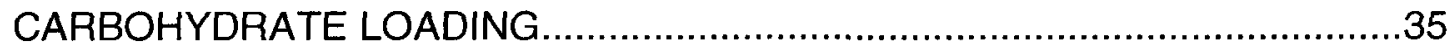

CARBOHYDRATE RESTRICTION .................................................36

CARBOHYDRATE MANIPULATION .................................................. 38

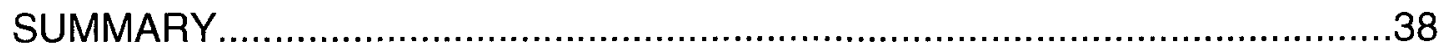

CHAPTER 3: METHODOLOGY ..............................................................................41

TABLE 1. PRESCRIBED DIETS BY MACRONUTRIENT COMPOSITION...........46

TABLE 2. COMPOSITION OF THE STANDARD BREAKFAST $\ldots \ldots \ldots \ldots \ldots \ldots \ldots \ldots . \ldots 7$

FIGURE3. EXAMPLE OF \% DECLINE IN BLOOD GLUCOSE.........................57

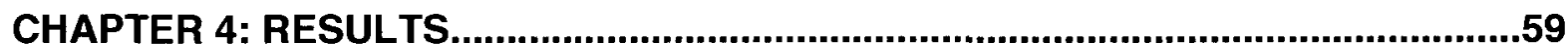

TABLE 3. DESCRIPTIVE BASELINE CHARACTERISTICS OF SUBJECTS........59

TABLE 4. AVERAGE OBSERVED DIET FOR THE 3 DAYS PRECEDING...........60

TABLE 5. REE, BW AND SUBSTRATE OXIDATION FOLLOWING EACH DIET...62

FIGURE 4. TOTAL EI FOR THREE EXPERIMENTAL CONDITIONS.....................63

FIGURE 5. MACRONUTRIENT ACROSS EXPERIMENTAL CONDITIONS......... 65

FIGURE 6. RATINGS OF HUNGER BASED ON VAS .................................68

FIGURE 7. EXAMPLE OF A DAILY BLOOD GLUCOSE PROFILE....................70

CHAPTER 5: DISCUSSION....................................................................................71

CHAPTER 6: LIMITATIONS, GENERAL CONCLUSIONS, FUTURE PERSPEC........80

REFERENCES........................................................................................................84

APPENDIX 1: LETTER OF ETHICS APPROVAL..................................................98

APPENDIX 2: INCLUSION CRITERIA QUESTIONNAIRE.....................................101 


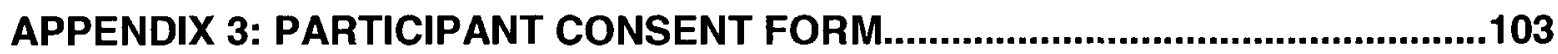

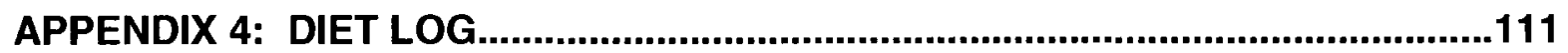

APPENDIX 5: MENU AND OPTION DESCRIPTIONS.............................................118

APPENDIX 6. OVERALL TIMELINE.....................................................................121

APPENDIX 7: THREE FACTOR EATING QUESTIONNAIRE (TFEQ).......................123

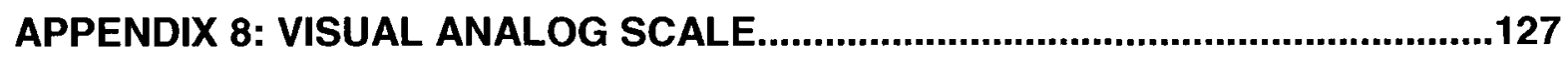




\section{CHAPTER I - INTRODUCTION}

\section{OBESITY PANDEMIC}

In 2005, a report from Statistics Canada outlined the increasingly prevalent issue of obesity in our country. The report suggested that 5.5 million $(23.1 \%)$ of the Canadian adult population (18 years and over) was obese (BMl of $30 \mathrm{~kg} / \mathrm{m}^{2}$ ). This value is significantly higher than estimates that were previously derived from selfreported data collected in 2003 . This 2003 data yielded an obesity rate of $15.2 \%$ with another $36.1 \%$ being considered overweight. This trend from 2003-2005 and even earlier continues to be prevalent worldwide. In 2007 the World Health Organization reported 1.6 billion individuals as overweight and another 400 million individuals as obese worldwide. In the context of this obesity epidemic our society finds itself in, due to either overconsumption, under expenditure or both, developing a better understanding of the mechanisms behind this is increasingly necessary.

\section{ENERGY BALANCE}

It is well accepted that energy balance is unavoidably the key to weight maintenance. Energy balance is achieved when the caloric intake equals caloric expenditure (Flatt, 1988). This equation is a difficult one to balance as one side of the equation is episodic, occurring only when food is ingested, where as the other side is continuously changing. These fluctuations in energy expenditure occur not only during blatant physical output of energy. In fact, the majority of this expenditure 
$(70 \%)$ occurs at rest (resting metabolic rate). Due to this, the body is essentially always in fluctuations between positive and negative balance. It is the sum of these fluctuations that will determine if one is gaining or losing weight. For example, when the sum of the positive energy balances exceeds those of negative balance over a period of time, weight gain will occur. This positive balance occurs in three major ways: An increase in energy intake, a decrease in energy expenditure, or a combination of the two. Although we acknowledge that output is just as important, the focus of this paper will be on feeding.

\section{APPETITE REGULATION}

Appetite or the desire to eat food is felt as hunger and exists to regulate adequate energy intake. The homeostatic controls of feeding are explained by the communication that occurs between the appetite centers in the central nervous system and peripheral signals. The main area of the CNS critical to the regulation of food intake is the hypothalamus (Neary, Goldstone and Bloom, 2007). Within the hypothalamus are a collection of nuclei (in the mediobasal region) including potentially the most important of these nuclei related to homeostatic control: the Arcuate Nucleus or ARC (Broberger and Hokfelt, 2001). The Arc contains different sets of neurons (explained in detail later in the literature review); some having orexigenic (decrease energy expenditure and increase energy intake) effects and some having anorexigenic effects (increase energy expenditure and decrease energy intake) (Fan, Boston et al, 1997). 


\section{MAYERS GLUCOSTATIC THEORY}

Over 50 years ago, Mayer developed a theory that proposed that changes in blood glucose levels are detected by glucoreceptors that affect energy intake. The idea behind Mayer's theory is that an increase in blood glucose is associated with feelings of satiety, whereas a drop in one's blood glucose concentration has the opposite effect (Mayer, 1953). Mayer's theory which laid the original foundation for many newer theories on appetite and feeding is essentially an extension of the homeostatic model of control; essentially, a given system has a desired state of balance or equilibrium where, when out of balance, these systems act to restore the balance.

Since Mayer's initial proposal of the glucostatic theory, it has become clear that glucose levels are linked with meal initiation. Mayer went on to conduct human studies that did indeed show that differences in blood glucose concentration were correlated with hunger ratings and food intake in some circumstances (Van Itallie, Beaudoin and Mayer, 1953). In a 1985 study, Campfield, Brandon and Smith found that blood glucose concentrations stay constant within one percent of the basal concentration between meals. Further, it was found that a decline of approximately 12 percent in blood glucose concentrations is sufficient to be detected by cells that depletion in usable glucose has occurred. This change in circulating glucose has been associated to the initiation of food intake (Campfield et al, 1985).

As blood glucose measurement technology became more and more reliable and available, studies involving humans became more common. A key study in 
1996 by Campfield, Smith, Rosenbaum and Hirsch found overall that in $83 \%$ of the subjects 18 healthy male subjects, changes in both ratings of hunger and verbal meal requests were preceded by and significantly correlated with transient declines in blood glucose (10\% below baseline at 27 minutes) (Campfield et al, 1996). As this technology has continued to evolve to the point where we can now continuously monitor blood glucose in humans with the use of Continuous glucose monitors (CGM), a renewed interest in this field is apparent. Recent studies have been taking Mayer's Theory and applying it as potential rationale for the effect of glycemia on weight gain and obesity (Chaput and Tremblay, 2009).

\section{THE QUESTION}

The glucostatic theory of appetite regulation proposed by Mayer over 50 years ago and introduced above, has established precepts that are still valid today (1955). However, this model of energy balance regulation based on single nutrient feedback may be too simplistic (Stubbs, 1996): when we consider glucose consumption in an evolutionary context, prior to the availability of refined sugar, humans were still able to achieve some level of satiety indicating numerous factors are obviously at play. Results of many studies have shown a system where changes in nutrient balance do not translate directly to changes in feeding behaviour. However, there are many studies that still show that patterns in glucose do indeed provide the signal to initiate food intake (Melanson, 1999). This in turn suggests that dietary carbohydrates are clearly involved in the short term control of 
the intake of energy (Blundell and Noury, 2001). With this in mind, Mayer's model should be revisited and built upon with our now greater understanding of macronutrient effects on appetite and feeding.

Up until this time, there has been a lack of studies related to blood glucose measures using spontaneous or subject-initiated feeding. Among researchers in this field, there has also been an expression of the need for additional studies of the onset of hunger and meal requests in human with not only normal but also disordered feeding behaviour. In order to aid in this gap on this topic, the current study targeted those with disordered feeding behaviour in the form of extreme fluctuations in macronutrient levels; in particular carbohydrates. This study aimed to show that changes in one's carbohydrate $(\mathrm{CHO})$ stores would cause predictable effects on one's feeding behaviour as predicted by Mayer's model. To investigate this, the following research questions were posed:

1. Does the level of $\mathrm{CHO}$ load have an effect on appetite? Will a greater $\mathrm{CHO}$ load result in higher or lower appetite? Will a low $\mathrm{CHO}$ load have the opposite effect?

2. Will the affect of the $\mathrm{CHO}$ load illustrated in the above question in fact result in a change in energy intake?

3. Will there be a change in preference for certain macronutrient following a change in a subject's $\mathrm{CHO}$ load?

4. Despite a change in $\mathrm{CHO}$ load, will a decline in blood glucose precede meal requests as illustrated by Mayer's model? 


\section{THE PURPOSE}

It is known that glucose excursions exist under conditions of energy balance but little is known as to the influence of large fluctuations in glucose stores on appetite under conditions of energy balance. The current research aimed to revisit the glucostatic theory of appetite regulation in states of varied glucose stores elicited through conditions of varying $\mathrm{CHO}$ availability. The energy expenditure of each subject was assessed through a combination of accelerometry and resting energy expenditure (REE). A dietary regimen based on these measures was administered and subjects were thus investigated under eucaloric (same amount of calories in a state of energy balance) and isocaloric (same amount of calories at any energy level) conditions. These manipulations were followed by full day measurements of each participant's appetite and energy intake throughout the day as well as measurements of their glucose levels throughout the day. The phases included a control phase $(\sim 45 \% \mathrm{CHO})$, a $\mathrm{CHO}$ reduced phase $(10 \% \mathrm{CHO})$ and a high carbohydrate phase $(75 \% \mathrm{CHO})$ all clamped at a predetermined caloric intake specific to each subject. The dietary manipulations were conducted for 3 days prior to each of the testing conditions. The day of testing involved a standardized breakfast followed by a REE test. The remainder of the day consisted of free feeding upon the subjects' request. This allowed for appetite and energy intake to be measured. Each session was randomly assigned. 


\section{HYPOTHESES}

1. It was proposed that when compared to the normal phase, appetite would be greater following the reduced $\mathrm{CHO}$ phase and lower following the high $\mathrm{CHO}$ phase.

2. It was proposed that when compared to the normal phase food consumption would be greater in following the low $\mathrm{CHO}$ phase and less so in the high $\mathrm{CHO}$ phase.

3. It was proposed that when compared to the normal phase, in addition to consuming more following the low $\mathrm{CHO}$ protocol, participants would also show a greater preference for foods high in $\mathrm{CHO}$. A lack of preference for $\mathrm{CHO}$ would also be seen in the high $\mathrm{CHO}$ phase.

4. It was proposed as an exploratory hypothesis that coinciding with the above hypotheses would be predictable changes in blood glucose levels as suggested by Mayer. It was predicted endogenous glycogen reduction ( $\mathrm{CHO}$ reduction) resulting in greater appetite, consumption and preference for $\mathrm{CHO}$ rich foods would be preceded by transient declines in blood glucose.

\section{DEFINITIONS}

In the present document, a eucaloric state refers to the subject being in a state of energy balance whereas the term isocaloric refers to the amount of calories being consistent across experimental trials. The term orexigenic refers to effects 
that decrease energy expenditure and increase energy intake and conversely, the term anorexigenic refers to effects that increase energy expenditure and decrease energy intake. A list of abbreviations to be used in this manuscript can be found at the end of this chapter.

\section{LIMITATIONS, DELIMINATIONS AND ASSUMPTIONS}

Over the course of this study, it is assumed that the participants will follow the protocol as prescribed including the 12 hour overnight fast prior to the blood draw as well as the required diet prior to each experimental condition. Participants will commit to these protocols during their acceptance of the informed consent. Accordance with diet will be verified through log records of food intake over the course of the study. Most importantly, it is assumed that any self reported values related to food intake while away from the laboratory as well as feelings of hunger and satiety etc will be done so truthfully; subjects will also be told it is imperative that they follow the prescribed diet as closely as possible however some error here is possible. The present study will be limited to a sample of healthy $\left(B M \mid<25 \mathrm{~kg} / \mathrm{m}^{2}\right)$, non-smoking, university aged males. 


\section{LIST OF ABBREVIATIONS}

CHO: Carbohydrate

REE: Resting Energy Expenditure

RER: Respiratory Exchange Ratio

BW: Body Weight

CNS: Central Nervous System

VAS: Visual Analog Scale

AUC: Area under the curve

El: Energy intake

SB: Standard Breakfast

$\mathrm{n}$ : number of Participants

NS: Not significant

SD: Standard Deviation

$\mathrm{N}$ : Normal Phase $(45 \% \mathrm{CHO})^{\star}$

HI: High CHO Phase $(75 \% \mathrm{CHO})^{*}$

LO: Low CHO Phase $(10 \% \mathrm{CHO})^{\star}$

*These phases will be detailed further in the Methods chapter. 


\section{CHAPTER II- LITERATURE REVIEW}

\section{BODY WEIGHT REGULATION}

In the context of the obesity epidemic our society finds itself in, due to either overconsumption, under expenditure or both, developing a better understanding of feeding and appetite is becoming increasingly necessary. It is well accepted that energy balance is unavoidably the quintessential key to weight maintenance. Energy balance is achieved when the intake of macronutrients equals the amount of energy expended (Flatt, 1988). This equation is a difficult one to balance as one side of the equation is episodic, occurring only when food is ingested, where as the other side is continuously changing. These fluctuations in energy expenditure occur not only during blatant physical output of energy. In fact, the majority of this expenditure $(70 \%)$ occurs at rest (resting metabolic rate). Due to this, the body is essentially always in fluctuations between positive and negative balance. It is the sum of these fluctuations that will determine if one is gaining or losing weight. For example, when the sum of the positive energy balances exceeds those of negative balance over a period of time, weight gain will occur. This positive balance occurs in three major ways: An increase in energy intake, a decrease in energy expenditure, or a combination of the two. Although we acknowledge that output is just as important, the focus of this paper will be on feeding. 


\section{APPETITE REGULATION}

The homeostatic controls of feeding are explained by the communication that occurs between the appetite centers in the central nervous system and peripheral signals. The main area of the CNS critical to the regulation of food intake is the hypothalamus (Neary, Goldstone and Bloom, 2007). Within the hypothalamus are a collection of nuclei (in the mediobasal region) including potentially the most important of these nuclei related to homeostatic control: the Arcuate Nucleus or ARC (Broberger and Hokfelt, 2001).

The ARC contains 2 neurochemically different sets of neurons some with orexigenic effects (decrease energy expenditure and increase energy intake) and some with anorexigenic effects (increase energy expenditure and decrease energy intake) (Fan, Boston et al, 1997). These sets of first order neurons include 1) Neuropeptide Y (NPY) and agouti-gene-related protein (AgRP) and 2) proopiomelanocortin (POMC). POMC leads to increases in energy expenditure and decreases in energy intake where as NPY and AgRP causes increases energy intake and decreases in energy expenditure.

These neurons are considered first order as they have direct contact with the peripheral hunger and satiety factors. Due to the lack of blood-brain barrier in the median eminence the axon terminals of these neurons are in direct contact with the bloodstream. Once a factor such as insulin or leptin comes in contact with these first order neurons, a series of events occurs activating other neurons leading to changes in feeding behaviour 
POMC gives rise to several bioactive peptides such as alpha and gamma Melanocyte-Stimulating Hormone (MSH) both of which have been shown to exert anorexigenic effects (Fan, Boston et al. 1997). Activation of POMC can also increase the release of cocaine- and amphetamine-regulated transcript (CART), another anorexigenic peptide.

NPY has a combined affect with POMC where NPY neurons are able to control POMC cells through the co-expression of AgRP. This release of AgRP, an endogenous melanocortin antagonist (Broberger, Johansen et al. 1998) will block melanocortin action and cause in increase in food intake. Although the brain seems to favor orexigenic NPY/AgRP over the anorexigenic melaocortin signaling, most appetite regulating hormones are anorexigenic such as insulin and leptin (Ollmann, Wilson et al. 1997).

The most relevant factor for this thesis is insulin as it is essential for glucose uptake, metabolism in peripheral tissues and the overall idea of glucose homeostasis (Jobst, Enriori et al, 2004). Although the amount of electrophysiology done on the mechanism of insulin is limited (Jobst, Enriori et al. 2004), the majority of evidence (both anatomical and physiological) shows that the activation of central insulin receptors causes a decrease in food intake and body weight (Woods, Porte et al. 1985). This is achieved through activation of anorexigenic POMC neurons and the inhibition of orexigenic NPY/AgRP neurons. In fact, by knocking out the insulin receptor in POMC neurons, Bruning and colleagues saw hyperphagia and obesity in mice (Bruning, Gautam et al. 2000) 


\section{TOP DOWN THEORY OF FEEDING}

When discussing feeding in any context, it is important to understand the feeding model which includes both the bottom-up control mechanism and the top down control mechanism. Bottom up control states that an individual will be driven to consume food due to signalling from the periphery through the factors illustrated in the previous section (Cameron and Doucet, 2007). The top down theory of eating on the other hand suggests that an individual will eat mainly for emotional or social reasons. Figure 1 illustrates the interplay between these factors. Although the topdown theory is non-homeostatic, it does still involve factors controlled by the CNS. The top down control theory of feeding may present a limitation to the subjective appetite questionnaires in this study as it deals with eating for emotional and motivational purposes rather than the individual's actual level of hunger and need for energy intake (Cameron and Doucet, 2007). While acknowledging that we cannot exclude the possibility that these two models interact, the present study on appetite will fit in the context of the bottom up model of feeding. 


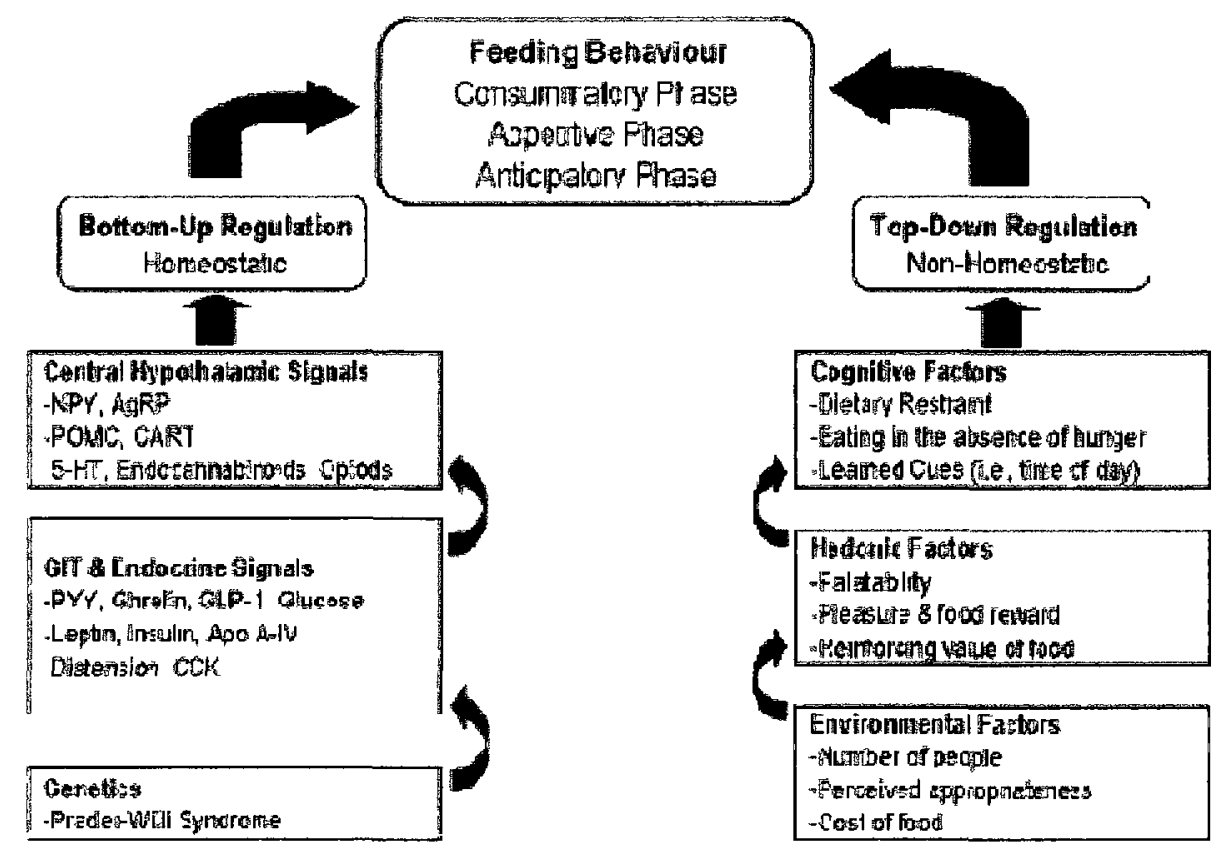

Figure 1: An illustration of the two-tier regulation of feeding (Cameron and Doucet, 2007)

It is proposed in the current study that, as suggested by Mayer years ago (1955) and as supported by researchers such as Smith and Campfield more recently $(1988,1993,1996,2003)$, glucose may there be another bottom up factor to consider in terms of feeding and appetite. Studies for quite some time have suggested that daily fluctuations in glucose levels seem to affect appetite regulation and are closely related to episodes of bottom-up initiated feeding (Smith and Campfield, 1993, Campfield et al 2003). 


\section{INFLUENCES ON CIRCULATING BLOOD GLUCOSE}

Circulating blood glucose levels are achieved through a homeostasis balance between appearance of glucose in the blood and disappearance from blood to elsewhere in the body. Simply put, blood glucose concentration is the difference between appearance and disappearance.

When examining the idea of glucose appearance in humans, numerous studies have been conducted to evaluate the fate of glucose following a meal (Fery, Plat and Balasse, 1998). In addition to postprandial glucose however it must also be considered that glucose can appear in the blood not only from a consumed meal but also following production of glucose in the liver. Typically studies assess the disposal of glucose from within a meal by measuring the net balance of glucose in the liver and muscles, whole body $\mathrm{CHO}$ oxidation and uptake by visceral and peripheral tissues following meal ingestion. As noted by Woerle et al in 2003 , it is not until glycolysis is examined in addition to these factors that a true understanding of routes for glucose disposal will be appreciated (Woerle, Meyer, Dostou, Gosmanov, Islam et al, 2003).

Glucose disappearance then is either disposal of glucose through either immediate storage or glycolysis. All of this storage is essentially glycogen formation in the liver and muscle tissue as de novo lipogenesis and adipose tissue glucose storage are both essentially negligible in humans (Marin, Hogh-Kristiansen, Jansson, Kritkiewski, Holm et al, 1992). With regards to the glucose undergoing glycolysis, this is either oxidative or non-oxidative. The glucose not undergoing 
oxidation undergoes nonoxidative glycolysis which leads to the formation of lactate, pyruvate and alanine. These compounds are then available to undergo gluconeogenesis and subsequently be stored as glycogen or be released into plasma as glucose (Woerle et al, 2003). The figure below illustrates the routes of postprandial glucose disposal discussed (Figure 2).

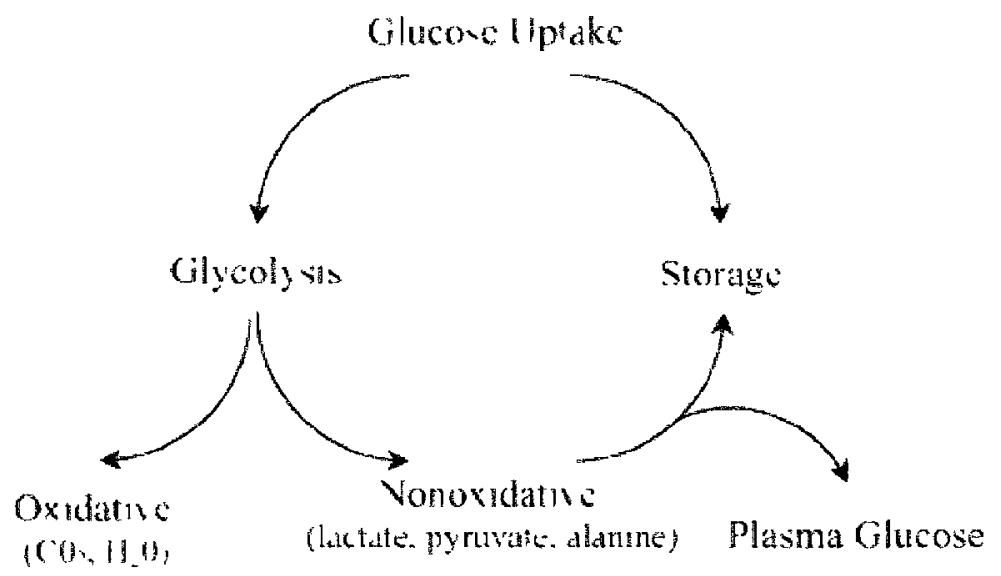

Figure 2. Postprandial glucose disposal. Adapted from Woerle et al, 2003.

As discussed above, circulating blood glucose concentrations are essentially the result of the balance between these appearance and disappearance of glucose in the blood; they should therefore be interpreted as such.

\section{GLUCOSE HOMEOSTASIS}

Glucose homeostasis is defined as the maintenance of these glucose levels during daily fluctuations due to physiological pressures: This includes eating, 
exercising, resting or disease. Essentially this process breaks down to control of glucose entry and output. The pancreatic hormones insulin and glucagon control plasma glucose concentrations together through a negative feedback loop. The amplitude of variations for normal fasting levels of glucose in blood is 3.89-6.11 $\mathrm{mmol} / \mathrm{L}$ (Chiasson et al 2004). An increase in plasma glucose concentration increases insulin secretion and decreases the secretion of glucagon resulting in an overall decrease in plasma glucose levels and vice versa.

In times of hyperglycaemia (fasting blood glucose levels greater than 7.78 $\mathrm{mmol} / \mathrm{L}$ ) circulating glucose is detected by $\beta$-cells in the pancreas (Chiasson at al., 2004). In response to this rising blood-glucose concentration, the beta cells release insulin which then triggers the liver and muscle to increase glycogenesis and to decrease glycogenolysis, the liver specifically to decrease gluconeogenesis and most other tissues to uptake glucose into cells. The result is an overall lowering of plasma glucose concentrations.

In times of low plasma glucose or hypoglycemia (fasting blood glucose levels below $3.33 \mathrm{mmol} / \mathrm{L}$ ), the alpha cells of the pancreas release glucagon which signals to the liver to increase glycogenolysis, increase gluconeogenesis, increase protein breakdown and ketone synthesis as well as decrease glycogen synthesis and decrease protein synthesis. This overall increase in hepatic glucose is then released into the bloodstream, thereby raising blood-glucose concentration to a desired level (3.89-6.11 mmol/L). This system is complex with the alpha and beta cells working continuously to achieve an optimal, regulated, homeostatic bloodglucose concentration. 


\section{MUSCLE GLYCOGEN AND HEPATIC GLYCOGEN}

Increased endogenous glucose production (hepatic production) leads to the development of fasting hyperglycaemia in individuals with impaired glucose tolerance (DeFronzo, 1988). As the glucose intolerance state worsens it is an increase in basal hepatic glucose production that is the major factor responsible for the progressive rise in fasting glucose levels (DeFronzo, Ferrannini, and Simonson, 1989). After the consumption of a carbohydrate rich meal there is a combination of impaired suppression of hepatic glucose production and decreased insulin-mediated glucose disposal which results in an increase in postprandial glycaemia. Further, under such conditions of hyperglycaemia, glucose utilization is known to take place mainly in skeletal muscle where insulin stimulates glucose uptake and oxidation as well as glycogen synthesis (Shulman et al, 1999). Both muscle glycogen and hepatic glycogen will be discussed related specifically to this study later on in this paper.

\section{CARBOHYDRATES AND FOOD INTAKE REGULATION}

Many studies have shown that the role of glucose is key in the metabolic control of food intake as it is one of the most important sources of energy in single stomached creatures (Langhans, 1996). Carbohydrates (CHO) typically account for anywhere from $40-60 \%$ of an individual's total food energy (Flatt et al, 1996). An individual's reserve of glycogen in the body is most likely not much greater than the amount of $\mathrm{CHO}$ consumed and oxidized on any given day. $\mathrm{CHO}$ in general hold a 
high fuel reserve combined with a high turnover rate resulting in a challenge to metabolic regulation with regards to appropriate glycogen stores and blood glucose level maintenance (Flatt et al, 1996). In fact, Mayer's 1953 hypothesis is based in part on the observation that $\mathrm{CHO}$ reserves are proportionally depleted between meals more so than reserves of protein or fat (Mayer, 1953). That being said, even with considerable variations in $\mathrm{CHO}$ intake can be accommodated by the body without invoked undue stress or affected usual daily activities and functions (Stubbs et al, 1995).

Earlier studies by Flatt et al in 1987 determined that glycogen can be maintained at appropriate levels under conditions of ad lib food intake if food intake were to be regulated in such a way that would sustain the balance between the use of glucose and the influx of CHO from one's diet. This is of course in addition to the adjustment of glucose oxidation to carbohydrate intake (Flatt et al, 1987).

Due to the large daily fluctuations in blood glucose mentioned earlier, there is a large amount of overlap between blood glucose levels under different nutritional and metabolic conditions. This has led to the idea that changes in hepatic glycogen or in liver substrate oxidation rates is a more suitable means for providing feedback signals to the CNS regarding feeding (Russek, 1981). This input could be better based on an integrated variable of substrate, $\mathrm{CHO}$ utilization as well as $\mathrm{CHO}$ availability. This has led to suggestions that the maintenance of $\mathrm{CHO}$ balance contributes to the regulation of food intake (Flatt, 1996). There is considerable indirect evidence of a causal relationship between decreasing levels of blood glucose alongside glucose availability and hunger in man. This is derived from 
studies where meals with slow release $\mathrm{CHO}$ were shown to produce smaller but longer sustained rises in blood glucose and a decrease in hunger ratings compared to other meals (Leathwood and Pollet, 1988; Torddottir et al, 1989)

As there is a small storage capacity for glycogen, any loss or gain in glycogen content are minor when compared to the amounts of glucose that are being turned over. When this is considered over a few days, the level of glucose oxidation is therefore essentially equal to the amount of $\mathrm{CHO}$ ingested (in addition to the relatively small amounts of glucose being produced in the body by gluconeogenesis of protein). Many studies have shown that when $\mathrm{CHO}$ intake or food intake in general is imposed, one's levels of glycogen are stabilizes by adjusting oxidation to intake (Stubbs, 1995).

Two studies by Flatt et al in 1987 and 1993 showed that increases and decreases in food intake occurring from day to day (with food readily available) are both negatively correlated with $\mathrm{CHO}$ balance from the previous day in mice (Flatt et al, 1987, Flatt et al, 1993). Stubbs and co-workers have shown this same trend more recently in humans (Stubbs et al, 1995). It has thus been concluded that changes seen in one's food intake from day to day appear to reflect a regulation that operates to maintain the body's glycogen reserves (Flatt et al, 1996). 


\section{THE GLUCOSTATIC THEORY OF APPETITE}

The glucostatic theory of appetite control proposed by Mayer et al. has laid the foundation for many theories on feeding behaviour (Mayer et al., 1953). This theory is mainly an extension of the homeostatic model of control which states that any given system has a desired state of balance or equilibrium: when out of balance, these systems act to restore the balance. Therefore, as discussed earlier, when blood sugar drops (hypoglycaemia), the glucostatic receptors in the pancreas signal this change to the lateral hypothalamus of the brain to increase feeding (Mayer, 1953). As mentioned earlier, changes seen in one's food intake from day to day depend on a regulatory operation that acts to maintain and balance the body's glycogen reserves (Flatt et al, 1996).

It has also been found that glucose-sensing neurons in the ventromedial hypothalamus (VMH) aid in the regulation of glucose homeostasis as well by altering their action potential frequency in response to physiological changes in extracellular components such as glucose and insulin (Niijima, 1983., Zhentao and Routh, 2006). Consequently, when faced with high blood sugar (hyperglycemia) one will experience a decrease in appetite and intake through the reverse of the aforementioned signalling model (Campfield and Smith, 1983; Melanson et al, 1999).

The regulation of this energy intake is achieved through feedback to the central nervous system (CNS) that allows for appropriate adjustments in feeding behaviour in an attempt to maintain energy balance. The glucostatic theory 
presented by Mayer suggests that low absolute glucose concentrations are associated with increase in hunger and energy intake. The activity of the satiety center in the ventromedial nuclei (VMN) is most likely governed by glucose sensitivity in the neurons (Mayer, 1953). A recent study on rats suggests that decreases in glucose sensitivity of VMN glucose-inhibited neurons may contribute to impairments in central glucose sensing mechanisms after recurring hypoglycaemia (Zhentao and Routh, 2006). These findings support a role for VMN neurons in hypoglycaemia detection and initiation of counter regulatory responses (both sympathoadrenal and neuroendocrine responses needed to restore euglycemia).

Mayer's original work also suggested that low arteriovenous glucose differences (an index of the rate of glucose utilization) can lead to increases in appetite (Mayer, 1953). Mayer went on to conduct human studies that did indeed show that differences in blood glucose concentration were correlated with hunger ratings and food intake in some circumstances (Van Itallie, Beaudoin and Mayer, 1953). However, other research comparing arteriovenous differences and food intake did not show this same correlation (Berstein and Grossman, 1956).

Arteriovenous glucose differences are mainly a measure of glucose as it is removed by tissues at a given arterial level. Such differences should enhance the correlation of arterial glucose levels with food intake as well as feelings of hunger and satiety (Van Itallie et al, 1953). It has generally been hypothesized that when glucose utilization is low and consequently, the arteriovenous glucose difference across these neurons is low, the activity across these neurons decreases. When 
these conditions are in place, the activity of the feeding center leads to a feeling of hunger and an increase in appetite (Melanson, 1999).

\section{EXPERIMENTAL SUPPORT FOR MAYER'S THEORY}

Since Mayer's initial proposal of the Glucostatic theory, it has become clear that glucose levels are linked with meal initiation. Between meals, blood glucose concentration is typically constant despite the fact that energy expenditure may be varying (Louis-Sylvestre, J., LeMagnen, J, 1980). In a 1985 study, Campfield, Brandon and Smith found that blood glucose concentrations stay constant within one percent of the basal concentration between meals. Further, it was found that a decline of approximately 12 percent in blood glucose concentrations is sufficient to be detected by cells that depletion in usable glucose has occurred. This change in circulating glucose has been associated to the initiation of food intake (Campfield et al, 1985).

A study in 1996 by Campfield, Smith, Rosenbaum and Hirsch involved 18 healthy adults isolated from each other as well as time cues. Following an overnight fast, blood was drawn and blood glucose was monitored over a 2-6 hour period. The subjects were able to control the light in the room and complete activities in the room as they desired. Visual analog ratings of hunger and satiety were completed approximately every 30 minutes. Subjects could request a meal at any time at which point the experiment ended. It was found overall that in $83 \%$ of the subjects, changes in both ratings of hunger and verbal meal requests were preceded by and 
significantly correlated with transient declines in blood glucose $(10 \%$ below baseline at 27 minutes) (Campfield et al, 1996).

Campfield and colleagues outline various potential explanations for such a decline in blood glucose (1985). Firstly, this transient decline could be due to a decrease in hepatic glucose production that could be modulated by hormonal changes (i.e. insulin, epinephrine and glucagon). This includes an increase in insulin concentration, a decrease in epinephrine or a decrease in glucagon and potentially glucocorticoids as well. The decline in blood glucose could also be caused neurally through the autonomic nervous system as controlled by the hypothalamus. In the end, it is likely that the decline could also potentially be caused by a combination of neural and hormonal effects. After many studies on the subject, Campfield et al hold that there is a causal relationship between blood glucose decline and meal initiation but the mechanism still has yet to be determined (Campfield, 1985).

Campfield and co-workers conducted a study in 1992 to illustrate this earlier idea that requests for meals and changes in ratings of hunger were related to changes in blood glucose concentration (Campfield and Smith, 1992). It is possible that these changes in ratings of hunger are also related to not only changes in blood glucose concentration but also factors relating to glycaemia such as oxidation and intake: two factors to be examined in the present study. Campfield and Smith's study also obtained results showing that hunger ratings increased after insulininduced transient declines in blood glucose (Campfield and Smith, 1992). In the same sample, no change in ratings of hunger were seen when blood glucose was 
stable. The results of this study support Mayer's theory by suggesting that patterns of blood glucose levels reflect a physiological event or signal that leads individuals to express feelings of hunger (Campfield and Smith, 1992).

Many studies have looked further into glucose and insulin concentrations in the blood prior to and following feeding. Strubbe, Steffens and DeRuiter measured levels of insulin and glucose every 20 minutes prior to meal initiation and then every ten minutes during feeding in rats (1977). There was no decrease in glucose in the 30 minutes directly preceding feeding. However, there was a significant decrease in insulin in small transient declines in blood glucose the 5 minutes before feeding indicating that this decrease in insulin may play a role in meal initiation. This may indicate that glucose utilization attains its lowest rate directly prior to feeding despite the constancy of the actual blood glucose concentration (Strubbe, Steffens and DeRuiter, 1977). The initial low blood glucose is most likely obtained following increased glucose utilization or decreased hepatic production of glucose.

A study by Campfield and Smith has shown that transient declines in blood glucose levels (about $11 \%$ in $\sim 18$ minutes) may coincide with meal initiation in free feeding rats (1986). It was also found that infusion of intravenous glucose caused a significant delay in meal initiation as it blunted this transient decline in blood glucose (Campfield and Smith, 1985).

In another study, Smith et al used IV fructose infusions to test the specificity of glucose to delay meal initiation and to attempt to induce transient declines in blood glucose and feeding (Smith, Driscoll and Campfield, 1988). Blood glucose 
and meal patterns of chronically cannulated rats were observed with and without fructose infusion. These observations imply that the effects of fructose may direct changes in blood glucose dynamics thus providing support for the hypothesis key in Mayer's early theory which states that the shape and/or pattern of transient decline in blood glucose is a control signal that is detected by the CNS and mapped into meal initiation. The results also support the conclusion that these transient declines are endogenous and that glucose dependant cues are required for meal initiation in free-feeding rats (Smith et al., 1988).

Although this accumulation of experimental support for Mayer's ideas has strengthened his theory, it has also highlighted the need to extend what we now know into more concrete situations and towards understanding under-researched areas in this field. Research has yet to be done on the effect of extreme variation of carbohydrate availability on this model: this is therefore what the present study will focus on.

\section{EXTENSION OF MAYER'S GLUCOSTATIC THEORY}

Many studies (even beyond those shared here) have shown a system as introduced by Mayer where changes in nutrient balance do not necessarily translate directly to changes in one's feeding behaviour. Because of this, Mayer's model should be revisited and reconsidered with our ever increasing understanding of macronutrient effects on appetite; specifically carbohydrates. Many studies have shown that both blood glucose levels and glucose utilization in single-stomached 
species increase during and after carbohydrate-containing meals (Strubbe \& Steffens, 1977; Nicolaidis, 1981; Flatt et al. 1985; Surina et al. 1993). The effect of major changes in carbohydrate availability on energy balance needs to be determined.

It is known that $\mathrm{CHO}$ has a considerable effect on short term levels of satiety although the mechanisms behind this are not clear. The glucostatic theory proposed that it is hypothalamic glucoreceptors responding to rises and falls in blood glucose that affects hunger and satiety. A rise in blood glucose activates hypothalamic satiety areas and suppresses eating where as a fall in these levels signal hunger (Lavin et al, 1996). In addition to this, others have suggested that it is in fact hepatic glucoreceptors that send information to the CNS to control eating behaviour (Lavin, 1996).

This idea is supported by a study conducted by Russek et al 1968 that used intraportal infusion on glucose in dogs resulting in suppressed feeding (Russek et al, 1968). The results of a study by Lavin et al in 1996 suggest that the presence of $\mathrm{CHO}$ in the small intestine reduces hunger and increases satiety through an interaction with pre-absorptive receptors (Lavin et al., 1996)

The proposed research study aims to revisit the glucostatic theory of appetite regulation and extend it to dietary manipulations involving a variety of levels of carbohydrate availability. Many studies have suggested that appetite and hunger could be functions of dietary $\mathrm{CHO}$ content through the effect of post absorptive hypoglycaemia (Geiselman, et al 1982). The goal of the proposed study is to show that changes in one's carbohydrate stores and oxidation will cause predictable 
effects on one's feeding behaviour as predicted by Mayer's model. This will be key to the development of Mayer's model as it has yet to be been considered under conditions of extreme variations of $\mathrm{CHO}$ availability.

\section{CARBOHYDRATE METABOLISM}

Mayer essentially argued that energy balance regulation predominantly occurs through short term glucostatic responses. Mayer believed that carbohydrates are the key factor that can be integrated with energy metabolism and its components (Mayer, 1955). Many other researchers in addition to Mayer have proposed that carbohydrate metabolism is instrumental in food intake regulation. This is due to its high turnover rate, its limited storage, immediate and tight regulation as well as its critical role as a fuel source for the CNS (Flatt, 1996). As discussed earlier, declines in blood glucose causing changes in short term food intake regulation may depend on carbohydrate availability as stated by the 'Gluconeostatic hypothesis' (Flatt, 1996). Flatt stated that this model suggests that individuals consume food to a level that maintains glycogen levels in the body (Melanson, 1999., Flatt, 1996). Further research on this 'Gluconeostatic hypothesis' seems to be very limited; a term rarely used and not researched in much detail. 


\section{CARBOHYDRATE LOADING}

Most past research on carbohydrate loading has been performed in the context of athletic performance. It has been shown on numerous occasions that significant increases in muscle and hepatic glycogen are achieved by increasing the carbohydrate intake over several hours to days before endurance performances (Hawley, Schabort, Noakes and Dennis, 1997). A study by Tarnopolsky and colleagues measured muscle glycogen stores in the anterolateral aspect of the vastus lateralis following an increase in dietary carbohydrates from $55-60 \%$ to $75 \%$ of energy intake for a period of 4 days (carbohydrate loading). The results showed that muscle glycogen concentration in men increased by $41 \%$ in response to the dietary manipulation (Tarnopolsky, 1995).

Another context for carbohydrate is the idea of pre-operative loading to counteract the catabolic action seen with the traditional pre-operative fasting which may in fact increase detrimental effects of surgery. A study by Yagci et al involved random assignment of either carbohydrate loading or overnight fasting to seventy patients scheduled for a moderate surgery (2008). Plasma glucose as well as serum insulin levels were obtained prior to, during as well as following the surgery. Plasma glucose levels prior to the surgery were found to remain significantly higher in patients in the experimental group. Plasma glucose levels were significantly higher in the treatment group (initial $4.78+/-0.61 \mathrm{mmol} / \mathrm{L}$, final $4.61+/-0.46 \mathrm{mmol} / \mathrm{L}$ ) than in the control group (initial $4.12+/-1.34 \mathrm{mmol} / \mathrm{L}$, final $3.94+/-1.24 \mathrm{mmol} / \mathrm{L}$ Serum levels were also elevated in the treatment group but returned to control levels at the time of surgery (Yagci, 2008). 


\section{CARBOHYDRATE RESTRICTION}

The majority of research on carbohydrate restriction on the other hand is based around weight loss or diet strategies. It is suggested that the obesity epidemic we are currently facing is due mainly to an increase in calories accounted for almost entirely by an overall increase in carbohydrate consumption (Trends, 2004). Modern diets have therefore focused on macronutrient restriction: often carbohydrate restriction specifically. Diets low in carbohydrates have been widely recommended to combat type 2 diabetes as well as the metabolic syndromes for various reasons (Accurso, A., Bernstein, R., Dahlqvist, A. et al, 2008). First of all, carbohydrate restriction improves glycemic control and reduces insulin fluctuations. Secondly, the beneficial effects of low carbohydrate diets include improvements in triglyceride levels, HDL cholesterol and LDL mean particle size (Accurso, A., Bernstein, R., Dahlqvist, A. et al, 2008).

The rationale behind the use of carbohydrate restricted diets is that, a reduced consumption of carbohydrates is accompanied by changes in insulin and glucagon concentrations that lead to a general change from a glucocentric metabolism to a more adipocentric metabolism. (This nutrient "centric" terminology is currently being used by many researchers to describe glucose focused (glucocentric) and fat focused (adipocentric) metabolism respectively.) The main fuel source changes to fatty acids (from dietary fat and adipose stores) and ketones (from dietary fat, protein and adipose stores) (Westman, Feinman, Mavropoulos et 
al, 2007). During this adipocentric state, tissues that depend on glucose still receive glucose through gluconeogenesis and glycogenolysis.

Even when there is no carbohydrate intake, it is estimated that $200 \mathrm{~g}$ glucose/day can still be converted from dietary protein and fat by the liver and kidney (Westman, Feinman, Mavropoulos et al, 2007). Although earlier studies saw starvation and low-carbohydrate states as similar, they in fact differ because under low carbohydrate conditions, glucose concentrations are sustained even when there is no intake (Westman, Mavropoulos, Yancy et al, 2003.) Although there is controversy on recommended values, Westman et al suggest that a low carbohydrate diet is defined by a daily intake of $50-150 \mathrm{~g} /$ day of carbohydrates (Westman, Feinman, Mavropoulos et al,2007).

An early laboratory investigation by Nilsson and Hultman directly measured liver glycogen levels in human specimens following total starvation and low carbohydrate diets followed by re-feeding (Nillson and Hultman, 1973). The results showed that there was a decrease in liver glycogen by a mean of $0.30 \mathrm{mmol} /$ glucosyl unit per $\mathrm{kg}$ of wet liver tissue per minute during rest, following an overnight fast and with an additional 4 hours of starvation. Further starvation and a eucaloric, low carbohydrate diet both decreased liver glycogen from a mean of 232 to $24-55$ mmol glucosyl units per $\mathrm{kg}$ within $24 \mathrm{hrs}$ (Nillson and Hultman, 1973). This carbohydrate depleted state was maintained over 9 days showing a consistently low muscle glycogen level. Upon re-feeding of a carbohydrate rich diet, a rapid increase in liver glycogen to values above normal (424-624 mmol glucosyl units per $\mathrm{kg}$ of wet liver tissue was observed (Nillson and Hultman, 1973). 


\section{CARBOHYDRATE MANIPULATION}

A normal, untrained individual consuming a regular diet ( $45 \%$ carbohydrate), is able to store approximately 100 grams of glycogen in the liver and about $280 \mathrm{~g}$ in muscle (Noakes, 1985). When this same individual consumes a high carbohydrate diet ( $75 \%$ carbohydrate), the glycogen stores may increase to $130 \mathrm{~g}$ in the liver and $360 \mathrm{~g}$ in muscle (Noakes, 1985). If a trained athlete were to consume a normal diet of $45 \%$ carbohydrate, glycogen levels would be about $55 \mathrm{~g}$ in the liver and $280 \mathrm{~g}$ in muscle. This same well conditioned athlete on a high carbohydrate diet could have glycogen levels closer to $160 \mathrm{~g}$ in the liver and $720 \mathrm{~g}$ in muscle (Noakes, 1985.,Wolinsky, Driskoll, 2007).

\section{SUMMARY}

A thorough review of the literature on the glucostatic theory of appetite regulation has shown a large gap in the knowledge surrounding Mayer's model. The present study will seek to show that changes in one's carbohydrate stores and oxidation will cause predictable effects on one's feeding behaviour as predicted by the glucostatic theory of appetite regulation. By considering extreme fluctuations in glucose concentrations and stores, Mayer's theory can potentially be extended to explain more complex changes in blood glucose stores: an important explanation needed to continue to understand diseases related to abnormal glucose fluctuations and metabolism. This includes a potentially better understanding of obesity, heart disease, high blood pressure, breathing problems, and even some cancers such as 
endometrial, breast and colon cancer as well as most notably; type 2 diabetes. With many of these conditions reaching epidemic proportions, this is a realm that demands a better understanding.

By exposing each subject to three individual phases of carbohydrate consumption while keeping caloric intake constant, the effect of these carbohydrate extremes on glucose excursions and appetite can be considered. Based on the available literature on both Mayer's theory, glucose metabolism and theories on appetite several hypotheses have been made.

First, it is proposed that appetite will be greater when carbohydrate intake is low: the endogenous glucose reduction will lead to lower levels of circulating glucose which will result in a greater appetite. Second, it is proposed that during the carbohydrate depletion phase, food consumption will be greater. Lastly, an exploratory hypothesis predicts that in addition to consuming more following the carbohydrate depletion protocol, participants will also show a greater preference for foods high in carbohydrates. The methods to examine these hypotheses are outline in the following chapter.

A fourth exploratory hypothesis is also being made with regards to changes in blood glucose levels with regard to this protocol and appetite. Is glucose in fact a bottom up factor influential enough to illicit changes in feeding behaviour as suggest by Mayer (1955)? Does this same trend introduced by Mayer and supported by so many in normal states of energy balance hold true with extreme fluctuations in glucose stores under conditions of energy balance? It is further hypothesized that 
the above hypotheses will coincide with predictable changes in blood glucose levels. Increasing the levels of $\mathrm{CHO}$ in one's diet (endogenous glycogen) will result in an increase in appetite, a consequent increase in intake and an increased preference for foods high in glucose. 


\section{CHAPTER III - METHODOLOGY}

\section{Study Description}

This study protocol was approved by the Research Ethics Board at the University of Ottawa (see Appendix 1 for the letter of approval). The participants were recruited from the University of Ottawa Campus through posters and word of mouth. Each potential subject was screened for inclusion/exclusion criteria through a pre-screening questionnaire (Appendix 2) during the initial meeting. Participants were told that the study would be looking at the effects of carbohydrate loading on various factors relating to appetite and feeding and that how these factors relate to changes in blood glucose would also be considered. Informed consent was obtained from all participants prior to the start of the protocol (see Appendix 3 for informed consent package presented to each potential subject).

\section{Subjects}

Six apparently healthy men were recruited from the University of Ottawa. These volunteer participants were screened using the following inclusion criteria: (1) university aged males (18-30); (2) weight stable (+/- $2 \mathrm{~kg}$ during the last 6 months); (3) non-smokers; (4) normal weight (BMI between 20 to 29; (5) non-diabetic. Additional criteria that could lead to exclusion were as follows: (1) history of eating disorder; (2) thyroid, chronic liver or renal disorder; (3) been on medication that may influence their energy intake (EI) or their energy expenditure $(E E)$. As stated earlier, this information was gathered during the pre-screening questionnaire and then 
further reinforced based on anthropometric measures in the following screening sessions. Participants that fit the inclusion criteria and gave their informed consent were asked to return to the laboratory for the completion of their initial visit where a pre-test evaluation was conducted. Table 3 in the results section presents the characteristics of each of the subjects at baseline.

\section{Study Design}

This study employed randomized crossover design which included three experimental conditions as follows:

1. Phase 1: 3 days of eucaloric diet with no manipulation (Carbohydrates, Protein and lipids 45\%, 25\%, and 35\% respectively)

2. Phase 2: 3 days of eucaloric diet with carbohydrate loading. (Carbohydrates, Protein and lipids $75 \%, 10 \%$, and $15 \%$ respectively)

3. Phase 3: 3 days of eucaloric diet with carbohydrate depletion. (Carbohydrates, Protein and lipids 10\%, 25\%, and 65\% respectively)

As stated above, subjects were investigated under eucaloric (in a state of energy balance) and isocaloric (same amount of calories across experimental trials) conditions. Each of the above experimental conditions was separated by a washout period of a minimum of 2 weeks. 
Experimental Sessions and Description of Measures

All tests were performed at the Behavioural and Metabolic Research Unit (BMRU) in Ottawa between May 2009 and December 2009. Each participant was subjected to a series of measurements and tests in various sessions during each of the 3 phases of this study as well as the screening session. The diet interventions consisted of a three day regimen which was followed by a series of laboratory measurements on the fourth day. Please refer to the 'Description of Measures at the end of this chapter for full detail on each protocol used.

Initial meeting:

This initial meeting was held at a location deemed convenient by the participant. This meeting involved an explanation of the study, what was to be required of them as well as an explanation of the consent form. Participants were asked to read the form through carefully and sign if they wished to participate. The participant had the option to take the form home to read over and consider with family prior to signing if they so desired. Before departing the participant received an accelerometer that they were instructed to wear for 7 days prior to their next session in order to determine their average daily caloric output from physical activities. 
Pre-screening Session:

This session was scheduled for at least one week following the initial meeting so that the participants were able to wear the accelerometer for 7 days. Subjects were asked to arrive at the laboratory at $7 \mathrm{~h} 30$ after an overnight fast from $19 \mathrm{~h} 30$ the night before. They were also required to return their accelerometer at this time. Upon arrival, blood was drawn to determine the baseline fasting blood glucose and insulin levels of each subject.

The second portion of this session involved a measure of the participant's Resting Energy Expenditure (REE). After resting in a supine position for 20 minutes, a 30-minute REE measure was taken as previously described (Bennard and Doucet, 2006). Values measured each minute in the mid steady state section of this 30 minute measure (first and last 5 minutes were not considered) were averaged to determine the subjects average daily resting metabolic rate ( $\mathrm{kcal} /$ day). This value was then combined with the average daily physical activity energy expenditure as determined by a week of accelerometer measures. This method is more valid and objective than simply multiplying REE by a physical activity level factor. The combination of these two values established the necessary caloric consumption for the subject. Intake was clamped at this level for all 3 pre-experimental sessions.

The final part of the preliminary session involved compiling baseline characteristics for each subject as follows as in previous studies in this lab (Cameron and Goldfield et al, 2008): Weight, height and waist circumference were measured using a standard stadeometer and digital scale and body composition 
was measured with the DEXA. Subjects also completed the Three Factor Eating Questionnaire to assess each participant's attitude towards eating. This 51 question questionnaire determines the participant's level of hunger, inhibition and restraint (Stunkard and Messick 1985). Following these measures, the first experimental phase was explained.

\section{Experimental Sessions (3):}

The experimental sessions were divided into 3 conditions each consisting of 3 days of dietary manipulations, 1 testing day and a two-week washout period in between conditions. Each condition involved a different macronutrient composition at a pre-determined caloric clamp as described above. For the first condition, participants were instructed to eat a diet similar to what they would normally eat to the caloric intake measured in the previous section ( $45 \%$ carbohydrate): this is referred to as the Normal or $\mathrm{N}$ phase. The second phase consisted of a eucaloric carbohydrate lowered diet ( $10 \%$ carbohydrate): this is referred to as the Low or LO phase. The third phase consisted of a eucaloric carbohydrate loaded diet $(75 \%$ carbohydrate) which was also clamped at the predetermined caloric intake. This final phase is referred to herein as the High or $\mathrm{HI}$ phase. The macronutrient composition of each diet is shown in Table 1 and is modelled closely to the work from Haman et al., 2004. 
Table 1. Prescribed Diets by Macronutrient Composition ( $n=6)$

\begin{tabular}{llll}
\hline & $\mathrm{N}$ & $\mathrm{HI}$ & $\mathrm{LO}$ \\
\hline Carbohydrate, \% & $45 \%$ & $75 \%$ & $10 \%$ \\
Protein, \% & $25 \%$ & $10 \%$ & $25 \%$ \\
Lipid, \% & $35 \%$ & $15 \%$ & $65 \%$ \\
Carbohydrate, g/day & $342.0 \pm 35.7$ & $566.5 \pm 65.2$ & $81.5 \pm 9.3$ \\
Protein, g/day & $118.5 \pm 13.0$ & $316.3 \pm 29.5$ & $191.0 \pm 22.2$ \\
Lipid, g/day & $151.3 \pm 14.2$ & $460.0 \pm 47.0$ & $215.0 \pm 22.9$ \\
\hline
\end{tabular}

${ }^{*}$ Total energy intake (kcal) vary across subject based on unique caloric clamp.

Participants were given a detailed log outlining the prescribed diet that they were required to fill out and return at the following session. The log included a break -down of how many servings were to be consumed as well as a description of what an appropriate serving would be. In this log system, foods were categorized into six groups as follows: Grains; fruits; vegetables; milk products; Meat and alternatives; fat \& oils; and extras (composed of food item containing $\leq 2.5 \mathrm{~g}$ carbohydrate per half cup). Participants had the flexibility to select their food within the meal plan that was individually designed for them based on their daily caloric prescription they simply had to ensure that they ate the appropriate amount of servings per food group. An example of the log book provided to each participant is shown in Appendix 4.

For each experimental condition, the participants were asked to come to the laboratory and subject themselves to a series of measurements as described below. The protocols used for the 3 testing sessions were adapted from the study by 
Campfield and colleagues 1993 (Campfield, Smith et al.,1996). Briefly, blood glucose levels were measured throughout the day during each experimental condition as described below. Subjects were asked to arrive at the lab at $7 \mathrm{~h} 30 \mathrm{am}$. For the first two hours of testing, the subject underwent REE testing to determine whole body substrate partitioning following each of the 3-day experimental conditions. A standardized breakfast as described in Table 2 was then served.

Table 2. Composition of the Standard Breakfast

\begin{tabular}{cccccc}
\hline & Total $\mathbf{( g )}$ & $\mathbf{C H O}(\mathbf{g})$ & Protien (g) & Lipid (g) & Total El (kcal) \\
\hline Orange Juice & 250 & 24 & 0 & 0 & 90 \\
Whole Wheat Toast & 74 & 33 & 7 & 3 & 187 \\
Peanut Butter & 35 & 7 & 7 & 19 & 210 \\
\hline Total Breakfast & 359 & 64 & 14 & 22 & 487 \\
\hline
\end{tabular}

Blood Glucose was measured continusously throughout the day using a continuous blood glucose monitor (Medtronic Minimed Inc., Northridge, CA, USA). This system included a sensor inserted in the abdominal subcutaneous tissue. The sensor, once calibrated would send blood glucose measures every 5 minutes to a handheld monitor. Blood Glucose values used for initial (pre and post breakfast) readings and for calibration were obtained using the traditional finger prick method (CONTOUR by Bayer Healthcare LLC, Terrytown, NY, USA). 
Visual analog ratings of appetite were measured every 30 minutes using a quasi-random schedule using a 4 question Visual Analog Scale (VAS). VAS were not administered during a meal so if food was requested over this collection point, the VAS was presented before the meal . Following the $7 \mathrm{~h} 30-9 \mathrm{~h} 30$ preliminary assessments and standard breakfast, participants were escorted to an isolated room for the remainder of the day. The room contained a desk and desk chair, a table on which was a TV and DVD player and a selection of DVDs and a hospital chair that could recline as the subject desired. Some subjects also chose to use a laptop (time cues disabled) during this time where others spent the day sketching, reading or writing. Any time cues in the room be it on the thermostat, TV or computer were disabled before the subject entered the room.

The subject remained in this room with the door closed so that they were isolated from sounds and smells from outside the room. The initial measurements of weight and RMR as well as the insertion of the CGM sensor were completed in other testing rooms where as finger prick blood glucose measures were completed in the isolation room. The standard breakfast and pre and post VAS were the only meal related components completed outside of the isolation room. For the remainder of the day, the only reason the subject would leave the room would be upon their request to use the bathroom. The bathroom was located just accross the hall so subjects were still isolated from any time cues.

Participants were instructed that meals would not be served at predetermined times however; food or drink would be made available to them all day: Spontaneous eating was allowed when the subjects requested it. Upon the subject's request, a 
menu was presented on which the subject could self-select any and as many items as they desired. Appendix $\mathbf{5}$ shows the menu that was presented as well as a table describing the macronutrient composition and serving size of each option. This allowed investigators to measure blood glucose, appetite, food intake (amount, composition and preference), triggers for hunger and food requests for the remainder of the day Following the testing day for one phase, the next phase was explained. Following the testing day there were 2 weeks before the next phase commenced. Each subsequent phase was again 3 days of diet logging followed by 1 day of testing. (See Appendix 6 for a diagram detailing the timeline of the above protocols)

\section{Description of Measures}

Anthropometric Measures:

The body weight and height of each participant were measured using a standard stadiometer and digital scale (HR-100 Height Rod and BWB-800AS Digital Scale from Tanita Corporation America, Inc. Arlington Heights, Illinois, USA). Prior to measurement, participants were asked to void their bladders, remove all clothing, shoes and accessories and to put on a hospital gown. Height was measured with the participant standing up as straight and tall as possible with heels and shoulders against the wall, feet together and following a normal inspiration. These measures were used to calculate BMI. Waist circumference was also recorded as a measure of visceral adiposity. A measuring tape was placed around the waist (the midpoint 
between the last rib and the iliac crest) and this measurement was also taken following a normal inspiration. All anthropometric measures were made using ACSM guidelines (American College of Sports Medicine, 2001).

Body composition:

Body composition was measured using dual energy $\mathrm{x}$-ray absorptometry (DEXA) (Lunar Prodigy, GE Medical Systems, Madison, Wis.) as described in previous work of our lab (Bennard and Doucet, 2006). The participant was asked to wear only a hospital gown for this procedure. The subject was instructed to lie in a supine position for approximately 10 minutes while a low intensity $\mathrm{x}$-ray scans their entire body. This scan indicates the bone mineral density of the participant as well as the percent body fat, fat mass and fat-free mass. Coefficient of variation and correlation for the DEXA was $1.8 \%(R=0.99)$ as determined in 12 healthy subjects.

Attitude towards food:

The Three Factor Eating Questionnaire (TFEQ) was administered during the initial screening process to determine the participant's individual attitude towards eating. This 51 question questionnaire determined the participant's level of hunger, inhibition and restraint (Stunkard and Messick 1985). (See Appendix 7 for a sample of the TFEQ questionnaire.) 
Appetite:

As in many previous studies on feeding in our laboratory (Cameron, Goldfield et al, 2008; Bennard and Doucet, 2006), participants were asked to rate their appetite on a 150mm visual analogue scale (VAS) adapted from Hill and Blundell (Hill and Blundell, 1986). The scales assessed the participant's appetite, desire to eat, hunger, fullness and prospective food consumption. Each factor was assessed by asking the participant to mark their current state with a vertical mark on a horizontal continuum. (See Appendix 8 for a sample of the VAS used.)

Blood Analysis:

Blood glucose was assessed continuously throughout the day using a continuous blood glucose monitor (CGM). CGMs determine blood glucose levels on a continuous basis (every few minutes). This system consists of three components. First, the sensor for this system was inserted by a registered nurse in the subcutaneous tissue on the subject's abdomen directly upon the subject's arrival to the lab to allow time for the monitor to initialize prior to calibration (2 hours).

Once inserted, the needle is removed leaving a cathader in the subject that contains the blood glucose sensor. A transmitter component is then attatched to the sensor to synchronize the values read by the sensor to the hand held monitor component. The sensor and transmitter are secured using an adhesive bandage for the duration of the day. Following the 2-hour initialization period, a calibration value is required before the monitor will start presenting values. 
A link between this sensor to a non-implanted transmitter allowed the monitor to display levels of blood glucose on a practically continuous basis. This method was calibrated (usually twice per day) using the traditional finger prick blood glucose measurement technique. The CGM used for this study was the Guardian REALtime system (Medtronic Minimed Inc., Northridge, CA, USA). During initialization period of the CGM during the first 2-hours of the testing day, blood glucose was measured using the traditional finger prick method and a Blood Glucose Meter (CONTOUR by Bayer Healthcare LLC, Terrytown, NY, USA) . Blood Analysis:

Blood glucose was assessed continuously throughout the day using a continuous glucose monitor (CGM). This technology, first approved by the FDA for commercial use in 2006, measures interstitial glucose levels through a sensor in subcutaneous tissue of the abdomen (every few minutes). Unlike Self Measured Blood Glucose (SMBG) that measure blood glucose levels through samples from the blood, CGM samples are obtained from the interstitial fluid under the skin. Blood glucose circulating through the body distributes into interstitial fluid where it is subsequently absorbed into cells. These levels obtained from interstitial fluid therefore lag behind blood glucose levels due to the time it requires for glucose to diffuse from the circulatory system into the interstitial fluid. Despite this lag, interstitial fluid measures may be more reflective of the actual amount of glucose that is available for cellular metabolism (Klonoff, Bernhardt, Ginsberg, Joseph, Mastrototaro et al, 2008).

This system consists of three components. First, the sensor for this system was inserted by a registered nurse in the subcutaneous tissue on the subject's 
abdomen directly upon the subject's arrival to the lab to allow time for the monitor to initialize prior to calibration ( 2 hours). Once inserted, the needle is removed leaving a cathader in the subject that contains the glucose sensor which will sense levels of glucose in the interstitial fluid. A transmitter component is then attatched to the sensor to convert this to synchronize the values read by the sensor to the hand held monitor component. The sensor and transmitter are secured using an adhesive bandage for the duration of the day. Following the 2-hour initialization period, a calibration value is required before the monitor will start presenting values.

A link between this sensor to a non-implanted transmitter allowed the monitor to display levels of glucose on a practically continuous basis. This method was calibrated (usually twice per day) using the traditional finger prick blood glucose measurement technique. The CGM used for this study was the Guardian REALtime system (Medtronic Minimed Inc., Northridge, CA, USA). During initialization period of the CGM during the first 2-hours of the testing day, blood glucose was measured using the traditional finger prick method and a Blood Glucose Meter (CONTOUR by Bayer Healthcare LLC, Terrytown, NY, USA).

Various studies have looked into the validity and accuracy of these monitors. Typically these studies involve pairing measures achieved through the CGM with SMBG achieved through the traditional finger prick method at the same time. In a 2003 study involving 125 subjects, Gross and colleagues collected 2726 SMBG tests entered into CGM over 4 days. It was found that of these pairs, $2477,(90.1 \%)$ matched $(C G M=S M B G)$ indicating that new $C G M$ approach is similar to the traditional SMBG method of measuring glucose levels in the body (2003). 
Sachedina and co-workers conducted a similar study that concluded that in terms of total duration of hyperglycemia, blood glucose oscillations and day to day variability, the two methods were similar (2003). When it came to measures of hypoglycaemia and postprandial hyperglycemia, the CGM was actually superior to the SMBG (Sachedina et al., 2003). An interesting point to note when considering the $9.1 \%$ of pairs that did not match in Gross et al's study is a finding by Brunner and colleagues in 1998. Brunner noted that this $9.1 \%$ difference between the CGM and the SBGM may be overestimated due to the fact that the CGM is calibrated by the traditional prick method: a method where $15-20 \%$ error is not uncommon, thus exaggerating the difference (Brunner et al., 1998).

Within the literature, two main limitations have been noted for the continuous glucose monitors. First of all, there is a need for recalibration at least four times daily. This limitation was easily integrated into our study design methodology and is therefore negligible in this non-commercial setting. The second potential limitation is due to the fact that the CGM sensors measure glucose levels in interstitial fluid and not the blood as discussed earlier. It has been found that there is a lag time ranging from 4-10 minutes between these two measures (Boyne et al, 2003).

This time lag is of concern in the commercial market as it may mean that these monitors do not indicate hypo/hyperglycemic events correctly. Due to this, it has been recommended that SMBG should be use at these points to confirm the levels. Boyne confirms however that this lag is not significant in euglycemic state (2003). Various studies prior to Boyne's have used microdialysis as an indirect method of estimating interstitial fluid glucose values and have found that interstitial 
fluid glucose levels are almost identical to venous plasma glucose in healthy individuals during steady state (Lonnroth et al, 1987; Jansson, Fowelin, Smith and Lonnroth, 1988). It is important to note that regardless, software programs have been designed to accommodate the lag in interstitial fluid glucose readings reducing its role as a potential limitation (Cengiz and Tamborlane, 2009). Further to this, when the current study is considered it was the fluctuation profile or change in levels that it was in question here rather than simply concentration values, therefore this potential lag time no matter how small was not a limitation in this setting.

Resting Energy Expenditure Measures

Resting Energy Expenditure (REE) both during the initial determination of the caloric clamp as well as following each testing day was conducted using the same protocol as previously described (Bennard and Doucet, 2006). Subjects began with a 30 minute resting period in the supine position prior to the actual measurement of REE. Upon arrival in the morning following a 12 hour fast, subjects were placed in an isolated, quiet, normal temperature room and were instructed to lie supine on a hospital bed with legs uncrossed. Patients were also instructed not to fall asleep, change position or speak during this time. Following the initial resting period, a plexiglass hood was placed over the subjects' head through which fresh air could be drawn. Expired gases were analyzed via a metabolic cart and values of VO2 and VCO2 were obtained for each minute. From this value, substrate oxidation values 
were calculated with the following equations (Livesey and Elia, 1988. Haman, 2004):

Total $\mathrm{CHO}$ oxidation $(\mathrm{g} / \mathrm{min})=4.59 \mathrm{VCO}_{2}(1 / \mathrm{min})-3.23 \mathrm{VO}_{2}(1 / \mathrm{min})$

Total Fat oxidation $(\mathrm{g} / \mathrm{min})=-1.7059 \mathrm{VCO}_{2}(1 / \mathrm{min})+1.70 \mathrm{VO}_{2}(1 / \mathrm{min})$

The values for $\mathrm{VCO}_{2}$ and $\mathrm{VO}_{2}$ were corrected for the volumes of $\mathrm{O} 2$ and $\mathrm{CO} 2$ corresponding to protein oxidation $(1.010 \mathrm{l} / \mathrm{g}$ and $0.843 \mathrm{l} / \mathrm{g}$ respectively) as seen in the study by Haman and colleagues from which our loading paradigms are modelled (2004). Protein oxidation was further calculated with the assumption that in this case as discussed by Haman et al, protein oxidation is equal to protein intake. Based on the amount of protein consumed during the diet phase (g) over 24hours, a value for protein oxidation in $\mathrm{g} / \mathrm{min}$ was determined.

\section{Area Under the Curve:}

The trapezoid method was used to calculate AUC for appetite scores and blood glucose levels. The trapezoidal method is a procedure that was used to approximate the area under the curve (AUC). Points on the concentration-time curve for each measurement were connected with straight line segments to form a polygon. Each segment of this polygon formed a trapezoid, hence the name of trapezoidal method. It was the area of this polygon (or the sum of the area of the trapezoids) that was used to approximate the actually area under the curve. 
Calculations for \% Blood Glucose Decline:

Calculations were also conducted to determine the percent change in blood glucose levels prior to each feeding episode. This detailed the percent decline, the time over which this decline occurred as well as the time prior to the request when the minimum in the decline was reached. For each session completed by each subject, daily blood glucose profiles were charted. Time points for each food request were marked on the blood glucose curve $(F R)$. From here, the max value preceding this time point was also marked on the curve (MAX). If the meal request did not fall on a minimum value, the minimum value achieved prior to the request was marked (MIN). Figure 3 below illustrates the above points.

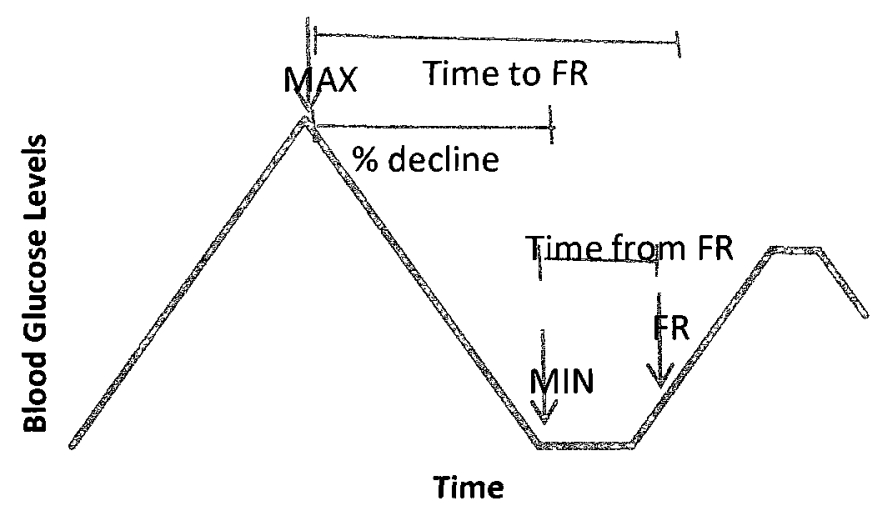

Figure 3. Example of \% decline in blood glucose.

The distance between MAX and MIN illustrates the total decline (expressed as a $\%$ decline). The time between MAX and MIN illustrates the time course of the decline (Time to FR). The time between MIN and FR indicates the amount of time 
prior to request that the decline occurred (Time from FR). The example below illustrates this concept.

Statistical analysis:

Primary outcomes of this study were to investigate the effects of carbohydrate loading as well as depletion on food consumption and appetite as well as specific macronutrient preference. The secondary outcome investigated whether spontaneous food requests would be preceded by declines in blood glucose as introduced by Mater (1953). This study was a randomized cross-over design so an ANOVA for repeated measures was therefore used to detect the differences in energy intake for each feeding episode as well as the for whole day. The effects of the different experimental conditions on the AUC for the appetite measurements and blood glucose profile was also assessed with an ANOVA for repeated measures with condition as the within subject factor (effect of condition versus effect of time (values assessed throughout the day)). Correlation analyses were performed between AUC of blood glucose and 1) total daily EI 2) total daily macronutrient content and 3) daily appetite profiles. A set of correlations were also conducted to determine the relationship between pre-feeding glucose levels and EI during these feeding episodes. Effects were considered significant at $p \leq 0.05$ and data was presented as mean \pm SD unless otherwise specified. 


\section{CHAPTER IV - RESULTS}

Participant characteristics

The six apparently healthy males who volunteered for this study were aged $23.8 \pm 1.3$ years (mean \pm SD) with a BMI of $22.8 \pm 1.8 \mathrm{~kg} / \mathrm{m}^{2}$ and body weight $76.5 \pm$ $7.9 \mathrm{~kg}$ at baseline. Table 3 presents descriptive characteristics of subjects at baseline. The Three Factor Eating Questionnaire (TEFQ) was administered during the pre-screening session to assess restraint, disinhibited eating and susceptibility to hunger.

Table 3. Descriptive Baseline characteristics of subjects $(n=6)$.

\begin{tabular}{llll}
\hline Variables & Mean & SD & Range \\
\hline Age (years) & 23.8 & 1.3 & $22.0-26.0$ \\
Body weight $(\mathrm{kg})$ & 76.5 & 7.9 & $70.0-89.9$ \\
Height $(\mathrm{m})$ & 1.8 & 0.05 & $1.7-1.9$ \\
BMI $\left(\mathrm{kg} / \mathrm{m}^{2}\right)$ & 22.8 & 1.8 & $20.4-25.6$ \\
RMR $(\mathrm{kcal})$ & 1871.3 & 52.7 & $1805.0-1932.0$ \\
Body fat $(\%)$ & 15.9 & 5.6 & $11.0-24.3$ \\
Restraint & 7.2 & 2.9 & $5.0-12.0$ \\
Hunger & 7.3 & 2.9 & $4.0-11.0$ \\
Disinhibition & & 1.6 & $2.0-6.0$ \\
\hline Means \pm SD, & these values are scores obtained through the TFEQ questionnaire.
\end{tabular}




\section{Experimental Conditions}

Total daily El level prescribed for the three experimental phases was on average $2922.9 \pm 321.3 \mathrm{kcal} / \mathrm{day}$ based on accelerometry and baseline resting energy expenditure as described in the methods. Although this was prescribed, the actual observed caloric consumption varied from this value. The variance in caloric intake based on subject diet log records for the three days preceding each testing day for the N, HI and LO phases, as well as the breakdown of these diets by macronutrient composition is shown in Table 4. Note however that caloric intake was nonetheless almost the same across conditions.. As expected, macronutrient composition was significantly different between conditions.

Table 4. Average Observed Diet for the 3 days preceding each Experimental Phase

\begin{tabular}{llll}
\hline & N & LO & HI \\
\hline & & & \\
Total El (kcal/d) & $2828.0 \pm 311.3$ & $2757.4 \pm 320.4$ & $2858.4 \pm 337.1$ \\
CHO (g) & $358.6 \pm 63.9^{\mathrm{a}}$ & $90.3 \pm 23.3^{\mathrm{b}}$ & $526.2 \pm 64.2^{\mathrm{c}}$ \\
Lipids (g) & $95.2 \pm 18.6^{\mathrm{a}}$ & $187.7 \pm 30.2^{\mathrm{b}}$ & $40.4 \pm 10.3^{\mathrm{c}}$ \\
Proteins (g) & $134.2 \pm 16.7^{\mathrm{a}}$ & $176.8 \pm 20.1^{\mathrm{a}}$ & $97.6 \pm 17.4^{\mathrm{c}}$ \\
CHO (\%) & $50.6 \pm 5.7^{\mathrm{a}}$ & $13.3 \pm 4.0^{\mathrm{b}}$ & $73.6 \pm 1.3^{\mathrm{c}}$ \\
Lipids (\%) & $30.4 \pm 5.6^{\mathrm{a}}$ & $61.04 \pm 0.3^{\mathrm{b}}$ & $12.6 \pm 2.1^{\mathrm{c}}$ \\
Proteins (\%) & $19.0 \pm 0.6^{\mathrm{a}}$ & $25.66 \pm 0.9^{\mathrm{b}}$ & $13.8 \pm 2.6^{\mathrm{c}}$
\end{tabular}

Values are means $\pm S D ; n=6$ subjects. Values in a given row not sharing the same letter are significantly different form one another. 
Table 5 below compares the REE and body weight (BW) following each of the three above described experimental diet phases. These measures were conducted after a 12-hr fast at the start of the each experimental day (following each condition). From here, carbohydrate oxidation and fat oxidation following each condition could be calculated. These values were corrected for the volumes of $\mathrm{O} 2$ and $\mathrm{CO} 2$ corresponding to protein oxidation $(1.010 \mathrm{l} / \mathrm{g}$ and $0.843 \mathrm{l} / \mathrm{g}$, respectively). Values for protein oxidation across each phase were calculated based on protein intake for each phase. As discussed in the paper by Haman and colleagues from which the present loading paradigms are modelled, it was found that in this context, protein oxidation is equal to the amount of protein consumed (2004). All substrate oxidation values were deemed significantly different across conditions as shown below. Note a $40 \%$ difference in carbohydrate oxidation between $\mathrm{HI}$ and $\mathrm{LO}$ phases. 
Table 5. Resting Energy Expenditure, body weight and substrate oxidation following each diet phase $(n=6)$.

\begin{tabular}{llll}
\hline & N & HI & LO \\
\hline $\begin{array}{l}\text { REE } \\
\text { (kcal/day) }\end{array}$ & $1985.7 \pm 195.3$ & $1914.9 \pm 217.1$ & $1915.5 \pm 186.7$ \\
$\begin{array}{l}\mathrm{CHO} \\
\text { ox }(\mathrm{g} / \mathrm{min})^{\star *}\end{array}$ & $0.11 \pm 0.03^{\mathrm{a}}$ & $0.10 \pm 0.06^{\mathrm{b}}$ & $0.04 \pm 0.04^{\mathrm{c}}$ \\
$\begin{array}{l}\text { Fat ox } \\
(\mathrm{g} / \mathrm{min})^{\star *}\end{array}$ & $0.06 \pm 0.02$ & $0.07 \pm 0.03$ & $0.06 \pm 0.02$ \\
$\begin{array}{l}\text { Protein ox } \\
(\mathrm{g} / \mathrm{min})\end{array}$ & $0.09 \pm 0.01^{\mathrm{a}}$ & $0.07 \pm 0.01^{\mathrm{b}}$ & $0.12 \pm 0.01^{\mathrm{c}}$ \\
$\mathrm{BW}(\mathrm{kg})$ & $77.5 \pm 8.4$ & $78.2 \pm 8.5$ & $78.0 \pm 8.8$ \\
\hline
\end{tabular}

Values are means $\pm S D ; n=6$ subjects. Values in a given row not sharing the same letter are significantly different form one another. ${ }^{* *}$ values corrected for protein oxidation

Total Energy Intake Across Experimental Conditions

Following REE, RER and Body Weight measures, as described in the methods, the subjects were then isolated for the remainder of the day to observe how the preceding diet conditions affected hunger, appetite and food intake. Figure 4 below illustrates the total energy intake based on spontaneous food requests observed following each experimental condition. Intake based on subject food request was $1625.5 \pm 561.5 \mathrm{kcal}, 1369.6 \pm 574.5 \mathrm{kcal}$ and $1592.1 \pm 545.3$ for the $\mathrm{N}$, $\mathrm{HI}$ and LO conditions respectively (NS, $\mathrm{p}=0.12, \mathrm{r}^{2}=0.34$ ). Note that in addition to the calories shown here, each subject consumed the standardized breakfast containing $487 \mathrm{kcal}$ as described Table 2. Also, a set of independent samples t-tests were 
conducted to address any differences in El by feeding episode. It was found that there was no significant difference in the El of meals requested across conditions.

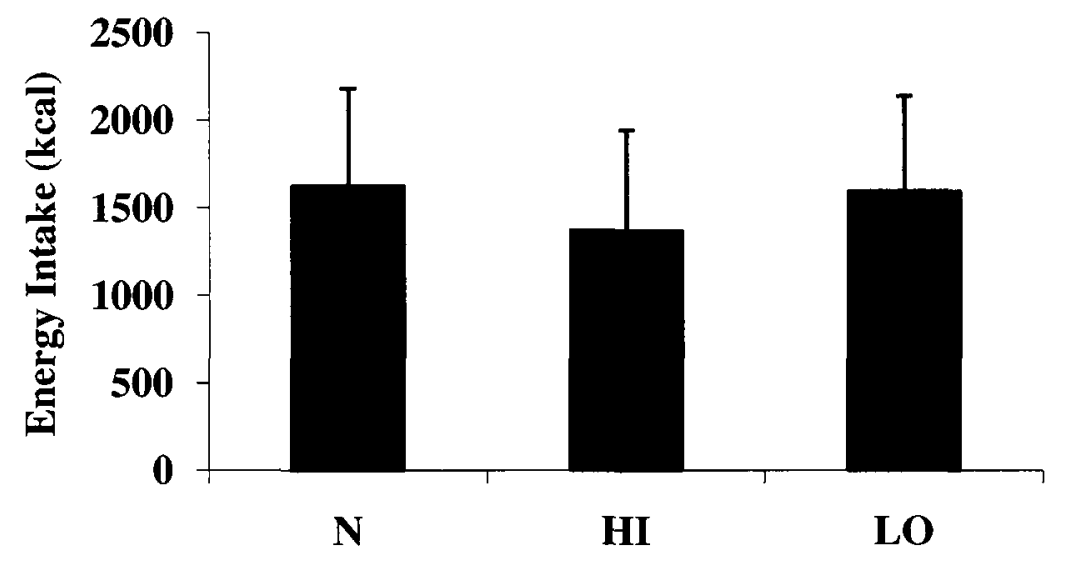

Figure 4. Total Energy Intake (EI) based on spontaneous meal requests during testing day for three experimental conditions (Normal, High and Low $\mathrm{CHO}$ ). $\mathrm{N}=$ Normal $(45 \% \mathrm{CHO}), \mathrm{HI}=\mathrm{High}(75 \% \mathrm{CHO}), \mathrm{LO}=\operatorname{Low}(10 \% \mathrm{CHO})$. 
Variations in Macronutrient Intake Across Experimental Conditions

Figure 5 below breaks down the total Energy Intake as illustrated in Figure 4 by macronutrient composition. Figure $5 \mathrm{~A}$ shows the amount (in grams) of $\mathrm{CHO}$ requested and consumed during each experimental phase. Figures $5 \mathrm{~B}$ and $5 \mathrm{C}$ show the amount of Proteins and Lipids (in grams), respectively. 
A)

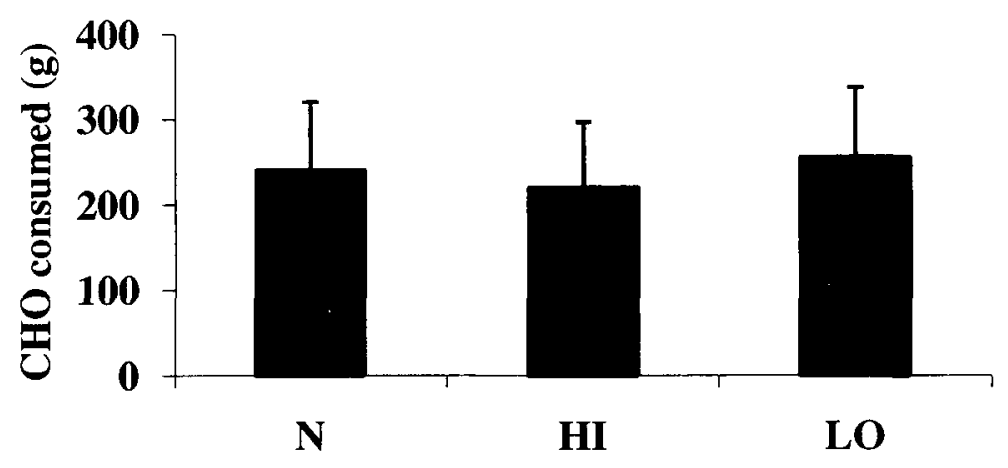

B)

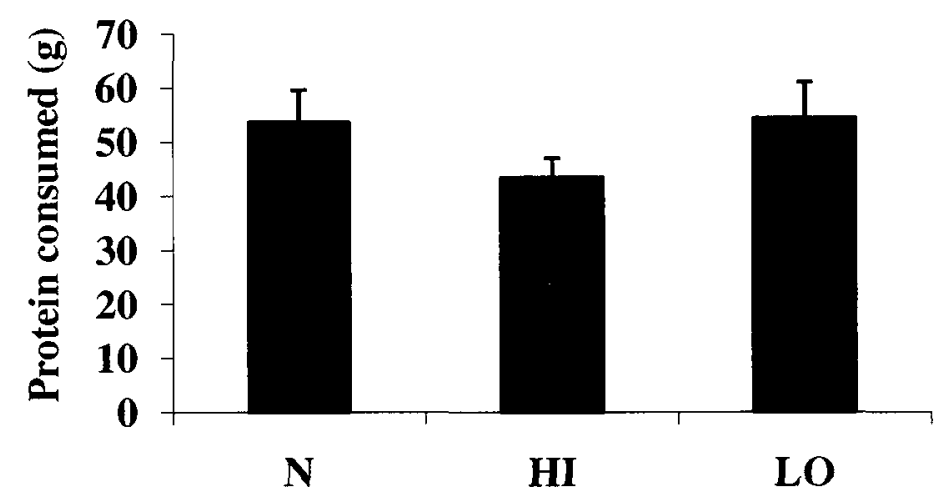

C)

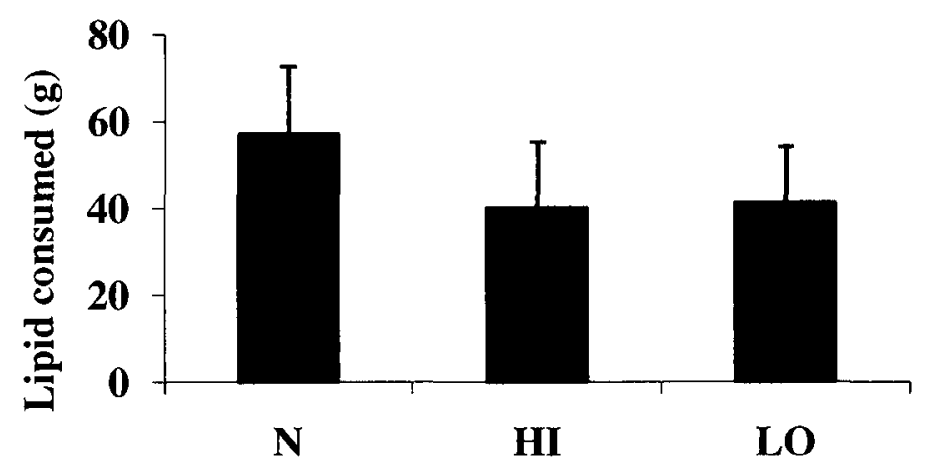

Figure 5. Macronutrient intake ((A) $\mathrm{CHO},(\mathrm{B})$ Protein and $(\mathrm{C})$ Lipid) across experimental Normal, High and Low Diet conditions in grams. 
Although analysis revealed no statistical significant for within subject contrasts, there are still some trends to observe as illustrated in Figure 5 . In compiling the above three figures, the following diet composition were observed for each phase: For the N phase, subjects consumed $63.7 \pm 7.9 \% \mathrm{CHO}, 3.6 \pm 1.7 \%$ Protein and $24.6 \pm 7.8 \%$ Lipid. For the $\mathrm{HI}$ phase, subjects consumed $65.8 \pm 9.4 \%$ $\mathrm{CHO}, 11.7 \pm 3.1 \%$ Proteins and $27.1 \pm 6.0 \%$ Lipids. For the LO phase, subjects consumed $60.6 \pm 3.4 \% \mathrm{CHO}, 13.2 \pm 2.8 \%$ for Proteins and $24.0 \pm 4.3 \%$ Lipids indicating that there was still a level of preference for $\mathrm{CHO}$ rich food items during all conditions.

Relative to their body weight, subjects consumed the following amounts of $\mathrm{CHO}$, Protein and Lipids respectively during each phase: $\mathrm{CHO}(\mathrm{N}=3.3 \pm 1.0 \mathrm{~g} / \mathrm{kg}$, $\mathrm{HI}=2.78 \pm 0.9 \mathrm{~g} / \mathrm{kg}, \mathrm{LO}=3.1 \pm 1.0 \mathrm{~g} / \mathrm{kg}, \mathrm{NS}, \mathrm{p}=0.14)$; Protein $(\mathrm{N}=0.7 \pm 0.2 \mathrm{~g} / \mathrm{kg}, \mathrm{HI}=$ $0.6 \pm 0.3 \mathrm{~g} / \mathrm{kg}, \mathrm{LO}=0.7 \pm 0.3 \mathrm{~g} / \mathrm{kg}, \mathrm{NS}, \mathrm{p}=0.43)$ Lipid $(\mathrm{N}=0.74 \pm 0.2, \mathrm{HI}=0.5 \pm 0.2$ $\mathrm{g} / \mathrm{kg}, \mathrm{LO}=0.54 \pm 0.2 \mathrm{~g} / \mathrm{kg}, \mathrm{NS}, \mathrm{p}=0.16)$.

Appetite Parameters Across Experimental Conditions

Visual Analog Scale Measurements are illustrated in Figure 6. Figure 6A shows ratings of Hunger across time as determined from VAS responses. This was conducted for all 4 questions (hunger, fullness, desire to eat and prospective food consumption) and from here, AUC values were calculated to see overall differences in ratings on these factors across phases. The AUC appetite score for desire to eat (N- 40331 \pm 11311 ; HI-40084 \pm 7576 ; LO- 40440 \pm 7502 , NS), hunger (N40044 $\pm 10397 ;$ HI-39602 \pm 5102; LO- $41218 \pm 6621, N S)$ fullness $(N-37098 \pm 11222$; 
HI-42073 \pm 6332 ; LO-40590 \pm 5321, NS) Prospective Food Consumption (N$43969 \pm 12408 ; \mathrm{HI}-41979 \pm 6255 ; \mathrm{LO}=44346 \pm 8207, \mathrm{NS}$ ) were all found to be not significant across conditions with $n=6$.

Figure 6B shows the ratings of hunger across time for each phase expressed as a percent change in rating. As seen here, average percent change in hunger ratings preceding all meal requests were $2.15 \pm 4.71 \%, 1.20 \pm 1.63 \%$ and $0.981 \pm$ $1.25 \%$ for the Normal, $\mathrm{HI}$ and LO phases respectively. A correlation analysis was conducted between increase in appetite and decline in blood glucose levels preceding a meal. Analyses of blood glucose declines and increases in appetite preceding meals were conducted to assess if there was a correlation between these two data sets. Weak or low negative correlations were found for the normal phase $(r=-.27, N S)$ and $\mathrm{HI}$ phase $(r=-0.06, N S)$. A weak positive correlation was found in the LO phase $(r=0.37, N S)$. None of these correlations were found to be significant. 
A.

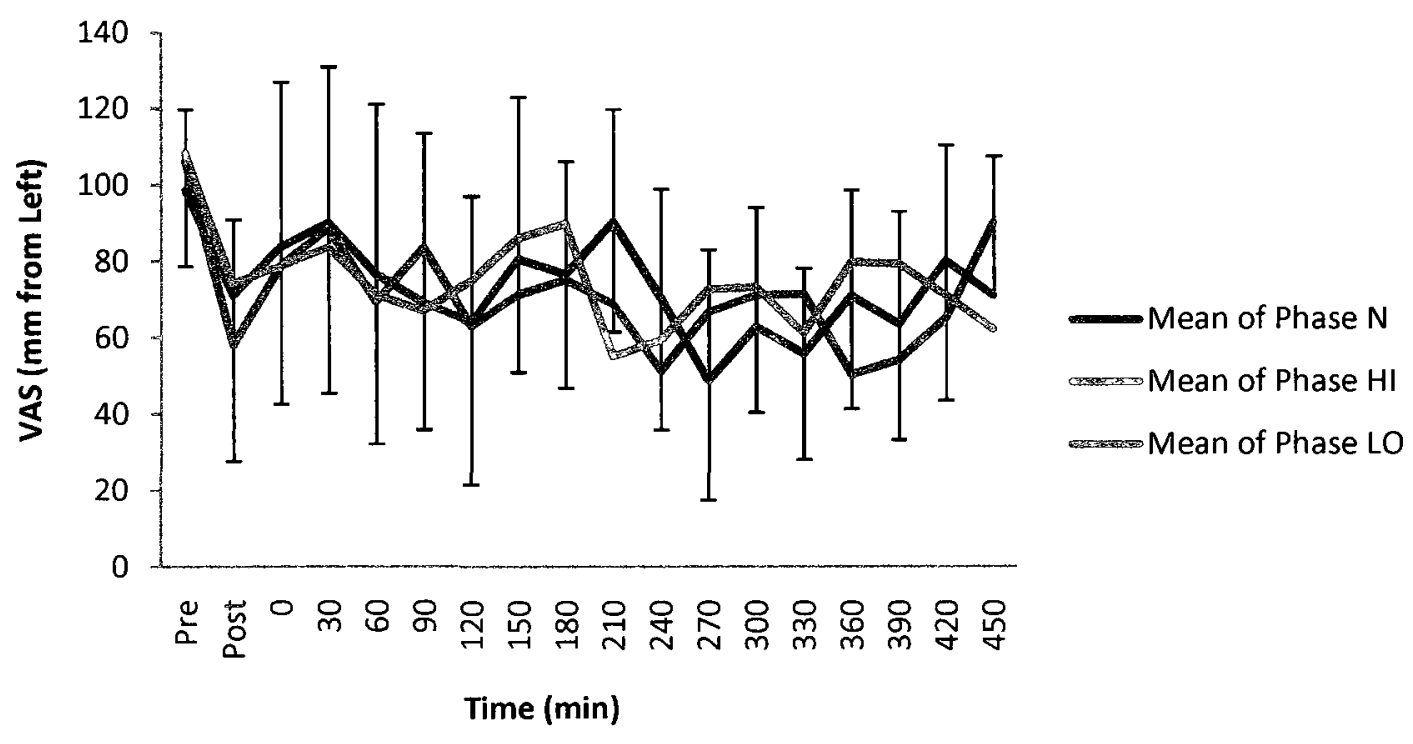

B.

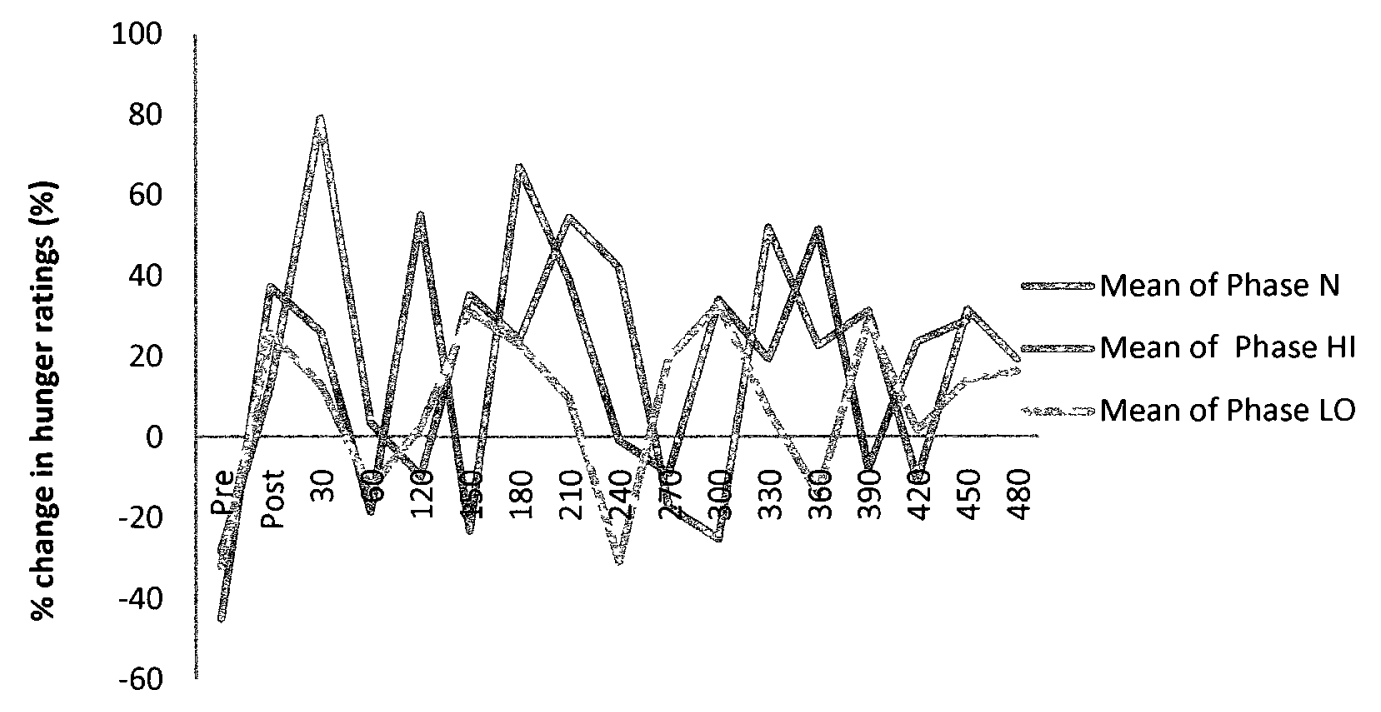

Figure 6. Ratings of Hunger based on Visual Analog Scale ratings A. In absolute values and $\mathbf{B}$. In percent change. 
Blood Glucose Profiles across Experimental Conditions

As described in the methods, blood glucose was also continuously monitored throughout the testing day for each phase. Analysis showed that AUC values for all daily profiles $(\mathrm{N}=17887.6 \pm 2345.4, \mathrm{HI}=17631.0 \pm 3373.8, \mathrm{LO}=17254.8 \pm 2894.8$, NS) did not differ significantly. More specifically, the decline in blood glucose prior to each food request was considered. Over the entire study it was found using the calculation described in the methods that prior to a meal request, blood glucose levels decreased by $7.8 \pm 11.1 \%$. This was calculated as described in detail in the methods section of this paper. Figure 7 below is an example of a daily profile for one subject with Food Requests marked.

The decline commenced $25.0 \pm 27.4$ minutes prior to the meal request. The minimum value of this decline before levels would plateau or begin to rise would come $3.0 \pm 6.2$ minutes prior to the subject's request for food $(\mathrm{N}=9.8 \pm 9.9 \%$ decline over $27.8 \pm 20.9$ minutes, reaching minimum value $4.6 \pm 7.5$ minutes prior to request. $H I=7.0 \pm 13.2 \%$ decline over $29.5 \pm 42.3$ minutes, reaching minimum value $3.3 \pm 6.9$ minutes prior to request. $\mathrm{LO}=6.7 \pm 10.1 \%$ decline over $17.8 \pm 18.9$ minutes, reaching minimum value $1.2 \pm 4.2$ minutes prior to request.). There was no significant difference between conditions with regards to percent decline, time of decline and time of decline to Meal request. 


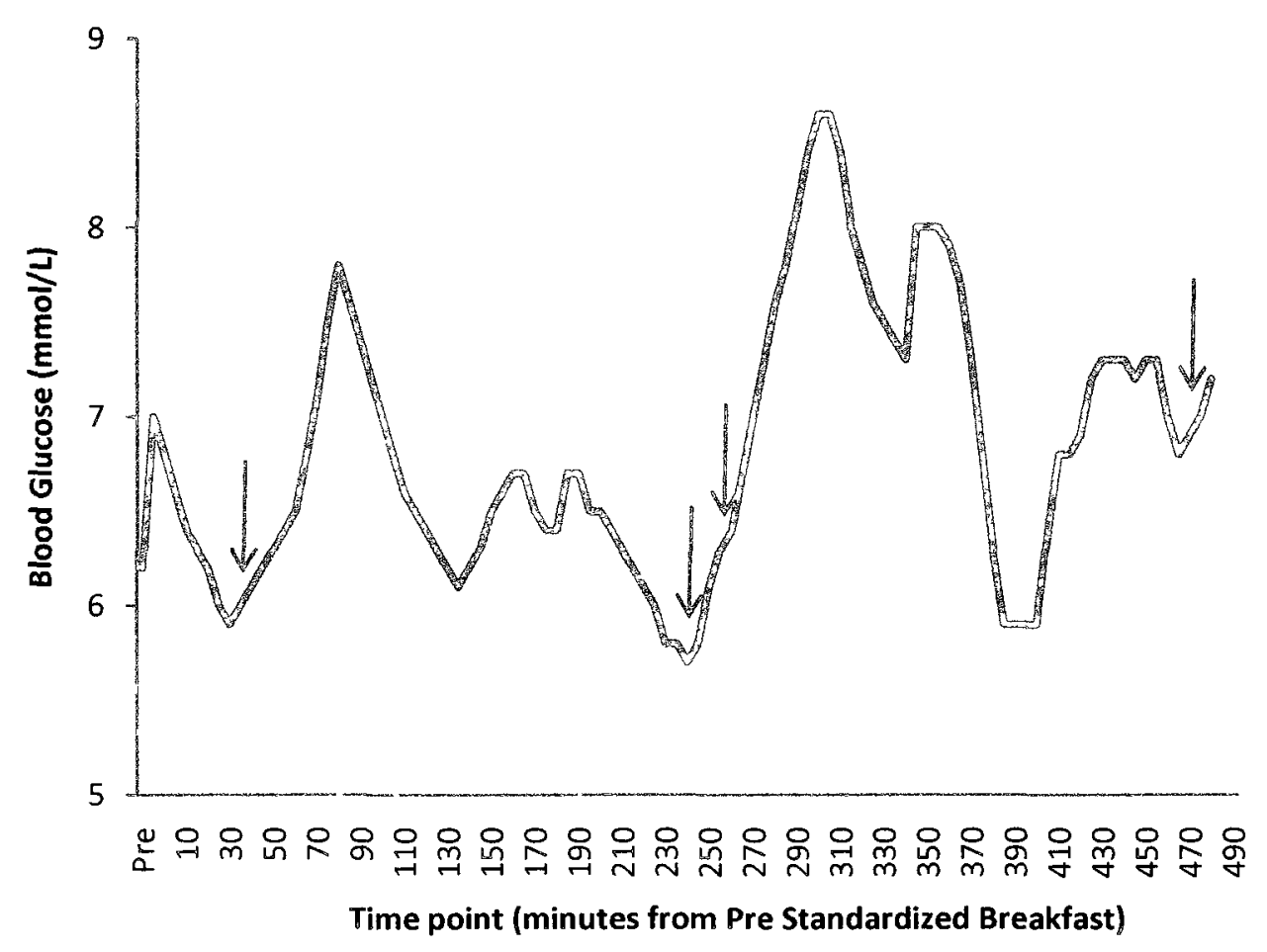

Figure 7. Example of a daily blood glucose profile. This particular sample is following the $\mathrm{N}$ phase. Arrows indicate time of meal request. Energy at each meal request from left to right was $700.8 \mathrm{kcal}, 455.9 \mathrm{kcal}, 636.4 \mathrm{kcal}, 277.9 \mathrm{kcal}$.

Correlation analyses were conducted to examine the potential association between AUC of blood glucose and total $\mathrm{El}$ as well as total $\mathrm{CHO}$ intake. No significant correlations were noted for the AUC of blood glucose and total El during the $\mathrm{N}$ and LO phases. A correlation was found however between AUC of blood glucose and total $\mathrm{CHO}$ intake $(r=0.85, \mathrm{p}<0.05)$ during the $\mathrm{HI}$ phase. Correlations conducted on appetite ratings of hunger and fullness and the above measures (total $\mathrm{EI}, \mathrm{CHO}$ intake and AUC of blood glucose) revealed no significant relationship. 


\section{CHAPTER V - DISCUSSION}

The present study was performed to investigate the effects of carbohydrate loading as well as depletion on appetite, food consumption and also macronutrient preference. Our secondary objective was to investigate whether spontaneous food requests would be preceded by declines in blood glucose levels as presented by Mayer (1953) and supported by many including Campfield et al. (1996). Along these lines, the present study design aimed at establishing whether this trend previously seen in normal states of energy balance held true during large fluctuations in glucose stores while subjects were maintained in a state of energy balance.

As shown in the results section, the present study was able to reproduce the findings of Mayer et al (1953) where, in a normal state of energy balance, feeding is preceded by a decline in blood glucose levels (Figure 5). However, aside from this, the current study rejected the current hypotheses as follows. The hypothesis of an increase in hunger, food intake and $\mathrm{CHO}$ preference following the $\mathrm{CHO}$ depletion (LO) phase was not currently supported here. There were also no significant correlations noted between blood glucose levels, appetite, food consumption and macronutrient preference.

Evidence of Protocol Standardization

First of note is the fact that the REE and BW values presented in the results were stable across conditions. This provides reassurance as to the experimental 
standardization with regards to the caloric clamp implemented across conditions. As noted in the results section, significant differences in RER values were seen across conditions indicating a difference in substrate partitioning across conditions. As expected, RER following the LO phase was lowest $(0.79 \pm 0.04)$. However, instead of then seeing $\mathrm{N}$ as a middle ground in terms of RER and the $\mathrm{HI}$ phase producing the highest RER values, the present study instead found RER values for the $N$ and $\mathrm{HI}$ phase to be $0.84 \pm 0.04$ and $0.81 \pm 0.04$ respectively.

Lundbaek et al, conducted a study on the differences in fasting RER following high and low CHO diets (2005). The results of this study found RER values of 0.848 on average following the high carbohydrate diet and 0.755 on the low carbohydrate (Lundbaek, 2005). This relation between amount of $\mathrm{CHO}$ consumed and the resultant fasting RER is in line with earlier literature on this topic (Flatt, 1985). These values found by Lundbaek et al indicate not only that the current $\mathrm{N}$ phase (RER of $0.84 \pm 0.04$ ) had higher than normal RER values as it was the same that would be expected with a $\mathrm{HI}$ phase, but more importantly that the RER values for $\mathrm{HI}$ (RER of $0.81 \pm 0.04$ ) were much lower than would be expected. The reason the $\mathrm{HI}$ phase in the current study yielded such a low RER value is not clear. However, there was still a shift seen in carbohydrate oxidation between the $\mathrm{HI}$ and LO phases indicating standardization with the $\mathrm{CHO}$ reduced (LO) phase; the LO phase had a $23 \%$ lower level of $\mathrm{CHO}$ oxidation then the $\mathrm{HI}$ phase $(\mathrm{HI}=0.1429 \mathrm{~g} / \mathrm{min}, \mathrm{LO}=0.1127$ $\mathrm{g} / \mathrm{min}$ ). The lower RER value following the LO phase is consistent with the decrease in $\mathrm{CHO}$ intake indicating that the decrease in $\mathrm{CHO}$ intake did result in less oxidation of $\mathrm{CHO}$. 
Further, the consistency of total El consumed (i.e. the ability of participants to keep on their prescribed diet with regards to calorie intake) during the diet for each experimental phase is again an indication of support for the standardization of the protocols used during this study. Analysis shows that there is a marked difference between the amount of each macronutrient during each phases' reported diet; specifically $\mathrm{CHO}(\mathrm{N}=358.6 \pm 63.9 \mathrm{~g}, \mathrm{HI}=526.2 \pm 64.2 \mathrm{~g}, \mathrm{LO}=90.3 \pm 23.3 \mathrm{~g})$. This is again in support of the standardization of the protocol used indicating that the reported diets were significantly different in terms of $\mathrm{CHO}$ content as intended in the methods.

\section{Appetite Parameters}

Mayer's (1953) Glucostatic theory states human cells with an affinity of glucose sense variations in the amount of glucose present, which ultimately results from changes in the production and disposal of glucose. It was originally suspected that these "glucoreceptors" were located in the CNS and probably in the hypothalamus (Mayer, 1956). As time passed, it was suspected and later demonstrated (Shiota and Magnuson, 2008) that these receptors were in fact located in hepatic circulation (Niijima, 1969; Russek \& Grinstein, 1974; Russek, 1981), the gastrointestinal tract (Mei, 1978), the causal hind brain (Ritter, 1981), and more recently the blood brain barrier (BBB) (Coiro, 2004). The decrease or increase in the utilization of glucose described above then in turn stimulates either satiety or hunger respectively along with a variety of other factors. It is important to realize 
that glucose fluctuations are not the only changes at play during this phenomenon. Factors such as insulin and other peripheral signals, among other things, are most certainly involved (Chapman et al, 1998; Stubbs, 1999; Woods and D'Alessio, D., 2008).

As discussed earlier, energy intake is regulated through feedback to the CNS that allows for alterations in feeding behaviour in order to maintain energy balance (Melanson, 1999). A fall in the amount of available glucose is signalled to the hypothalamic glucoreceptors acting as a signal for hunger. As discussed earlier in this document the Arcuate nucleus contains neurons that contain Neuropeptide $Y$ (NPY) and that are sensitive to glucose levels. It is suggested based on animal studies that in response to a reduction in the glucose concentration in the brain, these neurons release NPY and, subsequently, stimulate feeding (Muroya, Yada, Shioda and Taigawa, 1999).

In other words, when glucose utilization is low, decreases in the arteriovenous glucose differences and consequently a decrease in neuron activity leads to a feeling of hunger. Studies by et al (1956), Van Itallie (1960) and Campfield et al (1996) found that glucose infusion increases the electrical activity in ventromedial satiety areas while decreasing this type of electrical activity in lateral feeding areas resulting in an increase in satiety and decrease in hunger following infusion. In the current study however, even if $\mathrm{CHO}$ stores were in fact greater, this did not seem to translate into differences in circulating levels and resultant changes in satiety and hunger following intake. Contrary to our initial hypothesis we did not observe any differences in circulating glucose, which could explain why we were not 
able to observe clear differences in appetite and energy intake between conditions in spite of markedly different levels of glucose stores.

Studies such as those conducted by Davis et al found that glucose given to rats intracerebroventricularly decreased food intake (Davis et al, 1981). Interestingly enough, a decrease in circulating blood glucose is associated with an increase in norepinephrine turnover in the hypothalamus, in particular the paraventricular nucleus. It was found that central injection studies on rats such as those by Leibowitz in 1988 and 1992 lead to a stimulatory effect on norepinephrine on feeding: this could potentially contribute to the explanation of the relationship between the pre-meal decline in blood glucose on meal initiation discussed by Campfield et al $(1996,1985)$ and Louis-Sylvestre \& LeMagnen (1980). As in studies by Campfield and Smith (1983) and Melanson et al (1999) among others, our study quantified the blood glucose changes associated with the above appetite and intake changes. Prior to each feeding request, as modeled in Figure 7 of the results, there was a decline in blood glucose leveis. As shown in Figure 6 of the results, in addition to this change in blood glucose levels there was also a change in appetite: average percent change in hunger ratings preceding all meal requests were $2.15 \pm 4.71 \%, 1.20 \pm 1.63 \%$ and $0.981 \pm 1.25 \%$ for the Normal, $\mathrm{HI}$ and LO phases respectively. Changes in appetite were considered alongside this decline in blood glucose to see if there was a correlation. Weak or low negative correlations were found for the normal phase $(r=-.27, N S)$ and $\mathrm{HI}$ phase $(r=-0.06, N S)$. A weak positive correlation was found in the LO phase $(r=0.37, N S)$. Although not significant, as blood glucose decreased in the Normal and $\mathrm{HI}$ phases, appetite 
increased. For the low phase however this is not seen. This is interesting as, discussed in detail shortly, the overall appetite during the LO phase was highest although changes directly preceding meals were lowest. When compared across conditions, as shown in Figure 5 our results support earlier findings that transient decreases in blood glucose are associated to feeding requests however, we were not able to evidence that this relationship is altered by levels of glucose storage.

With regards to changes in appetite it was also hypothesized that subjects would have demonstrated higher ratings of hunger and consequently would consume more following the LO phase and vice versa with the HI phase. Although not statistically significant at $n=6$, levels of desire to eat, hunger and prospective food consumption as measured by VAS AUC were all lowest during the $\mathrm{CHO}$ loaded $(\mathrm{HI})$ phase, and highest during the $\mathrm{CHO}$ reduced phase (LO), paralleling many studies previously mentioned. Accordingly, ratings of fullness were actually higher in the HI phase when compared to the LO phase (NS), similar to findings of Rogers and Blundell (1989). This is contrary however to various studies showing no difference, or the opposite findings (higher fullness ratings following a $\mathrm{CHO}$ load or a load with a higher glycemic index) (Stevenson, Astbury, Simpson, Taylor and Macdonald, 2009). That being said, in the current project, no significant correlation was seen between appetite ratings and total $\mathrm{El}$ or $\mathrm{CHO}$ intake at $\mathrm{n}=6$. 


\section{Blood Glucose Profiles}

In rats, both scheduled (Muller et al, 1967) and spontaneous (Louis-Sylvestre and LeMagnen, 1980) feeding has been found to be preceded by a small decline in blood glucose (from 6-11\%). More recently, studies have shown a reported premeal decline in blood glucose in human subjects (Campfield, 1995; Melanson, 1999). Studies by Campfield et a/ found that hunger ratings increased following insulin-induced transient declines in blood glucose concentrations in participants not subjected to a pre-experimental diet (2003). The current study found declines in blood glucose concentrations to be about $7.8 \pm 11 \%$ at $25.0 \pm 27.4$ minutes. This is along the same lines as the declines observed in the $\mathrm{N}$ phase of the current study: $9.9 \%$ at 27.8 minutes. The declines observed in the $\mathrm{HI}$ and LO phases were much smaller $(\mathrm{HI}=7.0 \pm 13.2 \%$ decline over $29.5 \pm 42.3$ minutes. $\mathrm{LO}=6.7 \pm 10.1 \%$ decline over $17.8 \pm 18.9$ minutes), but regardless, a decline was indeed seen in each subject prior to the majority of the meal requests. Although this is in line with Mayer's theory, this could also be related to the cephalic phase of insulin. Even the mere anticipation of a meal should be sufficient to trigger insulin secretion causing some insulinization of the liver; although a potentially modest effect, this may contribute to a decrease in blood glucose levels seen prior to meal requests (Figure 5) (Becker et al 2001).

The results related to blood glucose are curious as quite different outcomes would have been expected based on the predicted blood glucose profiles and previous findings. For example, during a phase where $\mathrm{CHO}$ was preferred and chosen most often, it would be expected that spikes and drops and blood glucose 
would be more pronounced as seen by Melanson et al (1999). Meals heavy in lipid and protein would not create such marked spikes as the rise and fall of glucose is typically more delayed, gradual and longer (Melanson, 1999). However, the storage state in the current study design must first be considered. Following the $\mathrm{CHO}$ reduced or LO phase, it was hypothesized that $\mathrm{CHO}$ would be preferred but spikes and drops and blood glucose would not be seen. In fact, after a $\mathrm{CHO}$ rich meal when stores are reduced, the ingested glucose would become trapped in the liver as so far as it is glycogen depleted (Jeukendrup et al, 1996). Given this it would thus be expected that following the LO phase, when stores are reduced, spikes and drops in blood glucose levels would not be appreciated despite a preference in $\mathrm{CHO}$. However, these differences in blood glucose profiles were not seen.

As seen in the results section, although not significantly different, the AUC for blood glucose was highest in the $\mathrm{N}$ phase closely followed by the HI phase. This is in line with results from many studies that show that blood glucose levels in single stomached species increases during or after meals containing $\mathrm{CHO}$ (Strubbe \& Steffens, 1977; Flatt et al., 1985). However, in the HI phase, the highest blood glucose levels would be expected following a meal high in $\mathrm{CHO}$ as discussed earlier. This would be alongside a lower insulin level as insulinization of the liver is not required given blood glucose levels are sufficiently high and release of hepatic stores is not necessary. The high AUC seen in the $\mathrm{N}$ phase as opposed to the $\mathrm{HI}$ phase could have been due to the fact that in this study, when adjusted for bodyweight for example, there was in fact a higher level of $\mathrm{CHO}$ intake in the $\mathrm{N}$ 
stage. With this it is interesting to note that the RER for the $\mathrm{N}$ phase was higher than that of the $\mathrm{HI}$ condition. There is also a remote possibility that there were in fact no difference in $\mathrm{CHO}$ stores between these two conditions. However, this is unlikely as the loading paradigm used here was modelled after previous projects where the implemented diets resulted in a significant effect on glycogen stores. The present paradigm was modeled after that of Haman et al (2004) which consisted of a $\mathrm{CHO}$ loaded phase involving $71.0 \pm 0.5 \% \mathrm{CHO}$; again, this was sufficient to affect glycogen reserves significantly. Experiments prior to that of Haman et al found used this same approach and conducted muscle biopsies that showed strong evidence that the present glycogen loading protocol affects muscle glycogen levels significantly even when exercise is not included in the depletion/reduction phase (Young, et al, 1989; Conlee, 1987).

In summary, the current study rejected all three hypotheses. The hypothesis of an increase in hunger, food intake and $\mathrm{CHO}$ preference following the $\mathrm{CHO}$ depletion (LO) phase was not supported by results. However, the exploratory hypothesis stating that Mayer's Glucostatic theory will hold true during states of $\mathrm{CHO}$ depletion and loading was supported as we did observe a decline in blood glucose prior to meal requests during all phases of $7.8 \%$ over 25.0 minutes although this was not different between phases with different levels of $\mathrm{CHO}$ reserves. 


\section{CHAPTER VI - LIMITATIONS, GENERAL CONCLUSIONS AND FUTURE PERSPECTIVES}

When reflecting on the design of this study, there are certainly some recommendations to be made. Some of these recommendations aim to get the participant to become more accustomed to the protocol to ensure the best replication of 'real life' conditions while in the lab. Other recommendations include certain measurement techniques that could be employed in future studies for superior sampling if the funding is available. Included are also are future perspectives that would illicit interesting conditions for further observations but are outside the scope of this study.

First however, it is important to note main factor that may have limited the significance of the findings was the sample size of $n=6$. Effect size was low for AUC, VAS and total El across phases. . This could be an indication that a larger sample size may illustrate that changes seen across conditions can indeed be attributed to the treatment conditions implemented.

With regards to other design related limitations, several recommendations that became apparent with creating the most "true to life" testing environment for each subject. One issue is that participants were placed in a new environment, very different from what they are used to with potentially new types of food that they would not normally encounter in their day to day. Having a preliminary session where participants could be exposed to the "isolation" room prior to observation would be helpful in terms of acclimatization. During this preliminary session the idea 
of "spontaneous food requests" could be introduced. It seemed during the present study that subjects would be hesitant in asking for food as not to burden the tester although it was explained that they could ask at will. By the second and third session they seemed more at ease with asking for food: having a preliminary session to accommodate this learning curve would be beneficial.

There was potentially a learning curve with regards to serving sizes as well. This was clear as some subjects tended to request "double portions" of certain foods once they learned what the serving sizes were. Having a buffet during the preliminary session to illustrate serving sizes would help eliminate this learning curve during the sessions. This preliminary session could also be used to test for food preferences allowing each session's menu to cater to that ensure for example that if subjects had a craving for carbohydrates, they did not end up picking a high in protein item as they did not find any of the $\mathrm{CHO}$ options appealing for example.

The above recommendations can be summed up as the addition of the proposed 'preliminary session'. Although the addition of these components would add a lot to this type of study, the logistics and funding needed for such additions are unfortunately outside of the scope of this master's thesis project. However, they should be considered in future work of this nature. Another interesting addition to the current protocol would have been to have subjects record what they consumed when they returned home after each session. This way we could capture what was consumed if they were just approaching a meal request of if they tend to consume food later at night or simply, they would be free to obtain any food they want and a clear idea of food preference would be available. 
Although there is no evidence in this study that energy expenditure affected outcomes of BW or RER it is potentially important to note that the need to standardize energy output was simply not considered in this design. In order to ensure a stable IN and OUT of calories, a log of physical activity completed prior to the initial RMR measure should be completed and subsequent recommendations for the standardization of activity should be made to ensure that calories consumed and calories expended remain constant across conditions.

One of the main changes in protocol that would improve the current protocol would be the addition of urine samples to determine Cho oxidation. Many studies including Hurni et al (1981) analyse for urinary nitrogen using the Kjeldhal method as described by Hawk et al (1947). Also, many studies have used isotope labelling to determine glucose utilization and oxidation more specifically (Lefebvre et al, 1975). Certain naturally occurring sugars have a higher $C^{13}: C^{12}$ ratio when compared to other sugars. Because of this, if such sugars are used in an Oral Glucose Tolerance Test (OGTT), expired $\mathrm{CO} 2$ can be collected and then variations in the aforementioned ratio can indicate the fate of the exogenous glucose (Mosora et al, 1976). Although these protocols were considered during protocol planning, the scope of this study was again not wide enough to accommodate such protocols due to time and funding restraints. 


\section{CONCLUSION:}

In conclusion, although there were few significant differences seen across conditions during this study although positive trends towards potential relationships were seen. The current project acts as a pilot study that indicates the potential for support of our hypotheses. At this point however, a larger sample size is needed to show statistical significance. Important to note is that protocol standardization was supported by the significant difference seen in RER values across conditions paralleled with no changes in body weight across conditions. Interesting also is that despite the small sample size, the current study did show support Mayer's theory even in cases of $\mathrm{CHO}$ loading and depletion. Similar to the results of Campfield et al., the current study saw a decline of $7.8 \%$ over 25.0 minutes prior to each meal request. Further investigation of this nature with a larger population is warranted. 


\section{REFERENCES}

American College of Sports Medicine (ACSM). (2005) Lippincott, Williams, \& Wilkins, Baltimore, Md. ACSM's resource manual for guidelines for exercise testing and prescription. pp. 391-400.

Becker, K. L., Bilezikian, J., Bremner, W., Hung, W., Kahn, C., Loriaux, D., Nylen, E. et al. Principles and Pratice of Endocrinology and Metabolism (2001) Lippincott, Williams, \& Wilkins. Philadelphia, USA

Bennard, P.V. and Doucet, É. Acute Effects of Exercise Timing and Breakfast Meal Glycemic Index on Exercise-induced Fat Oxidation (2006) Applied Physiology, Nutrition and Metabolism. 31: 502-511

Bernstein, L., Grossman, M. (1956). An Experimental Test of the Glucostatic Theory of the Regulation of Food Intake. J Clin Invest. 35: 627-633

Blundell, J., Noury, J. (2001) Carbohydrates and appetite control. Aust J Nutr Diet. Suppl $1:$ S13-S18

Booth, D. A. (1972). Postabsorptively induced suppression of appetite and the energostatic control of feeding. Physiology and Behavior 9, 199-202.

Boule, N. G., Chaput, J. P., Doucet, E., Richard, D., Despres, J. P., Bouchard, C., et al. (2007). Glucose homeostasis predicts weight gain: Prospective and clinical evidence. Diabetes/metabolism research and reviews. 24: 123-129. 
Boyne, M., Silver, D., Kaplan, J., Saudek, C. (2003) Timing of changes in interstitial and venous blood glucose measured with a continuous subcutaneous glucose sensor. Diabetes. 52(11): 2790-4.

Broberger, C., Hokfelt, T. (2001) Hypothalamic and vagal neuropeptide circuitries regulating food intake. Physiol Behav. 74 (4-5): 669-82

Broberger, C., Johansen, J. et al (1998) The neuropeptide Y/agouti gene-related protein (AgRP) brain circuitry in normal, anorectic, and monosodium glutamate-treated mice. Proc Natl Acad Sci U S A. 95(25): 15043-8

Brouns, F., Saris, W., Rehrer N. (1987) Abdominal complaints and gastrointestinal function during long-lasting exercise. Int J. Sports Med. 8:175-189

Bruning, J., Gautam, D. et al (2000) Role of brain insulin receptor in control of body weight and reproduction. Science. 289 (5487): 2122-5

Brunner, G., Ellmerer, M., Sendhofer, G., Wutte, A., Trajonoski, Z., Schaupp, L., Quehenberger, F., Wach, P., Krejs, G., Pieber, T. (1998) Validation of Home Blood Meters with Respect to Clinical and analytical approaches. Diabetes Care.. 21(4) :585-591.

Cameron, J.D., Goldfield, G. S., Cyr, M.J., Doucet, E. (2008) The effects of prolonged caloric restriction leading to weight-los on food hedonics and reinforcement. Physiology and Behavior. 94: 474-480. 
Campfield LA, Brandon P, Smith FJ. (1985) On-line continuous measurement of blood glucose and meal pattern in free-feeding rats: the role of glucose in meal initiation. Brain Res Bull. Jun;14(6):605-16

Campfield, L., Smith F., Rosenbaum, M. (1992) Human hunger: is there a role for blood glucose dynamics. Appetite. 18(3):244 .

Campfield, L. A., \& Smith, F. J. (2003). Blood glucose dynamics and control of meal initiation: A pattern detection and recognition theory. Physiological reviews. 83(1), 25-58.

Campfield LA, Smith FJ. Transient declines in blood glucose signal meal initiation. (1994) Int J Obes.14 Suppl 3:15-31; discussion 31-4.

Campfield LA, Smith FJ, Rosenbaum M, and Hirsch J. (1996) Human eating: evidence for a physiological basis using a modified paradigm. Neurosci Biobehav Rev. 20: 133-137.

Campfield LA, Smith FJ. (1986) Functional coupling between transient declines in blood glucose and feeding behavior: temporal relationships. Brain Res Bull. 17(3):427-33.

Cengiz, E., Tamborlane, W. (2009) A Tale of Two Compartments: Interstitial versus Blood Glucose Monitor. Diabetes Technology and Therapeutics. 11(1) : S11-S17. 
Chapman, I., Goble, E., Wittert, G., Morley, J., Horowitz, M. (1998) Effect of intravenous glucose and euglycemic insulin infusions on a short-term appetite and food intake. Am J Physiol Interg Comp Physiol. 274(3):R596-R603

Chaput, J.P. \& Tremblay, A. (2009) The glucostatic theory of appetite control and the risk of obesity and diabetes. International Journal of Obesity. 33: 46-53.

Chiasson J, Rabasa-Lhoret R. (2004) Prevention of type 2 diabetes: insulin resistance and beta-cell function. Diabetes. 2004;53 Suppl(3):S34-38.

Coiro, V., Volpi, R., Capretti L., Manfredi, G., Galli, P., Saccani-Jotti, G., Chiodera, P. (2004) Glucoreceptors located inside the blood brain barrier mediate hypoglycaemia-induced LH inhibition in man. Horm Res. 61(5): 218-21.

Colditz G. (1999) Economic costs of obesity and inactivity. Med Sci Sports Exerc. 31: S663-667.

Davis, J.D., Wirtchafter, D., Asin, K.E. \& Brief, D. (1981) Sustained intracerebroventricular infusion of brain fuels reduces body weight and food intake in rats. Science. 212: 81-82

DeFronzo, R.A.(1988) The triumvirate: b-cell, muscle, liver. A collision responsible for NIDDM. Diabetes. 37: 667-87.

Defronzo, R. A., Ferrannini, E., Simonson, DC. (1989) Fasting hyperglycemia in non-insulin-dependent diabetes mellitus: contributions of excessive hepatic 
glucose production and impaired tissue glucose uptake. Metabolism. 38 (4): 387-395.

Eriksson, J., Lindstrom, J., Valle, T., Aunola, S. (1999) Prevention of type II diabetes in subjects with impaired glucose tolerance: the Diabetes Prevention Study (DPS) in Finland. Diabetologia. 42:793-801.

Eriksson, K., Lindegarde, F. (1991) Prevention of type 2 (non-insulin dependant) diabetes mellitus by diet and physical exercise: the 6 year Malmo feasibility study. Diabetologia. 34:891-898.

Fan, W., Boston, B. et al. (1997) Role of melanocortinergic neurons in feeding ad the agouti obesity syndrome. Nature. 385 (6612): 165-168

Fery, F., Tappy, L., Deviere J., Balasse, E. (1998) Mechanisms of whole-body glycogen deposition after oral glucose in normal subjects, Influence of nutritional status. J Clin Endocinol Metab. 83(8): 2810-6

Flatt, J. P. (1987). The difference in storage capacities for carbohydrate and for fat, and its implications for the regulation of body weight. Annals of the New York Academy of Sciences. 499, 104123.

Flatt, J. P., (1996) Carbohydrate balance and body weight regulation. Proc. Nutr. Soc. 55: $449-465$

Flatt, J.P., Ravussin, E., Acheson, K.J. \& Jequier, E. (1985) Effects of dietary fat on postprandial substrate oxidation and on carbohydrate and fat balances. Journal of Clinical Investigation. 76: 1019-1024 
Geiselman, P., Novin, D., (1982) The Role of Carbohydrates in appetite, hunger and obesity. Appetite. 3 (3): 203-223.

Haman, F., Peronnet, F., Kenny, G., Doucet, E., Massicotte, D., Lavoie, C., Weber, J. (2004) Effects of Carbohydrate availability on sustained shivering I. Oxidation of plasma glucose, muscle glycogen, and proteins. J Appl Phyiol. 96:32-40.

Harris, S., Lank CN. Canadian Diabetes Association (2003) Clinical Practice Guidelines for the Prevention and Management of Diabetes in Canada. Can J Diabetes. 27:S1-S15.

Hawk, P.B. (1947) Practical Physiological Chemistry, $12^{\text {th }}$ ed. Toronto: Blakiston

Hawley, J., Scharborte, E., Noakes, T., Dennis, S. (1997) Carbohydrate-loading and exercise performance: An update. Sports Medicine. 24 (2): 73-81.

Hays, N.P., Starling, R.D., Liu, X., Sullivan, D.H., Trappe, T.A., Fluckley, J.D., Evans, W.J. (2004) Effects of an Ed Libitum Low-Fat, High-Carbohydrate Diet on Body Weight, Body Composition, and Fat Distribution in Older Men and Women. Arch Intern Med. 164: 210-217.

Hurni, M., Burnand, B., Pittet, P., Jequier, E. (1981) Metabolic effects of a mixed and high carbohydrate low-fat diet in man, measured over $24 \mathrm{~h}$ in a respiration chamber. Br. J. Nutr. $47: 33-43$

Jobst, E., Enriori, P. (2004) The electrophysiology of feeding circuits. Trends Endocrinol Metab. 15(10): R992-8 
Kelley, D., Goodpaster, BH. (1999) Effects of physical activity on insulin action and glucose tolerance in obesity. Med Sci Sports Exerc. 31:S619-623.

Langhans, W. (1996) Metabolic and glucostatic control of feeding. Proceedings of the Nutrition Society. $55: 497-515$.

Lavin, J., Wittert, G., Horowitz, W., Morley, J., Read, N. (1996) Appetite regulation by carbohydrate: rold of blood glucose and gastrointestinal hormones. American Journal of Physiology. 271 Endocrinol. Metab. 34: 209-214.

Leathwood, P. \& Pollet, P. (1988). Effects of slow release carbohydrates in the form of bean flakes on the evolution of hunger and satiety in man. Appetite 10,111.

Lefebvre, P., Mosora, F., Lacroix, M., Luyckx, A., Lopez-Habibm, G., Duschene, J. (1975) Naturally labelled 13c-glucose. Metabolic studies in human diabetes and obesity. Diabetes 24,185

Livesey, G., Elia, M. (1988) Estimation of energy expenditure, net carbohydrate utilization and net fat oxidation and synthesis by indirect calorimetry. Am J of Clin Nutr 47:608-628.

Lonnroth, P., Jansson, P. (1987) A microdialysis method allowing characterization of intercellular water space in humans. Endocinology and Metabolism. 253(2) : E228-E231.

Louis-Sylvestre, J., LeMagnen, J. (1980) A fall in blood glucose level precedes meal onset in free-feeding rats. Neaurosci Biobehav Rev. 20:59-66. 
Lundbaek, K. (2008) Fasting Values of Blood Sugar, RQ, and Alveolar CO2 Tension on High and Low Carbohydrate Diet. Acta Physiologica. 7 (1): 29-33.

Manson JE, Skerett PJ, Greenland P, Vanltallie TB. (2004) The Escalating Pandemics of Obesity and Sedentary Lifestyle. Arch Intern Med. 164:249258.

Marin, P., Hogh-Kristiansen, I., Jansson, S., Krotkiewski, M., Holm, G., Bjorntorp, P. (1992) Uptake of glucose carbon in muscle glycogen and adipose tissue triglycerides in vivo in humans. Am J Physiol Endocrinol Metab. 263: E473E480

Martinez, A. Body-weight regulation: Causes of obesity. (2000) Proceedings of the Nutrition Society. 59: 337-345.

Mayer, J. (1953) Glucostatic mechanism of regulation of food intake. New England Journal of Medicine. (249), 13-16.

Mayer, J. (1955) Regulation of energy intake and the body weight. Annals of the New York Academy of Sciences. 63, 1543.

Mei, N. (1978) Vagal glucoreceptors in the small intestine of the cat. The Journal of Physiology. 282: 485-506.

Melanson, K.J., Westerterp, M.S., Saris, W.H., Campfield, L.A. (1999) Blood Glucose patterns and appetite in time-blinded humans: carbohydrate versus fat. J Physiol. 277 (Regulatory Integrative Comp. Physiol. 46): R337-R345. 
Mensah, G., Mokdad, A., Ford, E., Narayan, K., \& Giles, W. (2004). Obesity, metabolic syndrome, and type 2 diabetes: Emerging epidemics and their cardiovascular implications. Cardiol. Clin. 22, 485-504.

Mosora, F., Lefebvre, P., Pirnay, F., Lacroix, M., Luyckx, A., Duschesne, J. (1976). Quantitative evaluation of the oxidation of an exogenous glucose load using naturally labelled 13C-glucose. Metabolism 25, 1575-82

Nagaya, T., Yoshida, H., Takahashi, H., \& Kawai, M. (2007). Incidence of type-2 diabetes mellitus in a large population of Japanese male white-collar workers. Diabetes Res ad Clin. Prac. 74 (2): 169-174

Neary, N., Goldstone, A., Bloom, S. (2007). Appetite regulation: from the gut to the hypothalamus. Clinical Endocrinology. 60 (2): 153-160.

Nicolaidis, S. (1981). Lateral hypothalamic control of metabolic factors related to feeding. Diaberologia 20,426-441.

Niijima, A. (1969). Afferent impulse discharges from glucoreceptors in the liver of the guinea pig. Annals of the New York Academy of Sciences. 157: 690700.

Niijima, A. (1989) Neural mechanisms in the control of blood glucose concentration. J Nutr. 119: 833-840.

Noakes, T. (1985). The Lore of Running. Oxford University Press, Southern Africa. 
Ollmann, M., Wilson, B. et al (1997) Antagonism of central melanocortin receptons in vitro and in vivo by agouti-related protein. Science. 278 (5335): 135-138

Pan, X., Li GW, Hu YH, et al. (1997) Effects of diet and exercise in preventing NIDDM in people with impaired glucose tolerance: the Da Qing IGT and Diabetes Study. Diabetes Care. 20:537-544

Prentice, A., Jebb, S. (2008) Energy Intake/Physical Activity Interactions in the Homeostasis of Body Weight Regulation. Nutrition Reviews. 62: S98-S104

Rogers, PJ., Blundell, JE. (1989) Separating the actions of sweetness and calories: effects of saccharin and carbohydrates on hunger and food intake in human subjects. Physiol Behav. 45: 1093-9

Russek, M. (1981) Current Status of the hepatostatic theory of food intake control. Appetite. 2: 137-143

Russek, M. \& Grinstein, S. (1974) Coding of metabolic information by hepatic glucoreceptors. Neurohumoral Coding and Brain Function. Plenum Publishing Corporation: New York.

Russek, M., Rodriguz-Zendejas, A. M., Pina, S. (1968) Hypothetical liver receptors and the anorexia caused by adrenaline and glucose. Physiological Behaviour. 3:249-257.

Sachedina, N., Pickup, J. (2003) Performance assessment of the MedtronicMinimed Glucsoe Monitoring System and its use for measurement of 
glycemic control in Type 1 diabetic subjects. Diabetic Medicine. 20(12): 1012-1015.

Shiota, M., Magnuson, M. (2008) Hepatic glucose sensing: does flux matter? J clin. Invest. 118(3): 841-844

Shulman G, Rothman D, Jue T et al. (1990) Quantitation of muscle glycogen synthesis in normal subjects and in subjects with non-insulin dependent diabetes by $13 \mathrm{C}$ nuclear magnetic resonance spectroscopy. $N$ Engl J Med. 322: $223-8$

Smith, F. Campfield, L. (1993) Meal initiation occurs after experimental induction of transient declines in blood glucose. Am J Physiol. 265(6 Pt 2):R1423-9.

Smith F.J., Driscoll D.W., Campfield L.A. (1988) Short term effects of fructose on blood glucose dynamics and meal initiation. Physiol Behav. 44(4-5):625-31.

Statistics Canada. (2002) BMI international standard, by sex, household population aged 20-64 excluding pregnant women, Canada, provinces, territories, health regions and peer groups, 2000/2001. Health Indicators (Statistics Canada, Catalogue 82-221-XIE).

Statistics Canada (2005) Measured Obesity. Adult Obesity in Canada: Measured Height and Weight. Nutrition: Findings from the Canadian Community Health Survey. (Statistics Canada Catalogue 82-620-MWE2005001)

Stevenson, E.J., Astbury, N.M., Simpson, E.J., Taylor, M.A., Macdonald, IA. (2009) Fat Oxidation during Exercise and Satiety during Recovery are increased 
following a Low Glycemic Index Breakfast in Sedentary Women. J Nutr. 139:890- 897.

Stubbs, R. J. (1998) Appetite, feeding behaviour and energy balance in human subjects. Proceedings of the Nutrition Society. 57:341-356

Stubbs, R. J. (1999) Peripheral singals affecting food intake. Nutrition. 15(7): 614625.

Stubbs, R.J., Harbron, C.G., Murgatroyd, P.R., Prentice, A.M. (1995). Covert manipulation of dietary fat and energy density: effect on substrate flux and food intake in men eating ad libitum. American Journal of Clinical Nutrition. 62: 316-329.

Strubbe, J., Steffens, A. and DeRuiter, L. (1977) Plasma insulin and the time pattern of feeding in the rat. Physiol Behav. 18: 81-86.

Stunkard, A., Wolff, H., Plescia, A. (1956) Studies on the Physiology of Hunger. I. The Effect o Intravenous Administration of Glucose on Gastric hunger Contractions in Man. J clin invest. 35(9):954-963

Surina, D. M., Langhans, W., Pauli, R. \& Wenk, C. (199.3). Meal composition affects postprandial fatty acid oxidation. American Journal of Physiology 264, R1065$-R 1070$.

Tarnopolsky, M. A., Atkinson, S.A., Phillips, S.M. and MacDougall, J.D. (1995) Carbohydrate loading and metabolism during exercise in men and women. Journal of Applied Physiology. 78: 1360-1368. 
Torsdottir, I., Alpsten, M., Anderson, H., Schweizer, T. F., Tolli, J. \& Wiirsch, P. (1989). Gastric emptying and glycemic response after ingestion of mashed bean or potato flakes in composite meals. American Journal of Clinical Nutrition $50,1415-1419$.

Trends in intake of energy and macronutrients- United States, 1971-2000. (2004) MMWR Morb Mortal Wkly Report. 53:80-82

Van Itallie, T., Beaudoin, R., Mayer, J. (1953) Arteriovenous Glucose Differences, Metabolic hypoglycaemia and food intake in man. American journal of clinical Nutrition. 1: 208-217

Van Itallie, T., Hashim, S. (1960) Biochemical concomitants of Hunger and Satiety in Man. Am J Clin Nutr. 8: 587-594

Van Zant RS. (1992) Influence of diet and exercise on energy expenditure: a review. Int. J. Sports Nutr. 2: 1-19.

Westerterp K.R. (1993) Food Quotient, respiratory quotient and energy balance. AM J Clin Nutr. 57 (suppl):759S-65S

Westman, E., Mavropoulos, J., Yancy, W., Vikej, J. (2003) A review of low carbohydrate ketogenic diets. Curr Atheroscler Rep. 5: 476-83.

Westman, E., Feinman, R., Mavropoulos, J., Vernon, M., Volek, J., Wortman, J., Yancy, W., Phinney, S. (2007) Low-carbohydrate nutrition and metabolism. Am J Clin Nutr, 86: 276-84 
Woerle, H., Meyer, C., Dostou, J., Gosmanov, N., Islam, N., Popa, E., Wittlin, S., Welle, S., Gerich, J. (2003) Pathways for glucose disposal after meals ingestion in humans. Am J Physiol Endocrinol Metab 284:E716-725.

Wolinsky, I., Driskell, J.A. (2007) Sports Nutrition: Energy Metabolism and Exercise. CRC Press: Boca Raton, Florida

Woods, S. C., D'Alessio, D.A. (2008) Central control of body weight and appetite. J clin Endocrinol Metab. 93(11 Suppl 1):S37-50

World Health Organization. (2007). Obesity and overweight. Retrieved November 19,2007 , from http://www.who.int.proxy.bib.uottawa.ca/dietphysicalactivity/publications/facts/ obesity

Yagci, G., Fatih Can, M., Ozturk, E., Dag, B., Ozgurtas, T., Cosar, A., Tufan,T. (2008). Effects of preoperative carbohydrate loading on glucose metabolism and gastric contents in patients undergoing moderate surgery: A randomized, controlled trial. Nutrition. 24, 212-216

Zhentao, S., Routh, V. (2006) Recurrent hypoglycaemia reduces the glucose sensitivity of glucose -inhibited neurons in the ventromedial hypothalamus nucleus. Am J Physiol Integr Comp Physiol. 291: R1283-R1287. 


\section{APPENDIX I}

\section{ETHICS APPROVAL LETTER}




\section{Université d'Ottawa University of Ottawa \\ Service de subventions de recherche et déontologie Research Grants and Ethics Services}

\section{Ethics Approval Notice}

\section{Health Sciences and Science REB}

\section{Principal Investigator / Supervisor / Co-investigator(s) / Student(s)}

$\begin{array}{llll}\text { First Name } & \text { Last Name } & \text { Affiliation } & \text { Role } \\ \text { Énc } & \text { Doucet } & \text { Health Scicnces/Human Kinetics } & \text { Supervisor } \\ \text { Lauren } & \text { Roberts } & \text { Health Sciences / Others } & \text { Student Researcher }\end{array}$

File Number: H02-(09-08

Type of Project: Master's Thesis

Title: Carbohydrates and Feeding: An Extension of the Cilucostatic Theory of Appette Regulation

\section{Approval Date (mm/dd/yyyy)}

$05: 08 / 2009$

(Ia: Approval, Ib: Approval for initial stage only)

\section{Expiry Date (mm/dd/yyyy)}

$05 \% 07 / 2010$

\section{Approval Type}

Ia

\section{Special Conditions / Comments:}

N/A 


\section{Université d'Ottawa University of Ottawa \\ Strvice de subventions de techerche et déntologit $\quad$ Research (jrants and Ethics Servicts}

This is to confirm that the University of Ottawa Research Ethics Board identified above, which operates in accordance with the Tri-Council Policy Statement and other applicable laws and regulations in Ontario, has examined and approved the application for ethical approval for the above named research project as of the Ethics Approval Date indicated for the period above and subject to the conditions listed the section above entitled "Special Conditions / Comments".

During the course of the study the protocol may not be modified without prior written approval from the REB except when necessary to remove subjects from immediate endangerment or when the modification(s) pertain to only administrative or logistical components of the study (e.g. change of telephone number). Investigators must also promptly alert the REB of any changes which increase the risk to participant(s), any changes which considerably affect the conduct of the project, all unanticipated and harmful events that occur, and new information that may negatively affect the conduct of the project and safety of the participant(s). Modifications to the project, information/consent documentation, and/or recruitment documentation, should be submitted to this office for approval using the "Modification to research project" form available at:

http://www.rges.uottawa.ca/ethics/application_dwn.asp

Please submit an annual status report to the Protocol Officer 4 weeks before the above-referenced expiry date to either close the tile or request a renewal of ethics approval. This document can be found at: http://www.rges.uottawa.ca/ethics/application_dwn.asp

If you have any questions, please do not hesitate to contact the Ethics Office at exlension 5841 or by e-mail at ethics(ciuOttawa.ca.

Germain Zongo

Assistant Director, Ethıcs (Interim)

For Dr. Daniel Lagarec, Chair of the Heatth Sciences and Sciences REB 


\section{APPENDIX $\|$}

\section{INCLUSION CRITERIA QUESTIONNAIRE}




\section{Inclusion Questionnaire}

1) What is your age?

2) What is your weight?

3) What is your height?

4) Are you a smoker?

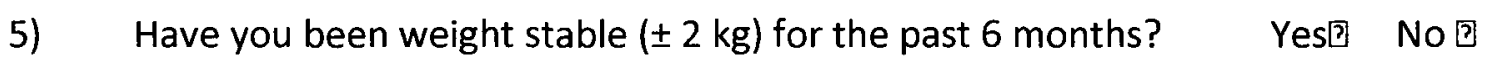

6) Are you sedentary?

If, no, how many minutes of physical activity do you participate in per week?

7) Are you taking any medication?

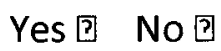

If so, which ones?

8) Are you diabetic?

Yes 0 임

9) Do you suffer from heart disease?

Yes 回 No 回

10) Do you suffer from hypertension?

Yes? No 回

11) Do you suffer from asthma or any other respiratory problems? Yes

12) Has your doctor ever said that you suffer from a thyroid gland disorder? Yes 9 No

15) Have you ever, or do you currently suffer from an eating disorder? Yes $0 \mathrm{No}$ If yes, which one:

16) Do you suffer from chronic liver disease or renal disorders ? 


\section{APPENDIX III}

PARTICIPANT CONSENT FORM 


\title{
CONSENT FORM
}

\section{Carbohydrates and Feeding: An Extension of the Glucostatic Theory of Appetite Regulation}

\author{
Principal Investigator: Eric Doucet \\ Co-investigator-Master's Student: Lauren Roberts \\ Faculty of Health Sciences, University of Ottawa \\ School of Human Kinetics
}

\section{PURPOSE OF THE RESEARCH}

In this Master's Thesis study, the researchers will investigate whether changes in one's carbohydrate stores and oxidation will cause predictable effects on one's feeing behavior as predicted by Mayer's model of Glucostatic theory of appetite regulation. In fact, the effects of high, normal and low carbohydrate diets on fluctuations in blood glucose levels, appetite and food preference will be investigated. For each diet condition, the amount of calories consumed will be predetermined for each participant and will be the same for each diet, only the amount of carbohydrates consumed will change.

\section{DESCRIPTION OF THE PROPOSAL}

My participation will consist essentially of attending a pre-screening visit $(\sim 1 \mathrm{hr})$, a screening visit ( $3.5 \mathrm{hrs}$ ) and three experimental conditions which will simply involve me adjusting and logging my diet accordingly during my regular day to day activities. Each condition will be followed by a testing day (approximately 10 hours per day) during which many measurements will be made. The testing sessions will be performed between $7 \mathrm{~h} 30$ and $17 \mathrm{~h} 30$. A detailed description of the visits is given in the following sections.

\section{Initial Meeting}

This initial meeting will be held at a location that is convenient to me. At this meeting the study will be explained to me in full. I will learn what is required of me if I chose to participate. This session will also be conducted to confirm I fit the inclusion criteria for this study. To achieve this, I will be asked to answer various 
inclusion criteria questions and to fill out health and dietary questionnaires. I will then be asked to read this form through carefully in full and sign it if I wish to participate. If I wish, I will be given the option to bring the consent form home to review and discuss with family members prior to signing. If this is the case, I will return the consent form on my next visit. Following this meeting, I will receive an accelerometer that I will wear during all my daily activities for the next 7 days. This accelerometer will measure my average daily caloric output.

\section{Screening}

This second visit will last approximately $3.5 \mathrm{hrs}$. I will be asked to come into the laboratory at $7 \mathrm{~h} 30$ after an overnight fast which started at $19 \mathrm{~h} 30$ the night before. I will return the accelerometer at this time. My resting metabolic rate (the amount of energy I burn during resting conditions) will be taken. Also, anthropometric data (height, body weight, body composition (Dual Energy X-ray Absorptiometry), and waist circumference) will be collected. My blood will be drawn by a certified nurse to determine my fasting blood glucose levels and insulin levels. Information on my current eating habits will also be collected.

\section{The intervention}

If my characteristics correspond to all the inclusion criteria and I accept to participate in this study, I will be subjected to the three experimental conditions of which the order will be randomized. During these days, I will be asked to follow 3 standard diet conditions. Each diet will last for 3 days after which I will come to the Lab to undergo a day of testing. The diets used will either consist of what I normally eat, and 23 -day period that resemble diets used by athletes before competitions. The day of testing will involve various tests as outlined below. For the duration of my participation in this study, I will be able to take part in my regular daily activities and will adjust my eating habits to fit each diet as it is prescribed to me.

\section{DESCRIPTION OF MEASURES}

I will also be subjected to a series of measurements that will be performed during three experimental conditions, each consisting of 3 testing days. The conditions must be separated by a minimum of 2 weeks. A detailed description of these sessions is given below. 


\section{Screening Session (7h30-11h00)}

\section{A. Arrival at the laboratory $7 \mathrm{~h} 30$.}

B. Resting (7h30-8h00) - I will have to rest comfortably in the reclining bed for a 30 minute period.

C. Resting Metabolic Rate (8h00-8h30) - After a 30 minute resting period in the supine position a measurement of resting energy expenditure will be done. The measurement of resting metabolic rate takes place early in the morning after an overnight fast. A plexiglass hood will be placed over my head through which fresh air will be drawn. The expired air will be sampled for analysis and percentages of oxygen and carbon dioxide determined for 30 minutes. By measuring the flow rate, the researchers will be able to determine the amount of oxygen that is consumed and derive energy expenditure. This test requires that I lie quietly and relaxed in bed for around 30 minutes. There are no risks associated with this procedure.

D. Body composition (8h30-9h15) - Body weight, height and waist circumference will be measured. A method called dual-photon $x$-ray absorptiometry (DEXA) will be used to measure bone density, percent body fat and percent lean body mass. I will have to lie on an examination table, fully clothed, while a low intensity $x$-ray will scan the entire body. The measurement takes 20 minutes. The only risk is a minimal $x$-ray exposure of less than 0.5 millirem. This exposure is less than the natural background from 1 day of exposure to sunlight.

E. Blood Profile (9h15-9h45) - A small blood draw will be conducted by a certified nurse to measure my fasting blood glucose levels and insulin levels. A needle will be inserted into my arm in a standard blood draw protocol. There may be a slight bruise associated with the needle insertion but the risk associated with this is minimal. My blood samples will be stored in a freezer at -80 degrees Celcius located at E021 Lees Campus at the University of Ottawa for the duration of the study ( 8 weeks). Following this, the samples will be disposed of with the appropriate biohazard procautions. 
F. Health and Dietary Questionaires. (9h45-11h00) - I will be asked to fill out various health and dietary questionaires to determine my health status and eating habits prior to commencing the study.

Pre Condition Meeting (45 mins)

A. Arrival at the predetermined meeting place convenient to subject (ideally following testing day) - A 45 minute meeting will take place prior to each experimental condition. I will decide on a time and place that is convenient to me where I will meet with the researcher.

B. Explanation of the phase (45mins) - During this meeting I will be given a log book which will contain instructions for each diet as well as space for me to fill in my food consumption. I will be able to eat a certain amount of servings from each food group. This book will indicate what I can eat and how much. I will keep track for the three days of the diet and honestly record both what I ate and how much. I will bring this log book back to the lab with me on the test day following each condition.

Experimental Testing (7h30-17h30)

For each experimental condition, I will have to come to the laboratory and subject myself to the sequence of measurements described below.

\section{A. Arrival at the laboratory $7 \mathrm{~h} 30$.}

B. Body composition (7h30-8h00) - Body weight will be taken.

C. Resting Energy Expenditure (8h00-9h00)- After a 30 minute resting period in the supine position a measurement of resting energy expenditure will be done. A plexiglass hood will be placed over my head through which fresh air will be drawn. The expired air will be sampled for analysis and percentages of oxygen and carbon dioxide determined for 30 minutes. By measuring the flow rate, we will be able to determine the amount of oxygen that is consumed and derive energy expenditure. This test requires that I lie quietly and relaxed in bed for around 30 minutes. There are no risks associated with this procedure. 
D. Standardized breakfast test meal and appetite ratings (9h00-9h30) - After an overnight fast, I will be served a variety of foods at $9 \mathrm{~h} 00$. I will be asked to eat a standardized breakfast test meal, which will consist of one slice of whole wheat bread, peanut butter, and $125 \mathrm{ml}$ (1/2 cup) of milk. The meal will be designed to have an energy content of $225 \mathrm{kcal}$. Appetite ratings (ie. How hungry I feel) will be measured before and after breakfast and every 30 minutes for the remainder of the testing day.

\section{E. Remainder of the day $(9 \mathrm{~h} 30-17 \mathrm{~h} 30)$}

I. For the remainder of the testing day I will remain in the lab isolated from time cues. I will be able to read, write or engage in any other activity throughout the day that I normally would. Meals will not be provided to me at set times. Levels of appetite, hunger and desire to eat will be measured throughout the day. When I am hungry and desire food, I can request a meal. I will then be given five menu options of which I can choose any portion size I desire. Throughout the day, I will also be wearing a blood glucose monitor so that my blood glucose levels can be measured throughout the day. The certified nurse will outfit me with a standard system just like those that are used everyday by diabetics across North America and the world and can be obtained with or without a prescription. The insertion of this tiny sensor will be just a simple insertion done by the nurse just under the skin on my abdomen. The insertion is so simple that when used daily by diabetics, they even insert the sensor themseleves. The tiny sensor is placed just under the skin and is held in place with an adhesive pad that comes with each fresh sensor. The sensors are designed to stay inserted and in place for 3 days use as they are marketed for commerical use by diabetics to measure blood glucose 24 hours a day, everyday. Since I will only be wearing this monitor on testing days for 10 hours at a time, there is no risk involved with the sensor remaining inserted for this period of time. I may see slight bruising from the insertion of this sensor but this is unlikely and if does occur will be minimal. Wearing this monitor will not pose any other risk to me.

\section{H. END OF SESSION $17 \mathrm{~h} 30$}

\section{FORESEEABLE RISKS}

The risks associated with this study are low. The proposed measurements, such as anthropometrical measurements, blood samples, continuous blood glucose monitoring, body composition and resting metabolic rate pose very little risk to me. 
The initial blood draw and insertion of the blood glucose monitor will be conducted by a certified nurse to further minimize the already low risks.

I may see a slight bruising from the insertion of the blood glucsoe monitor sensor but this is unlikely and if does occur will be minimal. Wearing this monitor will not pose any other risk to me. It is also possible for the initial blood sampling to cause a small bruise at the location of the puncture that can remain for a few days.

\section{BENEFITS}

My participation in this study will allow me to gather information on my body composition as well as on other health indicators (e.g. resting metabolic rate, glucose profile...).

\section{MONETARY COMPENSATION}

Parking at the laboratory is free for participants, as are all scientific tests. I will receive a compensation of $\$ 100.00$ which will be paid in increments of $20 \$$ at the beginning of the screening visits, as well as following each experimental condition ( $\$ 40$ for the last session). If I am unable to complete a session for whatever reason, I will be compensated as if I did. I will not be compensated for a session for which I did not show up to.

\section{CONFIDENTIALITY AND ANONYMITY}

In order to guarantee the confidentiality and anonymity of participants, all precautions and necessary measures will be taken to ensure that results and personal information of participants is kept under the strictest of confidentiality.

My name will not appear on any reports. A number code will be used to identify me on all research documents.

$\square$ All material and information which can be linked to myself will not be made public and will be kept under the strictest confidentiality.

The data collected will be kept in a locked file cabinet with limited access at the behavioural and metabolic unit in the Lee's Campus Laboratory. In addition, the computer files will be protected by a password. The data will be destroyed five years following their publication.

Primary Researchers (Eric Doucet and Lauren Roberts: contacts below) will have access to all data collected relating to me. Any other individuals involved this study as it pertains to my involvement, testing and data will sign a pledge of confidentiality before interacting with me or having access to data (research assistants, nurse who conducts blood draw etc). 


\section{VOLUNTARY PARTICIPATION}

My participation in this study is entirely voluntary.

- I will be made aware of new findings that might influence my decision to take part in the present study.

\section{RIGHTS OF THE PARTICIPANTS}

The researcher guaranties that:

$>$ I can withdraw from the project at any time.

$>$ The confidentiality of the information gathered as well as the anonymity of all participants will be rigorously protected as indicated above.

Any information about my rights as a research participant may be addressed to the Protocol Officer for Ethics in Research, 550 Cumberland Street, Room 159, Ottawa, ON K1N 6N5. (613) 562-5841 or ethics@uottawa.ca .

There are two copies of the consent form, one of which I may keep.

If I have any questions about the conduct of the research project, I may contact the researcher (Eric Doucet, edoucet@uottawa.ca) or graduare student Lauren Roberts Montpetit Hall, 200 Lee's Campus,

Researcher's signature:

Date:

Graduate Student's signature:

Date:

I, , agree to participate in the above research of the School of Human Kinetics at the University of Ottawa.

Participant's Signature:

Date: 
APPENDIX IV

DIET LOG 

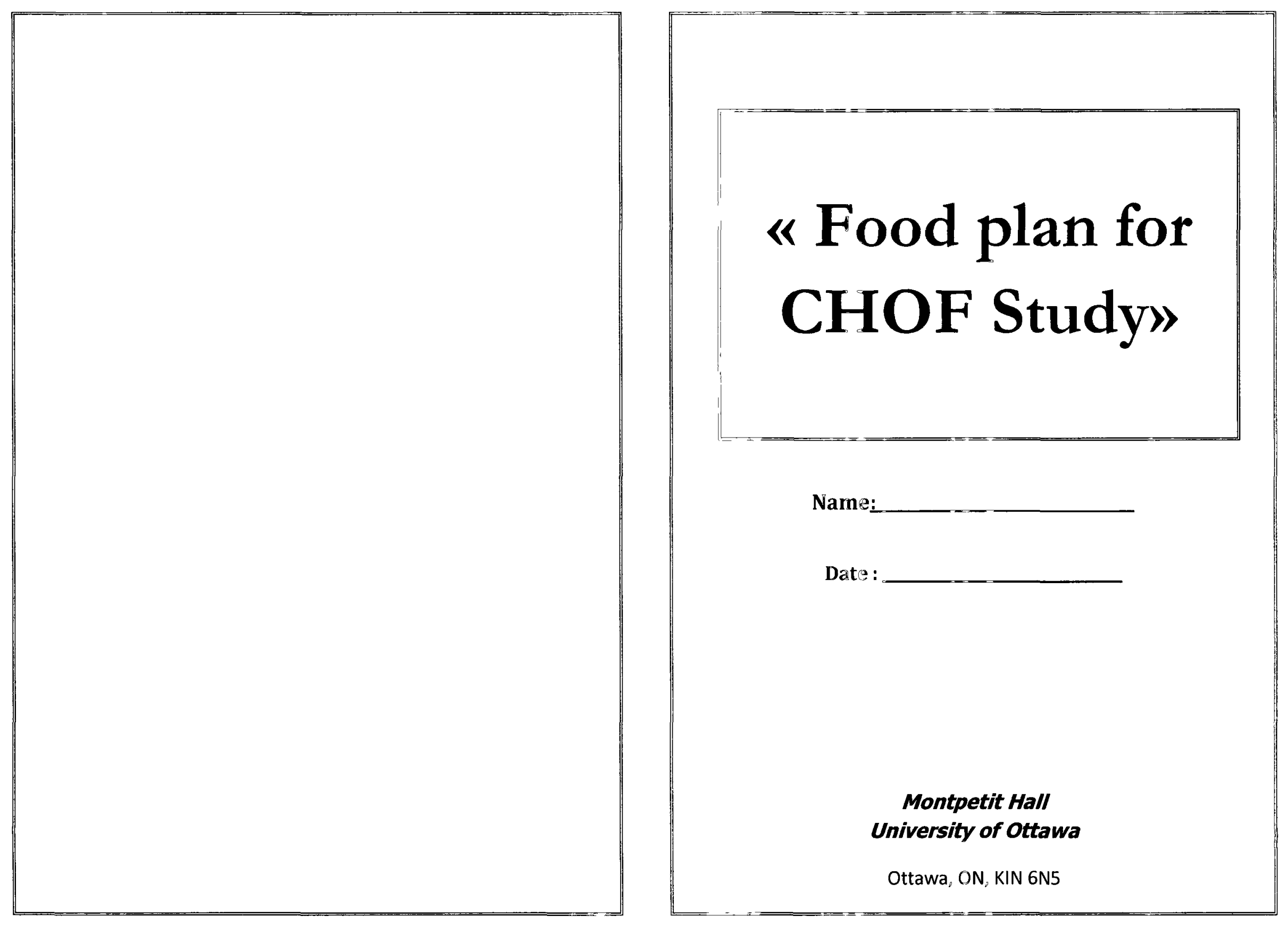

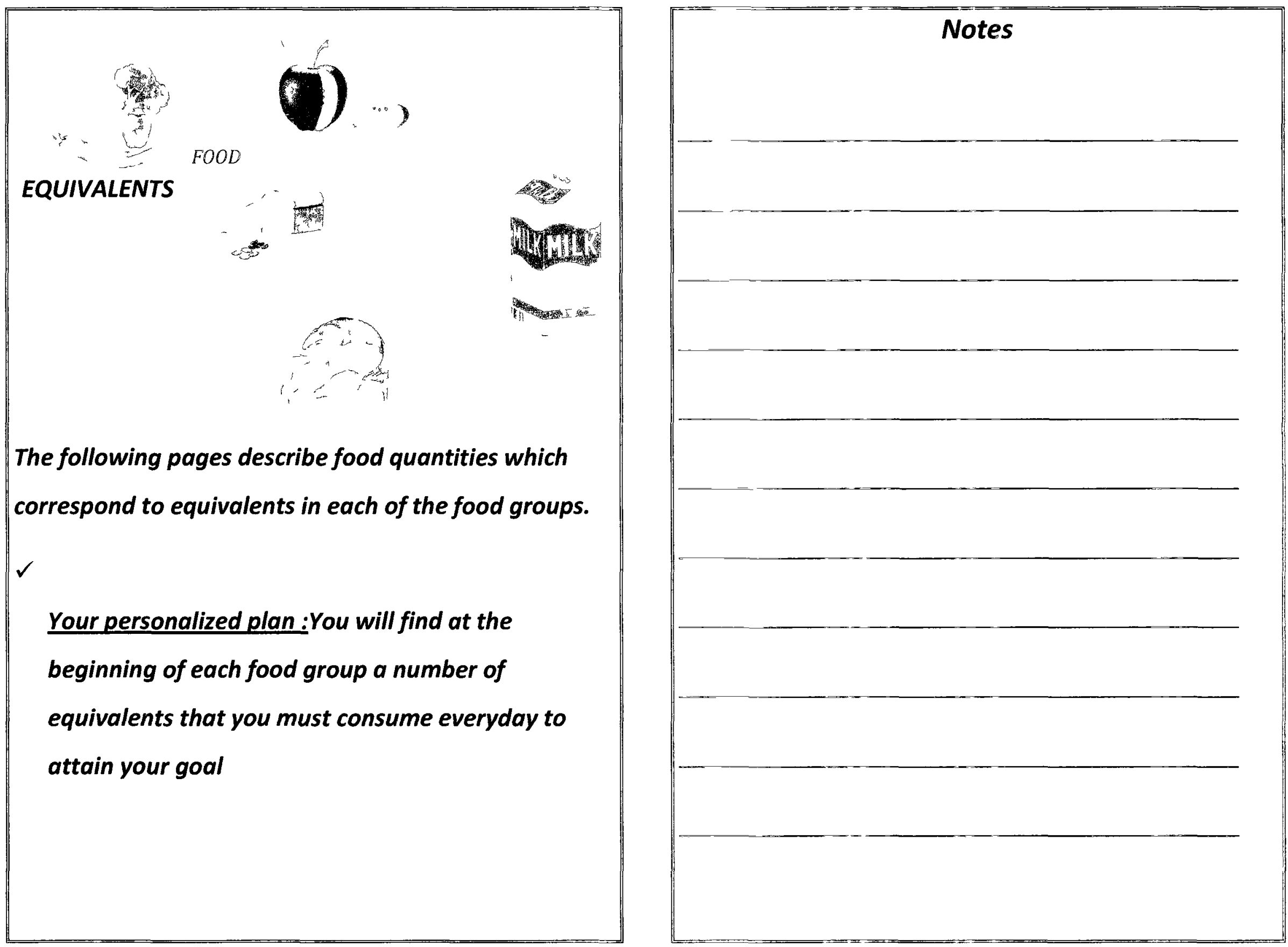


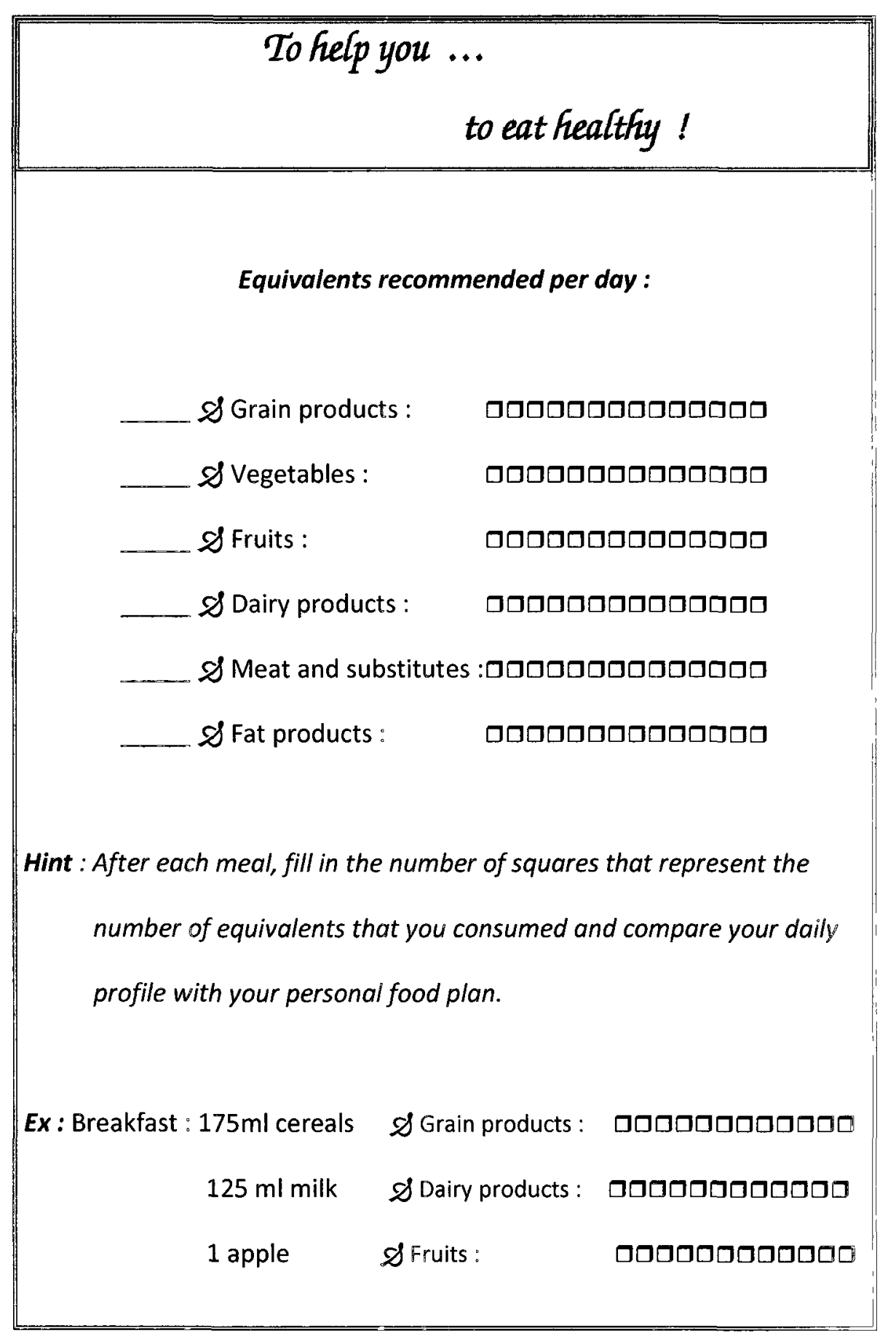

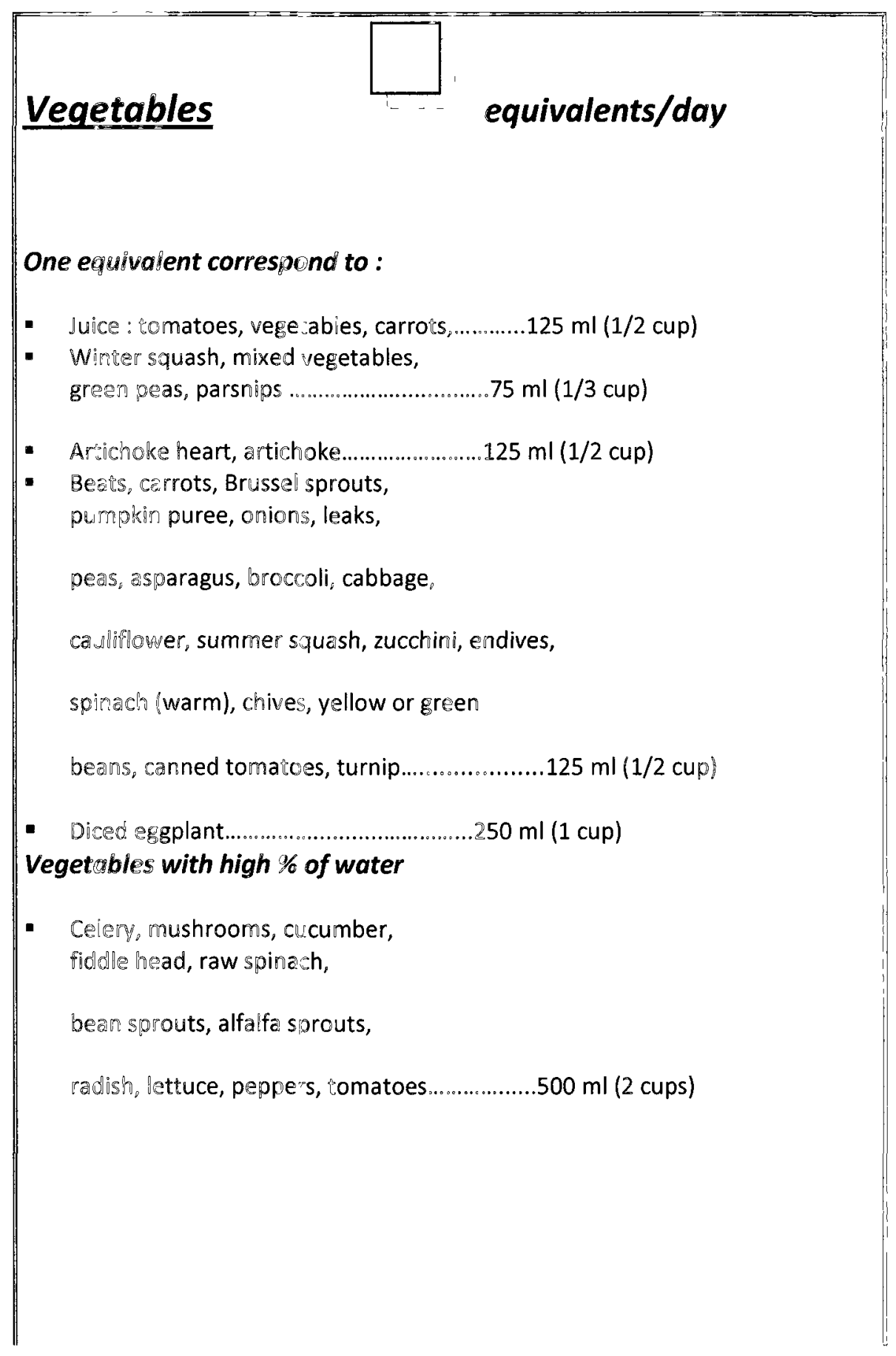




\begin{tabular}{|c|c|c|}
\hline$\therefore \quad \therefore 8$ & Date : & Date:- \\
\hline $\begin{array}{l}\text { Grain } \\
\text { prod.: }\end{array}$ & 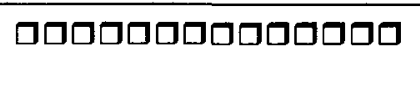 & 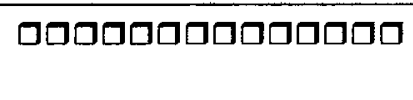 \\
\hline Vegetables: & 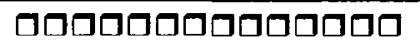 & 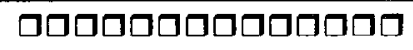 \\
\hline Fruits : & 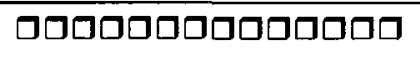 & 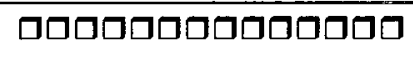 \\
\hline Dairy prod. : & 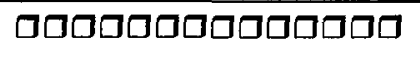 & 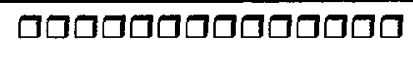 \\
\hline Meat: & 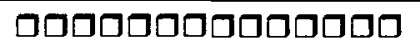 & 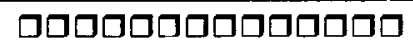 \\
\hline Fat prod.: & 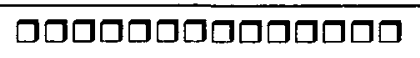 & 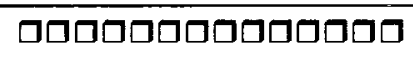 \\
\hline & Date :_ & \\
\hline $\begin{array}{l}\text { Grain } \\
\text { prod.: }\end{array}$ & 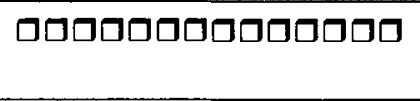 & \\
\hline Vegetables: & 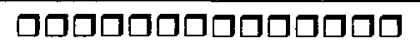 & \\
\hline Fruits : & 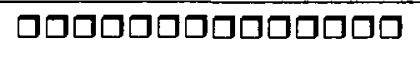 & \\
\hline Dairy prod. : & 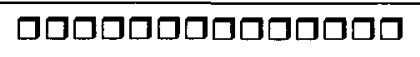 & \\
\hline Meat : & 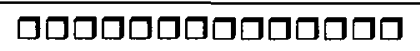 & \\
\hline Fat prod.: & 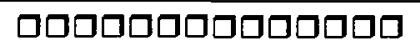 & \\
\hline
\end{tabular}

\section{Fruits}

\section{equivalents/day}

One equivalent correspond to :

- Abricoss, kiwi, dattes, fig, Clementine, prunes..................................2 fruits

- Fruit compotes, salads or jus and canned fruit (unsweetened).....................125 $\mathrm{ml}$ (1/2 cup)

- Banana, mangoes, kaki, grapefruit, papaya..................................2/2 fruit

- Nectarine, orange, peach. pear, apple, tangerine ............................... 1 fruit

- Cantaloupe............................................ 1/4 fruit

- Honeydew.............................................1/8 fruit

- St awberries, currant, raspberries, water melon, honeydew.............................250 $\mathrm{ml}$ (1 cup)

- Rhubarb ..............................................500 ml (2 cup) 


\section{Grain products}

\section{$\square$ equivalents/day}

One equivalent correspond to :

- Toasted bread, dry crackers (all kinds)............2 units

- Soda Crackers, Melba...............................5 units

- Breakfast cereals (warm or ready to serve, little or no sugar)............................30 g (3/4 cup)

- Rice, couscous, pasta, mashed potatoes, corn................................125 ml (1/2 cup)

- Popcorn (no butter) $.750 \mathrm{ml}$ ( 3 cups)

- Hamburger or hot dogs buns, bagel English muffin, Keiser, pita. $.1 / 2$ unit

- Sliced bread, small salad bread. 1 unit

- Baguette $1 \frac{1}{2}$ slice .4 units

Pasta soup. $250 \mathrm{ml}$ ( 1 cup)

- Pea soup ............................................125 ml (1/2 cup)

\section{Meat \& substitutes}

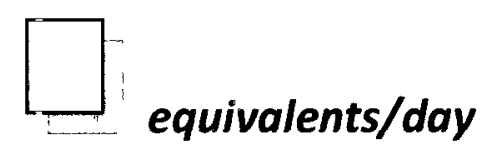

One equivalent correspond to :

- Cheese (skimmed ( / à $18 \%$ m.f.)........30 g (1 ounce)

- Regutar cheese ( $>20 \%$ m.f.) ${ }^{*}$............30 g (1 ounce)

- Cortage cheese $1 \%, 2 \%$ m.f.

or ricotta (skimmed').....................60 ml (1/4 cup)

- Weat, poultry, fish..............................30 g (1 ounce)

- Shrimp.....................................5 big, 1.8 small

- Egg...........................................1 unit

- Pearu butter...................................15 ml (1 table sp.)

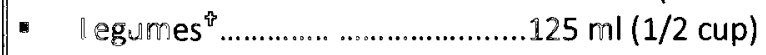

- Tofu.......................................125 ml (1/2 cup)

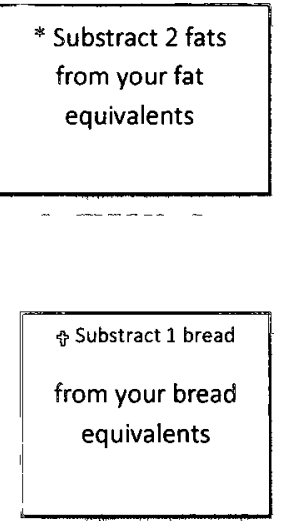

- 


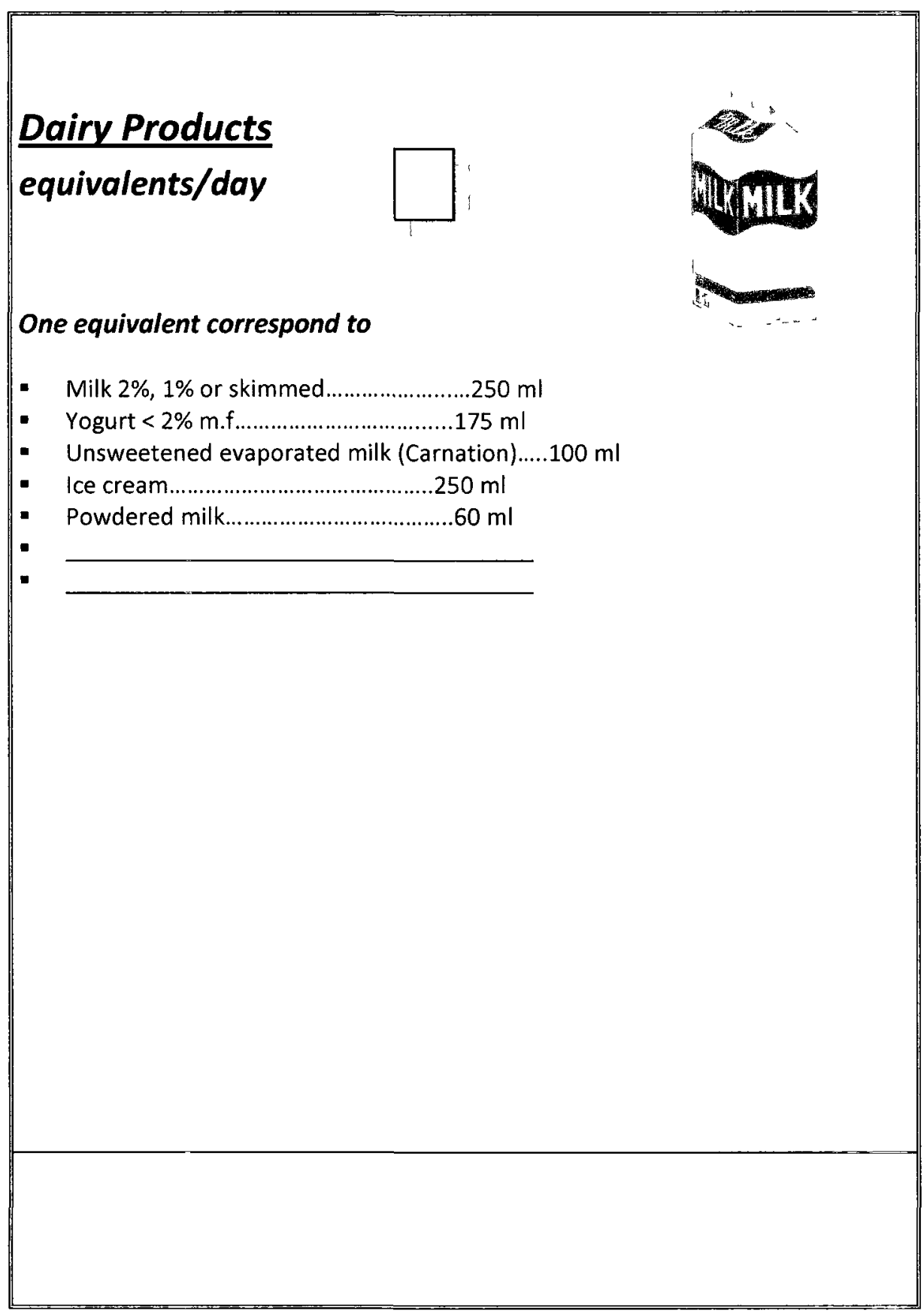

\section{Fat products}

equivalents/day

One equivalent correspond to (5 $\mathrm{g}$ of fat products) :

- Butter, margarine, mayonnaise,

0 il... .......................................5 $\mathrm{ml}$ (1 tea $\mathrm{sp}$.

- Sream cheese, light margarine,

light mayonnaise, light salad

dressing, vinaigrette .........................15 $\mathrm{ml}$ (1 table sp.)

- Avocado.......................................1/8 unit

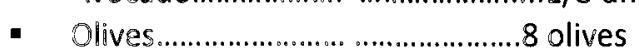

- Nuts and grains...............................15 ml (1 table sp.)

\section{Unlimited consumption!!}

- Seasoning

- Bouillons and Consommés

- Diet soft drinks

- Tea, coffee, herbal sea

- Soya sauce, Worcescershire

- Dry os prepared mustard, Ketchup, Vinaigar

- Mayonnaise and dressing ULTRA LOW IN FAT 


\section{APPENDIX V}

\section{MENU AND OPTION DESCRIPTIONS}


A. Menu. The following menu was presented to each subject on every occasion of spontaneous food request.

\begin{tabular}{|c|c|}
\hline Food Items & Food Item \\
\hline $\begin{array}{l}\text { Fried Chicken and Mashed Potatoes } \\
\text { meal }\end{array}$ & Apple \\
\hline Kit Kat Bar & Ritz Crackers and Cheese Snack \\
\hline Orange & Peanut Butter and Jam Sandwich \\
\hline Nutri Grain Muffin Bar & Glass of 7up \\
\hline Cheesy Doritos Nacho Chips & Chocolate Chip Cookies \\
\hline Glass of Coke & Yogourt \\
\hline Vegetable Thins Crackers & Glass of Apple Juice \\
\hline Lasagna & Bowl of Ice cream \\
\hline Glass of Fruit Punch & Glass of Chocolate milk \\
\hline Carrots and dip & Chicken Stir Fry and Rice Meal \\
\hline Glass of Water & Deluxe Pizza Meal \\
\hline Macaroni and Cheese Meal & Smarties \\
\hline Banana & Cheetos Snack Chip \\
\hline Glass of Orange Juice & Glass of Milk \\
\hline Snickers Bar & \\
\hline
\end{tabular}

B. Option Descriptions: The breakdown of meals is provided on the following page. 


\begin{tabular}{|c|c|c|c|c|c|c|c|c|c|}
\hline & Total eaten $(\mathrm{g})$ & $\begin{array}{l}\text { Calories } \\
\mathrm{kcal} / \mathrm{g}\end{array}$ & $\begin{array}{l}\text { Total Eaten } \\
\text { (kcal) }\end{array}$ & $\% \mathrm{CHO}$ & $\begin{array}{l}\mathrm{CHO} \\
\text { Eaten (g) }\end{array}$ & \%Lipids & $\begin{array}{l}\text { Lipids } \\
\text { eaten (g) }\end{array}$ & $\%$ Protein & $\begin{array}{l}\text { Protein } \\
\text { Eaten (g) }\end{array}$ \\
\hline 1 apple & 140.00 & 0.52 & 73.08 & 0.14 & 19.18 & 0.00 & 0.00 & 0.00 & 0.00 \\
\hline Orange & 110.00 & 0.49 & 53.90 & 0.13 & 14.15 & 0.00 & 0.00 & 0.01 & 0.79 \\
\hline 1 banana & 150.00 & 0.89 & 133.47 & 0.23 & 34.35 & 0.00 & 0.00 & 0.01 & 1.27 \\
\hline baby carrots & 80.00 & 0.35 & 28.24 & 0.08 & 6.59 & 0.00 & 0.00 & 0.01 & 0.94 \\
\hline Dip & 15.00 & 4.19 & 62.79 & 0.07 & 1.05 & 0.44 & 6.63 & 0.02 & 0.35 \\
\hline Yogurt & 100.00 & 0.35 & 35.00 & 0.05 & 5.00 & 0.00 & 0.00 & 0.04 & 4.00 \\
\hline Lasagne & 210.00 & 1.18 & 247.17 & 0.16 & 33.77 & 0.05 & 9.89 & 0.03 & 6.59 \\
\hline 1 pizza & 142.00 & 2.75 & 390.50 & 0.29 & 41.00 & 0.13 & 19.00 & 0.10 & 14.00 \\
\hline PB and Jam sandwich Bread & 70.00 & 2.53 & 177.10 & 0.45 & 31.71 & 0.04 & 2.80 & 0.09 & 6.51 \\
\hline PB J - Peanut Butter & 45.00 & 6.00 & 270.00 & 0.20 & 9.00 & 0.53 & 23.85 & 0.20 & 9.00 \\
\hline PB and J Jam & 25.00 & 4.00 & 100.00 & 0.87 & 21.67 & 0.00 & 0.00 & 0.00 & 0.00 \\
\hline $\begin{array}{l}\text { Michelinas Fried Chicken, } \\
\text { potatoes/gravy }\end{array}$ & 220.00 & 1.27 & 278.96 & 0.10 & 22.73 & 0.07 & 15.49 & 0.05 & 11.35 \\
\hline mac and cheese & 180.00 & 1.45 & 261.18 & 0.19 & 34.59 & 0.05 & 8.47 & 0.06 & 10.59 \\
\hline Chicken stir fry meal & 180.00 & 1.53 & 275.29 & 0.22 & 39.53 & 0.05 & 9.18 & 0.05 & 8.47 \\
\hline 1 bowl of ice cream & 125.00 & 0.96 & 120.00 & 0.14 & 17.00 & 0.05 & 6.00 & 0.00 & 0.10 \\
\hline Nutri-grain Bar & 40.00 & 3.78 & 151.35 & 0.70 & 28.11 & 0.08 & 3.24 & 0.05 & 2.16 \\
\hline 2 choc chip (1 serving) & 50.00 & 4.67 & 233.35 & 0.73 & 36.65 & 0.20 & 10.00 & 0.03 & 1.65 \\
\hline 1 snickers bar & 59.00 & 4.75 & 280.25 & 0.61 & 35.99 & 0.24 & 14.00 & 0.07 & 4.00 \\
\hline 1 box of smarties & 50.00 & 4.60 & 230.00 & 0.80 & 40.00 & 0.14 & 7.00 & 0.04 & 2.00 \\
\hline kit kat bar & 45.00 & 5.11 & 229.95 & 0.64 & 28.98 & 0.27 & 12.00 & 0.07 & 3.00 \\
\hline 1 ritz (9 crackers) & 25.00 & 5.50 & 137.50 & 0.60 & 15.00 & 0.05 & 1.25 & 0.30 & 7.50 \\
\hline 1 cheetoes & 28.00 & 5.71 & 159.99 & 0.50 & 14.00 & 0.07 & 2.00 & 0.39 & 11.00 \\
\hline Doritos zesty nacho chips & 28.00 & 5.36 & 150.00 & 0.61 & 17.00 & 0.29 & 8.00 & 0.07 & 2.00 \\
\hline 1 glass 7 up & 250.00 & 0.42 & 105.63 & 0.11 & 28.17 & 0.00 & 0.00 & 0.00 & 0.00 \\
\hline 1 glass of coke & 250.00 & 0.45 & 112.75 & 0.12 & 30.25 & 0.00 & 0.00 & 0.00 & 0.00 \\
\hline Glass of Tropicana Orange Juice & 250.00 & 0.36 & 90.00 & 0.10 & 24.00 & 0.00 & 0.00 & 0.00 & 0.00 \\
\hline 1 glass of Fruitopia fruit punch & 250.00 & 0.36 & 90.00 & 0.10 & 24.00 & 0.00 & 0.00 & 0.00 & 0.00 \\
\hline 1 glass of $2 \%$ chocolate milk & 250.00 & 0.69 & 173.08 & 0.12 & 30.00 & 0.01 & 2.31 & 0.04 & 9.23 \\
\hline 1 glass of apple juice & 250.00 & 0.48 & 120.00 & 0.12 & 29.00 & 0.00 & 0.00 & 0.00 & 1.00 \\
\hline 1 glass of $1 \%$ milk & 250.00 & 0.44 & 110.00 & 0.05 & 12.00 & 0.01 & 2.50 & 0.04 & 9.00 \\
\hline
\end{tabular}




\section{APPENDIX VI}

OVERALL TIMELINE 


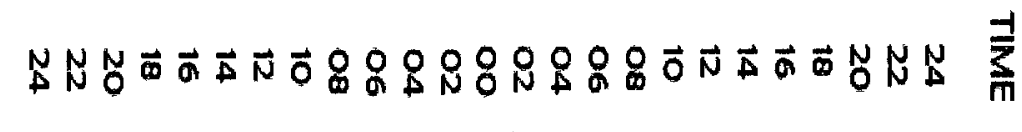

Initial Meeting

$\frac{0}{0}$

Dre-screen/ $\mathrm{Ph} .1$ Meeting

$\stackrel{\substack{0 \\ \frac{0}{0}}}{\stackrel{0}{0}}$

Ph. 2 Meeting

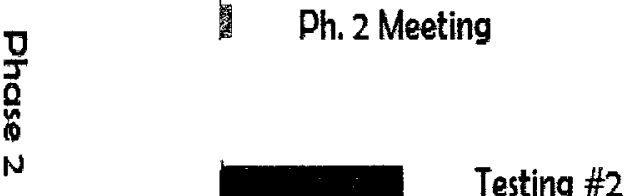

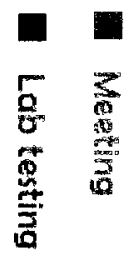

Testing \#1

Testing \#2

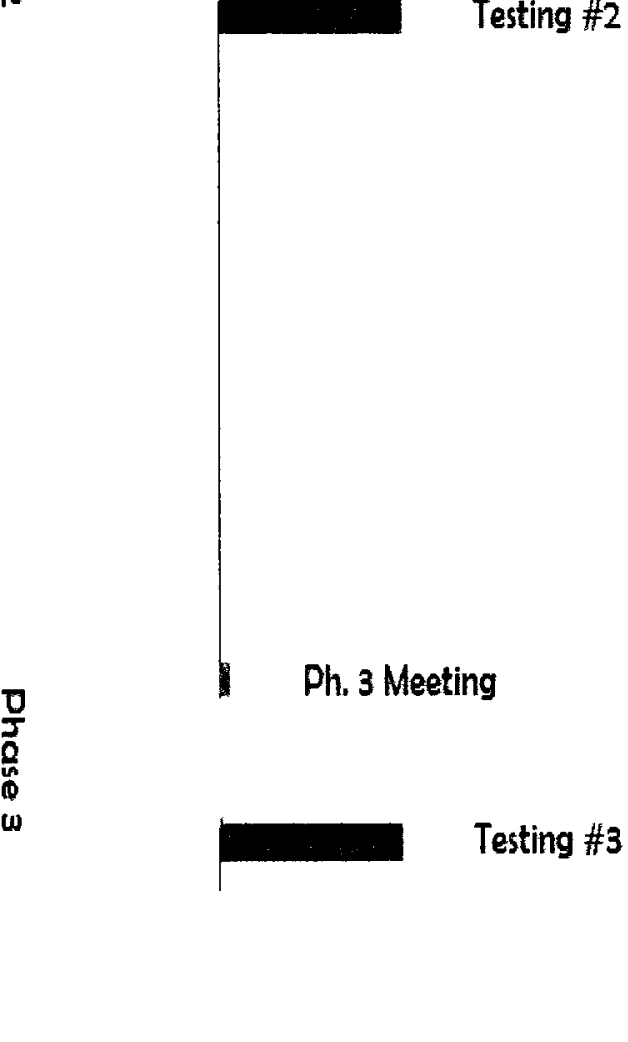




\section{APPENDIX VII}

\section{THREE FACTOR EATING QUESTIONNAIRE}




\title{
THREE FACTOR EATING QUESTIONAIRRE
}

\author{
Stunkard, Albert J.; Messick 1985
}

\section{Part I}

1. When I smell a sizzling steak or see a juicy piece of meat, I find it very $\quad T \quad F$ difficult to keep from eating, even if I have just finished a meal.

2. I usually eat too much at social occasions, like parties and picnics. $\quad T \quad F$

3. I am usually so hungry that I eat more than three times a day. $\quad T \quad F$

4. When I have eaten my quota of calories, I am usually good about not eating $\quad T \quad F$ any more.

5. Dieting is so hard for me because I just get too hungry. $\quad T \quad F$

6. I deliberately take small helpings as a means of controlling my weight. $\quad T \quad F$

7. Sometimes things just taste so good that I keep on eating even when I am $\quad T \quad F$ no longer hungry.

8. Since I am often hungry, I sometimes wish that while I am eating, an expert $T \quad F$ would tell me that I have had enough or that I can have something more to eat.

9. When I feel anxious, I find myself eating.

10. Life is too short to worry about dieting.

11. Since my weight goes up and down, I have gone on reducing diets more than once.

12. I often feel so hungry that I just have to eat something.

13. When I am with someone who is overeating, I usually overeat too.

14. I have a pretty good idea of the number of calories in common food.

15. Sometimes when I start eating, I just can't seem to stop.

16. It is not difficult for me to leave something on my plate.

17. At certain times of the day, I get hungry because I have gotten used to $\quad T \quad F$ eating then.

18. While on a diet, if I eat food that is not allowed, I consciously eat less for a $T \quad F$ period of time to make up for it.

19. Being with someone who is eating often makes me hungry enough to eat $T \quad F$ also.

20. When I feel blue, I often overeat.

21. I enjoy eating too much to spoil it by counting calories or watching my $\quad T \quad F$ weight.

22. When I see a real delicacy, I often get so hungry that I have to eat right $\quad T \quad F$ away.

23. I often stop eating when I am not really full as a conscious means of $\quad T \quad F$ limiting the amount that I eat.

24. I get so hungry that my stomach often seems like a bottomless pit. $\quad T \quad F$

25. My weight has hardly changed at all in the last ten years. 
26. I am always hungry so it is hard for me to stop eating before I finish the $\quad T \quad F$ food on my plate.

27. When I feel lonely, I console myself by eating.

28. I consciously hold back at meals in order not to gain weight.

29. I sometimes get very hungry late in the evening or at night.

30. I eat anything I want, any time I want.

31. Without even thinking about it, I take a long time to eat.

32. I count calories as a conscious means of controlling my weight.

33. I do not eat some foods because they make me fat.

34. I am always hungry enough to eat at any time.

35. I pay a great deal of attention to changes in my figure.

36. While on a diet, if I eat a food that is not allowed, I often then splurge and $T \quad F$ eat other high calorie foods.

\section{Part II}

Directions: Please answer the following questions by circling the number above the response that is appropriate to you.

37. How often are you dieting in a conscious effort to control your weight?

$\begin{array}{cccc}1 & 2 & 3 & 4 \\ \text { Rarely } & \text { Sometimes } & \text { Usually } & \text { Always }\end{array}$

38. Would a weight fluctuation of $5 \mathrm{lbs}$ affect the way you live your life?

$\begin{array}{cccc}1 & 2 & 3 & 4 \\ \text { Rarely } & \text { Sometimes } & \text { Usually } & \text { Always }\end{array}$

39. How often do you feel hungry?

$\begin{array}{cccc}1 & 2 & 3 & 4 \\ \text { Rarely } & \text { Sometimes } & \text { Usually } & \text { Always }\end{array}$

40. Do your feelings of guilt about overeating help you control your food intake?

$\begin{array}{cccc}1 & 2 & 3 & 4 \\ \text { Rarely } & \text { Sometimes } & \text { Usually } & \text { Always }\end{array}$

41. How difficult would it be for you to stop eating halfway through dinner and not eat for the next four hours?

$\begin{array}{cccc}1 & 2 & 3 & 4 \\ \text { Rarely } & \text { Sometimes } & \text { Usually } & \text { Always }\end{array}$

42. How conscious are you of what you are eating?

$\begin{array}{cccc}1 & 2 & 3 & 4 \\ \text { Rarely } & \text { Sometimes } & \text { Usually } & \text { Always }\end{array}$

43. How frequently do you avoid 'stocking up' on tempting foods?

$\begin{array}{cccc}1 & 2 & 3 & 4 \\ \text { Rarely } & \text { Sometimes } & \text { Usually } & \text { Always }\end{array}$

44. How likely are you to shop for low calorie foods? 

Rarely
Sometimes
Usually
Always

45. Do you eat sensibly in front of others and splurge alone?

$\begin{array}{cccc}1 & 2 & 3 & 4 \\ \text { Rarely } & \text { Sometimes } & \text { Usually } & \text { Always }\end{array}$

46. How likely are you to consciously eat slowly in order to cut down on how much you eat?

$\begin{array}{cccc}1 & 2 & 3 & 4 \\ \text { Rarely } & \text { Sometimes } & \text { Usually } & \text { Always }\end{array}$

47. How frequently do you skip dessert because you are no longer hungry?

$\begin{array}{cccc}1 & 2 & 3 & 4 \\ \text { Rarely } & \text { Sometimes } & \text { Usually } & \text { Always }\end{array}$

48. How likely are you to consciously eat less than you want?

$\begin{array}{cccc}1 & 2 & 3 & 4 \\ \text { Rarely } & \text { Sometimes } & \text { Usually } & \text { Always }\end{array}$

49. Do you go on eating binges though you are not hungry?

$\begin{array}{cccc}1 & 2 & 3 & 4 \\ \text { Rarely } & \text { Sometimes } & \text { Usually } & \text { Always }\end{array}$

50. On a scale of 0 to 5 , where 0 means no restraint in eating (eating whatever you want, whenever you want it) and 5 means total restraint (constantly limiting food intake and never 'giving in'), what number would you give yourself?

$$
\begin{gathered}
0 \\
\text { eat whatever you want, whenever you want it } \\
1 \\
\text { usually eat whatever you want, whenever you want it } \\
2 \\
\text { often eat whatever you want, whenever you want it } \\
3 \\
\text { often limit food intake, but often 'give in' } \\
4 \\
\text { usually limit food intake, rarely 'give in' } \\
5 \\
\text { constantly limiting food intake, never 'giving in' }
\end{gathered}
$$

51. To what extent does this statement describe your eating behaviour? 'I start dieting in the morning, but because of any number of things that happen during the day, by evening I have given up and eat what I want, promising myself to start dieting again tomorrow.'

1

Not like me
2

Little like me
3

Pretty good description of me
4 Describes me perfectly 


\section{APPENDIX VIII}

\section{VISUAL ANALOG SCALE}


Visual Analogue Scale (150 mm)

\begin{tabular}{|l|l|}
\hline Procedure & $\begin{array}{l}\text { Please quantify your sensation for the feeling mentioned } \\
\text { below. Consider the line as two extremes of this } \\
\text { sensation. Draw a vertical line that best represents this } \\
\text { sensation at this moment in time. }\end{array}$ \\
\hline
\end{tabular}

1. How strong is your desire to eat?

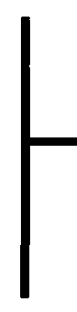

Very weak

Very strong 
Visual Analogue Scale (150 mm)

\begin{tabular}{|l|l|}
\hline Procedure & $\begin{array}{l}\text { Please quantify your sensation for the feeling mentioned } \\
\text { below. Consider the line as two extremes of this } \\
\text { sensation. Draw a vertical line that best represents this } \\
\text { sensation at this moment in time. }\end{array}$ \\
\hline
\end{tabular}

2. How hungry do you feel?

Not hungry

As hungry as I

at all

have ever felt 
Visual Analogue Scale $(150 \mathrm{~mm})$

\begin{tabular}{|l|l|}
\hline Procedure & $\begin{array}{l}\text { Please quantify your sensation for the feeling mentioned } \\
\text { below. Consider the line as two extremes of this } \\
\text { sensation. Draw a vertical line that best represents this } \\
\text { sensation at this moment in time. }\end{array}$ \\
\hline
\end{tabular}

3. How full do you feel?

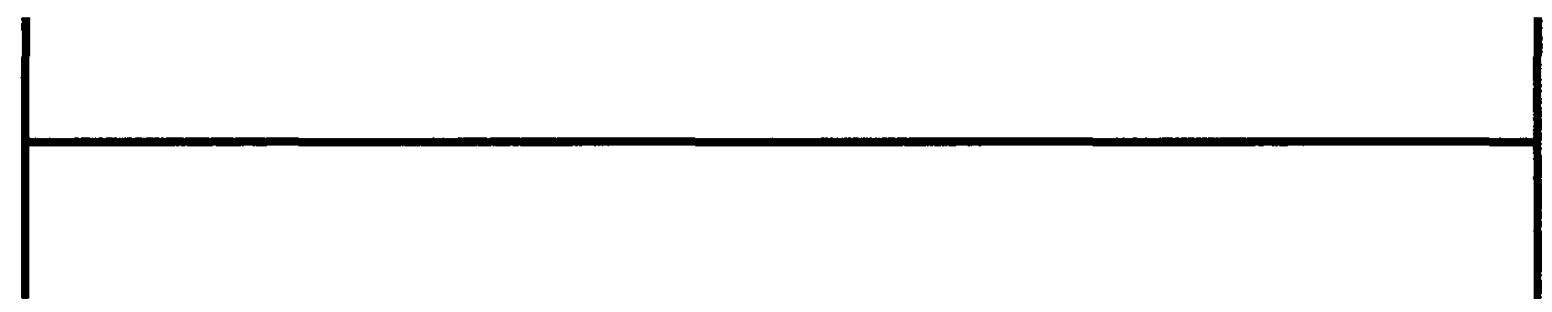

Not full

Very full at all 
Visual Analogue Scale $(150 \mathrm{~mm})$

\begin{tabular}{|l|l|}
\hline Procedure & $\begin{array}{l}\text { Please quantify your sensation for the feeling mentioned } \\
\text { below. Consider the line as two extremes of this } \\
\text { sensation. Draw a vertical line that best represents this } \\
\text { sensation at this moment in time. }\end{array}$ \\
\hline
\end{tabular}

4. How much food do you think you could eat?

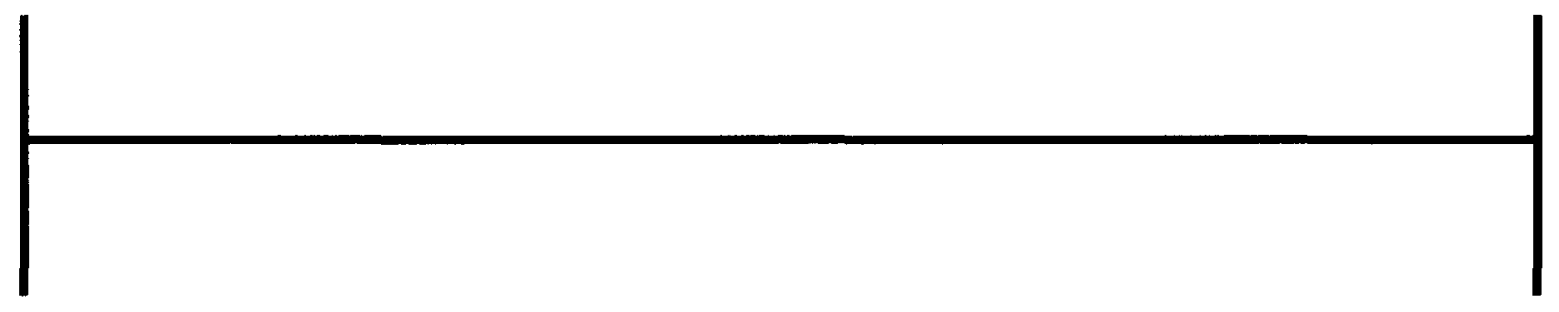

Nothing at all

A large amount 